\title{
Mobile money adoption and household welfare in Uganda
}

\author{
Dissertation \\ to obtain the Ph.D. degree \\ in the International Ph.D. Program for Agricultural Sciences in Goettingen (IPAG) \\ at the Faculty of Agricultural Sciences, \\ Georg-August-University Göttingen, Germany
}

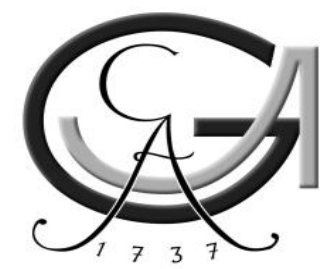

presented by

Conrad Murendo

born in Mutasa, Zimbabwe

Göttingen, May 2015 
D7

1. Name of supervisor: Prof. Dr. Meike Wollni

2. Name of co-supervisors: Prof. Dr. Matin Qaim, Prof. Dr. Stephan von Cramon-Taubadel Date of dissertation: 23 July 2015 


\section{Summary}

Over the last 10 years mobile money has emerged as an important innovation with a potential to increase financial access in developing countries. Mobile money is making an important contribution to financial inclusion in many ways. First, it's increasing access to financial services to a large number of people, who are effectively excluded from the commercial banking system by virtue of the fact that they live too far from banks or do not have sufficient funds to meet the minimum deposit requirements to open a bank account. Second, mobile money agents are now located in remote locations where it would not be economically viable to open a bank branch, allowing mobile money services to be extended into remote locations. Households are now able to receive remittances and social grants through mobile money. Furthermore, mobile money is now being used to facilitate access to insurance, credit and savings even for poor households in remote areas. Access to basic financial services through mobile money could enhance the ability of rural households to invest in their livelihoods and improve welfare. Because of its potential to contribute to financial access especially for the poor in developing countries, mobile money has generated immense interest among policy makers and researchers. Despite the importance of mobile money on the lives of rural households, there is limited empirical evidence on the drivers of mobile money adoption and its broader welfare effects on adopting households.

This dissertation comprises three related essays on the adoption and welfare effects of mobile money (a new financial innovation). In the first essay, we analyse whether social networks affect the adoption of mobile money. In the second essay, we analyse whether the use of mobile money technology has an effect on household food security. In the third essay, we analyse the effect of mobile money on household welfare and poverty. In the second and third essays, we specify two alternatives of the treatment variable. We used a dummy variable for mobile money use as well as intensity of using mobile money. We address these questions using cross-section data collected from rural households in Uganda. Uganda offers an interesting case study because the use of 
mobile money is growing rapidly. About $27 \%$ of the population in Uganda is using mobile money and this has surpassed $20 \%$ of the population with bank accounts. In addition, over $70 \%$ of the population resides in rural areas where banking infrastructure is underprovided.

In the first essay, we analyse the effect of social networks on the adoption of mobile money. In developing countries, financial information services are underprovided, limiting household's ability to adopt new financial innovations. In most cases, households rely on social networks to get information on new innovations. Interestingly, no previous studies have systematically analysed how social networks affect mobile money adoption. We contribute to this limited literature by using unique social interactions household level data collected through the random matching within sample approach. A conditional logistic regression model is estimated controlling for household characteristics, correlated effects, and other possible information sources. We find that information exchange within social networks helps disseminate information about mobile money and has enhanced its adoption. An increase in the exchange adopters within household social network increases the odds of adopting mobile money by $77 \%$ points. However, the structure of the social network appears to have no effect on mobile money adoption. We also analyse the effect of social networks, separately for poor and non-poor households. Our results show that social network effects, and in particular the size of exchange adopters appear to be more pronounced for non-poor households. These findings have important policy implications for the diffusion of mobile money. In particular, they suggest that exchange within social networks help disseminate information about mobile money. The adoption of mobile money is likely to be increased if promotion programs reach more social networks. Furthermore, mobile money promotion programs need to reach the poor, because our evidence suggests that the poor may be trapped in information-poor networks and thus social network multiplier effects will most likely not automatically work in their case. Improving rural household's access to informal information channels is particularly important in developing countries, where formal information institutions 
are lacking. There is a need for policy makers, mobile money service providers and extension to strengthen and utilize informal institutions to disseminate information about mobile money.

In the second essay, we analyse the effect of mobile money on household food security. Mobile money technology is growing rapidly in developing countries. However, empirical studies of the broader welfare effects of the technology on rural households are limited. This essay contributes to the emerging literature on mobile money in several ways. First, we study the effects of mobile money on food security - an issue high on the global policy agenda. This has not been addressed in previous literature. Second, unlike studies that use one measure of food security, we contribute methodologically by using two measures of food security. We account for potential endogeneity of mobile money by using treatment effects and instrumental variable regression techniques. Controlling for other factors, use of mobile money decreases household relative food insecurity by 0.20 index points. Furthermore, we find that use of mobile money and intensity of using mobile money increases monthly food expenditure per adult equivalent by $9 \%$ and $1.4 \%$ points respectively. We conclude that mobile money positively affects food security. Interventions and strategies to improve household food security should consider the promotion of mobile money among rural households in Uganda and other developing countries.

In the third essay, we extend our analysis and study the effect of mobile money on household welfare and poverty. We measured welfare using household consumption expenditure. We measured poverty using the consumption poverty and multidimensional poverty index. We estimate instrumental variable and endogenous switching probit regressions to control for the potential endogeneity of mobile money. Model results show that use and intensity of using mobile money increases consumption expenditure by $10 \%$ and $2 \%$ points respectively. Based on consumption poverty, our model estimates highlight that use of mobile money reduces the probability of being poor among users by $10 \%$ points. Furthermore, among non-users the probability of being could be reduced by $5 \%$ points if they were to use mobile money. In 
addition, higher intensity of using mobile money reduces the likelihood of being poor by $1 \%$ point. The use of mobile money reduces multidimensional poverty by 0.67 index points. We find that a unit increase in the intensity of using mobile money reduces multidimensional poverty by 0.07 index points. Our results for the effects of mobile money are robust to alternative specifications of the treatment and poverty outcome variables. The results confirm that mobile money is welfare-enhancing and reduces household poverty. Policy interventions to improve household welfare and reduce poverty should embrace the promotion of mobile money among rural households in Uganda. In the last part of this dissertation (Chapter 5), we conclude and summarize the key study findings. We derive policy recommendations and elaborate the study limitations and considerations for future research. 


\section{Acknowledgements}

I would like to thank the entire staff of GlobalFood Research Training Group and chair of International Agricultural Economics for their support, patience and understanding throughout the completion of this work. Special thanks to my academic advisor and thesis supervisor, Professor Dr. Meike Wollni, for the years of mentoring and guidance. I am also indebted to my thesis committee member Professors Matin Qaim and Stephan von Cramon-Taubadel, for cosupervising me.

This research was financially supported by the German Research Foundation (Deutsche Forschungsgemeinschaft, DFG) as part of the GlobalFood RTG and German Academic Exchange Service (DAAD). This financial support is gratefully acknowledged. The support of Grameen Foundation in fieldwork coordination and the dedicated team of enumerators, is also much appreciated.

I appreciate my loving wife, Tendai and daughters, Grace and Carryl, who stood by me and encouraged me throughout the entire period of my study. I also appreciate my parents and family for nourishing my life with care and love. 


\section{Table of Contents}

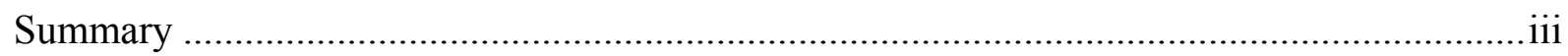

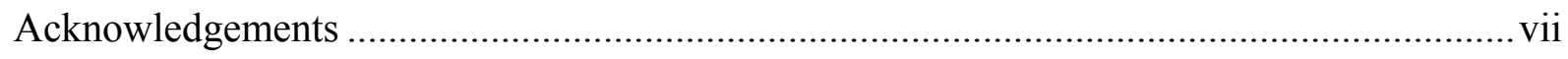

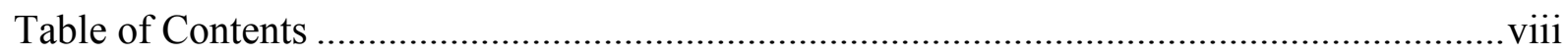

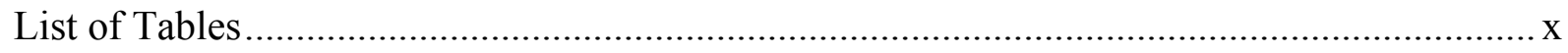

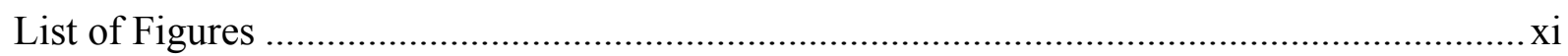

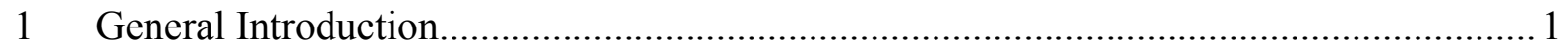

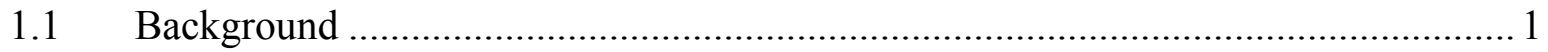

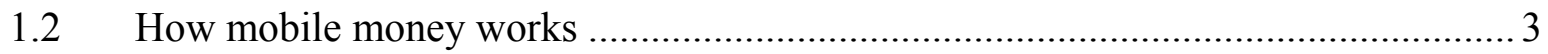

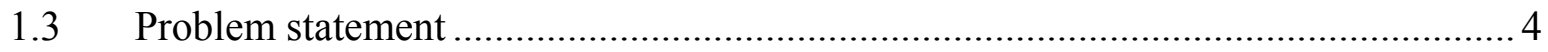

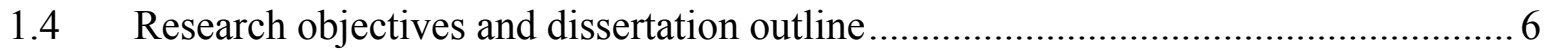

2 Social network effects on mobile money adoption in Uganda...................................... 8

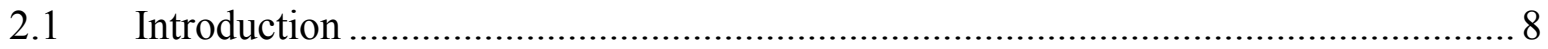

2.2 Conceptual framework and hypotheses............................................................ 10

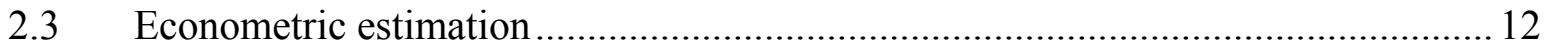

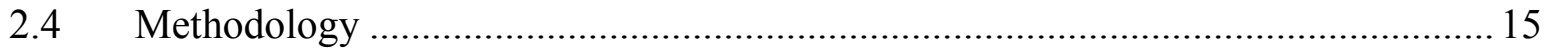

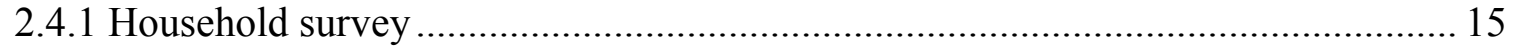

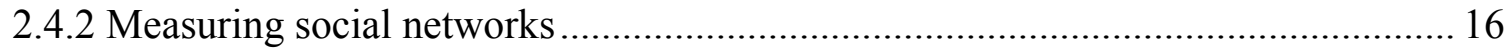

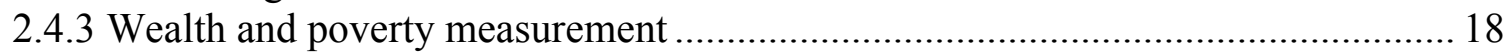

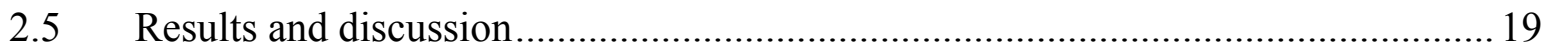

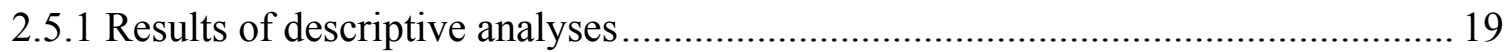

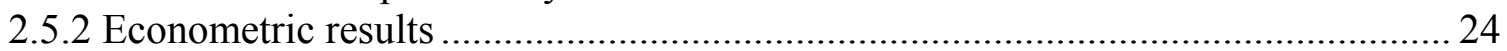

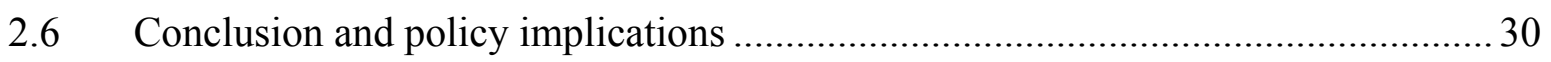

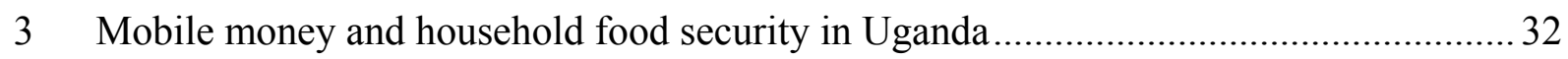

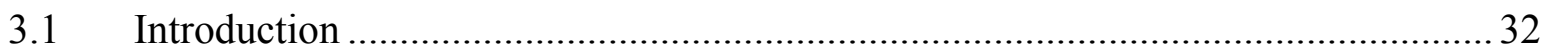

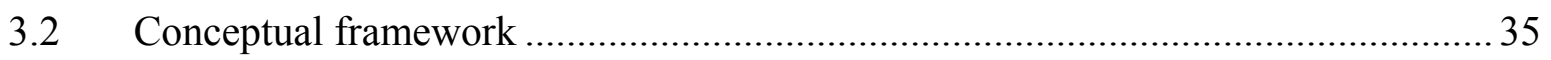

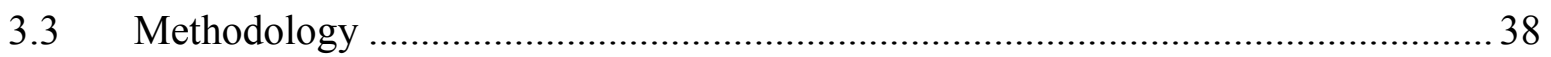

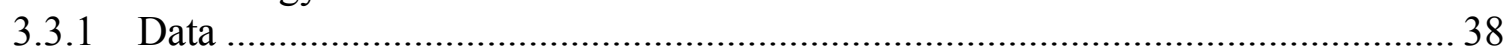

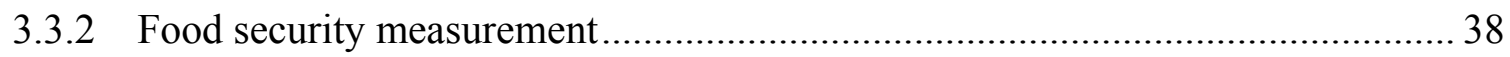

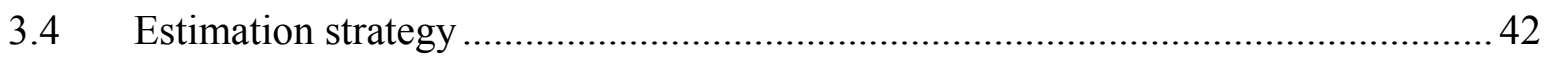

3.4.1 Continuous outcome variables: food insecurity index and food expenditure ...... 44

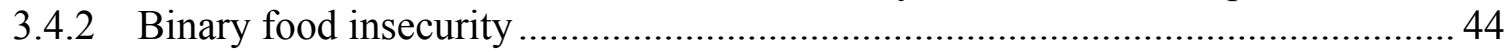

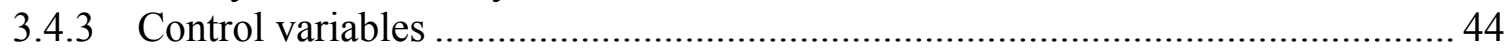

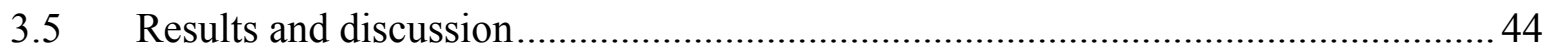

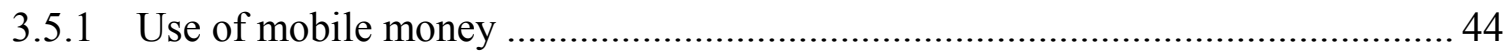

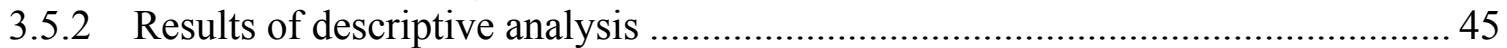

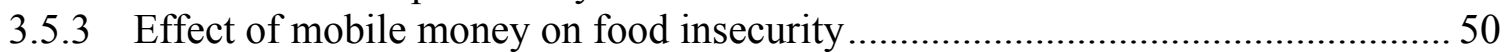

3.5.4 Effect of mobile money on food expenditure.................................................. 54

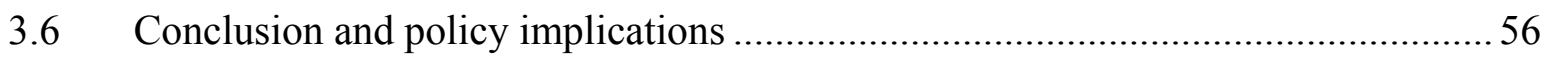


4 Mobile money, household welfare and poverty in Uganda.........................................58

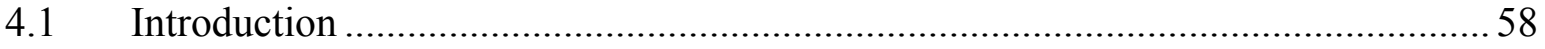

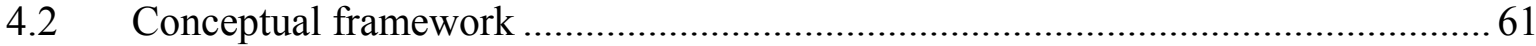

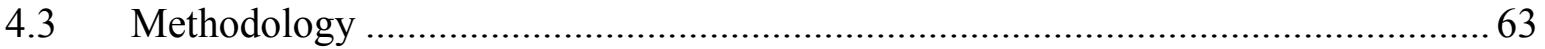

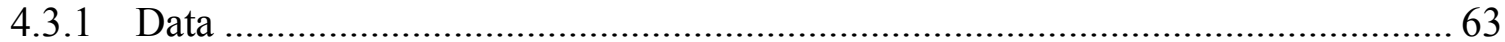

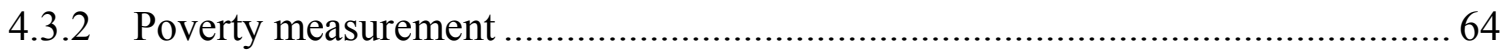

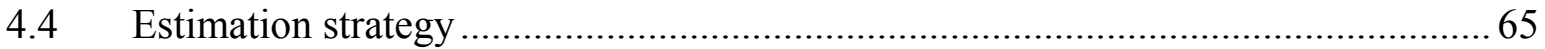

4.4.1 Consumption expenditure and multidimensional poverty index.........................66 66

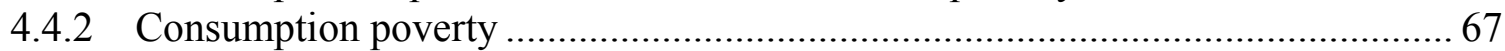

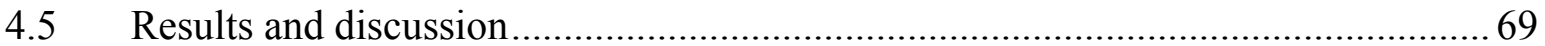

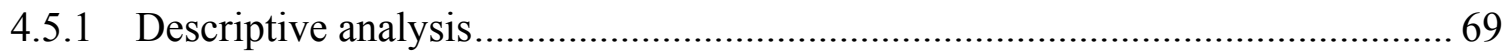

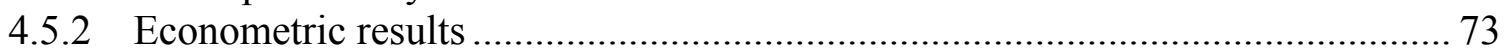

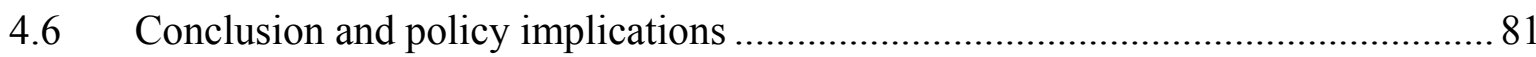

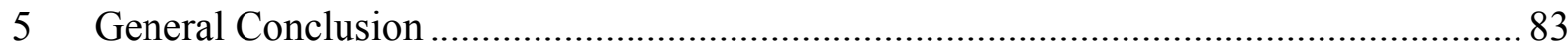

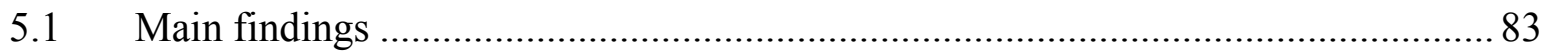

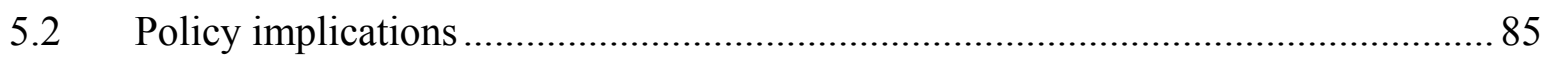

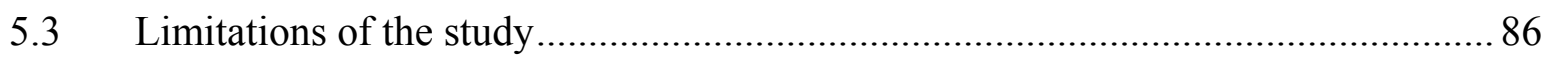

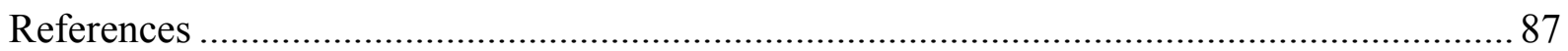

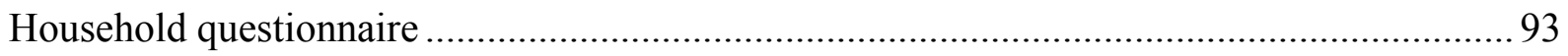




\section{List of Tables}

Table 2. 1. Sample differentiated by mobile money adoption status ......................................16

Table 2. 2. Variables used in constructing wealth index and their factor loadings ...................19

Table 2. 3. Variable names, definitions and descriptive statistics.........................................20

Table 2. 4. Size of household's social network .....................................................................2

Table 2. 5. Frequency distribution of adopters within a household's social network ..............22

Table 2. 6. Social network variables by adoption status .......................................................22

Table 2. 7. Social network and information variables by poverty status ...............................23

Table 2. 8. Determinants of mobile money adoption: Conditional logistic regression.............25

Table 2. 9. Social network effects differentiated by poverty status .......................................29

Table 3. 1. Sample statistics for the sub-domains (Percentage response on occurrences in the last 30 days) 46

Table 3. 2. Differences between mobile money users and non-users 49

Table 3. 3. Estimated effects of mobile money on food insecurity index .52

Table 3. 4. Estimated effects of mobile money on binary food insecurity: probit model ........ 53

Table 3. 5. Estimated effects of mobile money on monthly food expenditure per AE $(\log ) \ldots 55$

Table 4. 1. Dimensions, indicators and deprivation cut-offs used in multidimensional poverty measurement. 70

Table 4. 2. Outcome indicators and socio-economic differences between mobile money users and non-users

Table 4. 3. Effect of mobile money use and intensity on monthly consumption per AE (UGX $\log$ )

Table 4. 4. Effect of mobile money use on consumption poverty - endogenous switching probit model .76

Table 4. 5. Mean treatment effect of mobile money use on consumption poverty .77

Table 4. 6. Effect of intensity of using mobile money on consumption poverty .78

Table 4. 7. Effect of mobile money use and intensity on multidimensional poverty index. 80 


\section{List of Figures}

Figure 2. 1. Mobile money adoption differentiated by household poverty

Figure 3. 1. Pathways through which mobile money affect household food security and poverty

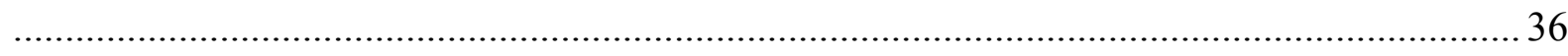

Figure 3. 2. Activity household performed with mobile money …..................................... 45

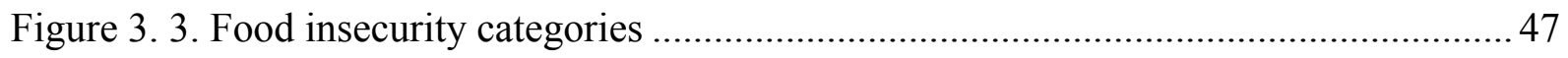




\section{General Introduction}

\subsection{Background}

There is strong consensus that improved financial inclusion (access) ${ }^{1}$ through savings, credit, insurance and payment services contribute to economic growth (Anzoategui et al., 2014; Beck \& Demirguc-Kunt, 2008; Donovan, 2012; Dupas \& Robinson, 2013). However, it is estimated that 2.5 billion people in developing countries have no bank account and do not use any formal financial services (World Bank, 2014; GSMA, 2015). Formal financial institutions are mostly concentrated in urban areas with limited presence in rural areas. One reason is that financial institutions find it too expensive to deal with poor rural people who usually save in small amounts. Lack of access to basic financial services limit the ability of rural households to invest in their livelihoods, protect their assets and manage risks and step out of poverty (Dupas \& Robinson, 2013; Munyegera \& Matsumoto, 2014). Because of lack of access to formal financial services, majority of the poor rural households rely on insecure informal financial services to save money (e.g. under mattresses, in jewellery) and send and receive money (e.g. bus, friends) (Karlan et al., 2014; Kikulwe et al., 2014).

On the other hand, more than one billion of these financial excluded people have access to a mobile phone (GSMA, 2015). Their mobile phones can potentially be used to facilitate access to financial services such as payments, transfers, insurance, savings and credit through the new mobile money innovation. Mobile money refers to the use of mobile phones to perform financial and banking functions and includes among others remittance transfers, airtime purchase, utility bills and school fees payments, saving and mobile banking (IFC, 2011; Donovan, 2012). The

\footnotetext{
${ }^{1}$ In this dissertation, we use financial inclusion and access interchangeably. According to Diniz et al. (2012) and Beck \& Demirguc-Kunt (2008) financial inclusion is defined as the access to formal financial services at an affordable cost for all groups of people including the low-income groups.
} 
growth in mobile money has been spurred by an increase in penetration and use of mobile phones in rural areas coupled with expansion of mobile money agents (MMA).

Since 2009, there are now over 100 million active mobile money users worldwide (GSMA, 2015). In most developing countries there are now more mobile money accounts than bank accounts. According to GSMA (2015), there are currently over 2.3 million mobile money outlets globally and these outnumber the traditional financial and remittance service networks. As of 2013, Uganda had 16.4 million mobile money users ${ }^{2}$ compared to 7.6 million individuals who hold bank accounts at financial institutions (InterMedia, 2012; World Bank, 2014). This shows that mobile money users now exceed the number of customers holding conventional bank accounts. Furthermore, there are over 50000 mobile money agents in Uganda, which reflect more points of financial services compared to the combined 900 bank branches and 800 automated teller machines (GSMA, 2014).

Over the last years, mobile money has emerged as an important innovation with a potential to increase financial inclusion in developing countries in many ways. First, it increases access to financial services to a large number of people, who are effectively excluded from banks due to longer travel distances or insufficient funds to meet the minimum deposit required to open a bank account as mobile money attracts modest and proportionate withdrawal fees (Jack et al., 2013; Kikulwe et al., 2014). With mobile money, households can transfer money on their mobile phones without physically visiting the bank or through mobile money agents that are now widespread even in remote villages. This reduces households travel time and costs. In addition, mobile money is associated with fast and timely transfer of money, hence reduces transaction costs associated with accessing financial services. Furthermore, a range of financial services are now being offered through mobile money for example micro insurance (IFC, 2011).

\footnotetext{
${ }^{2}$ This includes individuals, households and institutions.
} 


\subsection{How mobile money works}

Mobile money provides a convenient way to send money to anyone anywhere no matter the network or mobile money service provider. Mobile money service providers work in partnership with one or more banks, making it possible for clients to make banking transactions on their mobile phones without visiting the bank. Mobile money users have two options of conducting mobile money transfers: a) through transfers on their own or on mobile phones of their relatives or friends provided they have activated the mobile money account, and b) visiting a registered MMA, who conducts the transfers on behalf of the client. The mobile money account is an electronic money account which receives electronic value either after the account holder deposits cash via an agent or receives a payment from elsewhere (IFC, 2011).

The services offered by different mobile money service providers have many similarities: They all allow registered mobile money users (individuals, businesses, institutions etc) to load money into their mobile money accounts or transfer through MMA (cash-in), make transfers to other users (both registered or not), buy airtime and withdraw money (cash-out) (InterMedia, 2012). Though mobile money registration is free, all transactions have a predetermined fee (InterMedia, 2012; MTN, 2014). The transaction fees are calculated differently for registered and nonregistered mobile money users as well as differently when transferring money to the same and different network. Some households have multiple mobile money accounts from different service providers to take advantage of this flexibility. In addition, MMAs work for more than one mobile money service provider at a time thus bringing a variety of financial services under one roof. When sending mobile money through mobile phone the sender is charged while the recipient is not. On the other hand, if one transfers money through a mobile money agent, the transaction fees are charged upon withdrawal.

For Uganda, Mobile Telephone Network (MTN) launched the first mobile money (MTN mobile money) in March 2009. Another provider, Uganda Telecom launched the second mobile money 
(M sente) in 2010. In 2011, Warid Telecom joined the industry and introduced Warid Pesa and this was followed by Airtel Money from Airtel in 2012. The mobile money industry continued to grow and Orange money from Orange Telecom was launched in 2013. In early 2013, Airtel merged with Warid Telecom to offer Airtel-Warid Pesa.

\subsection{Problem statement}

Mobile money is increasing access to financial services to a large number of people, who are effectively excluded from the banking system because of long physical distance or insufficient funds to meet the minimum bank account deposit (Kikulwe et al., 2014). Second, mobile money is now being used to facilitate access to insurance, credit and savings, social transfer programs, for example pensions and aid. With mobile money, all people and even the poor can be able to save even small amounts of money. Furthermore, mobile money services can now be extended into remote locations. Mobile money - a new financial innovation, is therefore expected to bridge the financial inclusion gap thus allowing for welfare improvements among the poor rural households. Despite the relative importance of mobile money in the lives of rural households, there is limited empirical evidence on the factors influencing mobile money adoption and its broader welfare effects on adopting rural households. Furthermore, with the exception of Munyegera \& Matsumoto (2014), there are no studies that analyse the welfare effects of mobile money in Uganda. Most of the recent empirical studies are based on Kenya (Jack et al., 2013; Jack \& Suri, 2014; Kikulwe et al., 2014; Kirui et al., 2013).

Despite its potential benefits, mobile money has not been widely adopted by rural households in developing countries. One possible reason for the existence of mobile money adoption gap is poor access to information. This is particularly true for developing countries, where formal financial information institutions are limited. In developing countries, informal institutions such as social networks constitute an important channel for information about new financial innovations. A qualitative study by InterMedia (2012) in Uganda showed that social networks 
positively influence the adoption of mobile money. However, this qualitative study lacks econometric rigour to draw any appropriate inferences. Kikulwe et al. (2014) proxied neighbourhood effects by the percentage of households owning a mobile phone at the village level and found a positive effect on mobile money use in Kenya. However, this approach fails to adequately capture the presence of information exchange. Empirical studies analysing the effects of social networks on mobile money adoption are hardly available. Therefore an important research question to answer is: What is the effect of social networks on mobile money adoption?

Empirical evidence suggests that enhancing households' access to finance will lead to a more efficient allocation of resources, increased production, and higher welfare (Beck \& DemirgucKunt, 2008; Dupas \& Robinson, 2013). There is an emerging and growing body of literature analysing the effects of mobile money on household welfare in developing countries (Kikulwe et al., 2014; Jack et al., 2013; Jack \& Suri, 2014; Munyegera \& Matsumoto, 2014). Jack et al. (2013) analysed the effect of mobile money on the volume of internal remittances in Kenya. In another study, Jack \& Suri (2014) found that mobile money had a significant effect on the ability of households to smooth consumption in Kenya. Kikulwe et al. (2014) found that mobile money had a positive effect on household income in Kenya. For Uganda, Munyegera \& Matsumoto (2014) found that mobile money increased household monthly per capita consumption.

Mobile money has also a potential to improve food security and reduce poverty through enhanced liquidity and lower financial transaction cost. Yet, we are not aware of any studies that have looked at food security and poverty implications of mobile money for households in developing countries. Furthermore, and methodologically, most of the studies mentioned above use a dummy variable to capture mobile money use. However, from a policy perspective, the intensity of using mobile money is also of relevancy. In this dissertation, we address this methodological limitation by using two specifications of the treatment variable: dummy for mobile money use and intensity of using money. This dissertation comprises three related essays on the adoption and welfare 
effects of mobile money. The first essay focuses on the effect of social networks on the adoption of mobile money. In the second essay, we analyse the effect of mobile money on household food security. Lastly, in the third essay, we analyse the effect of mobile money on household welfare and poverty.

\subsection{Research objectives and dissertation outline}

The broad objectives of this dissertation are to analyse the effect of social networks on adoption of mobile money and effects on mobile money on food security, welfare and poverty using data from rural households in Uganda. This dissertation addresses the following specific research objectives:

1. To analyse the effect of social networks on the adoption of mobile money by rural households?

2. To analyse the effect of mobile money on food security among rural households?

3. To analyse the effect of mobile money on welfare and poverty among rural households?

To address these research objectives, we rely on cross-section household level data collected in Uganda in 2013 from 477 rural households. For analysing objective 2 and 3, we use data from 476 rural households. The specific details on data collection are contained in the household questionnaire, which is attached in the Appendix at the end of the dissertation. Uganda offers an interesting case study because the use of mobile money is growing rapidly. About $27 \%$ of the population in Uganda is using mobile money and this has surpassed $20 \%$ of the population with bank accounts. In addition, over $70 \%$ of the population resides in rural areas where banking infrastructure is underprovided. The rest of the dissertation is organized as follows: Chapter 2 presents the first essay titled "Social network effects on mobile money adoption in Uganda". In the analysis, we account for potential correlated effects in mobile money adoption using conditional logistic regression. Chapter 3 presents the second essay titled "Mobile money and 
household food security in Uganda”. This study uses treatment effects and instrumental variable regressions to estimate the effects of mobile money on household food security in Uganda. Chapter 4 presents the third essay titled "Mobile money, household welfare and poverty in Uganda”. In the analysis, we use household consumption expenditure as indicator of welfare. We measure poverty using consumption poverty and multidimensional poverty index. We estimate instrumental variable and endogenous switching probit regressions to control for the potential endogeneity of mobile money. In chapter 5, the main findings and conclusion are summarized. We derive the policy recommendations and elaborate the study limitations and considerations for future research. 


\title{
2 Social network effects on mobile money adoption in Uganda ${ }^{3}$
}

\begin{abstract}
.
Social networks are important for information exchange that can drive the diffusion of new financial innovations. This is particularly relevant for developing countries where financial information services are underprovided, limiting household's ability to adopt mobile money. This article identifies the effect of social networks on the adoption of mobile money in Uganda. Using data from a survey of 477 households, a conditional logistic regression model is estimated controlling for correlated effects and other information sources. Results show that the size of exchange adopters has a positive effect on the adoption of mobile money. Hence, information exchange within social networks positively affects the adoption of mobile money. The structure of social network however has no effect. The effect of the size of exchange adopters is more pronounced for non-poor households. Mobile money adoption is likely to be enhanced if promotion programs reach more social networks.
\end{abstract}

\subsection{Introduction}

Despite the tremendous growth in mobile money, the technology has not been widely adopted by households. One possible reason for the existence of mobile money adoption gap is information asymmetries that limit households' ability to make informed decisions to take advantage of mobile money technology. This is particularly true for developing countries where extension and formal financial information services are underprovided. Social networks constitute an important channel through which households obtain information about new financial innovations and this helps to reduce information asymmetry and transaction costs for innovation adoption (Röper et al., 2009; Zhang et al., 2012). In Uganda, informal assessments by InterMedia (2012) show that

\footnotetext{
${ }^{3}$ This paper was published in the GlobalFood Discussion Paper Series No. 58 (2015). The co-authors of this article are Meike Wollni, Alan de Brauw and Nicholas Mugabi. This paper has been accepted for oral presentation at the International Conference of Agricultural Economists in Milan, Italy on 8-14 August 2015.
} 
individuals started using mobile money because of recommendation from family members, friends or other acquaintances. However, this study did not provide rigorous econometric evidence to show that information from one's social network leads to mobile money adoption.

Previous research has analysed the adoption of mobile money by households in developing countries (Munyegera \& Matsumoto, 2014; Kikulwe et al., 2014). Munyegera \& Matsumoto (2014) analysed the determinants of mobile money adoption by households in Uganda. Kikulwe et al. (2014) proxied neighbourhood effects by the percentage of households owning a mobile phone at the village level and found a positive effect on mobile money use in Kenya. However, this study does not capture the presence of information exchange explicitly. Studies analysing the effects of social networks on mobile money adoption are scarce. Our paper is closely related to recent studies that link social networks to financial decision making by rural households (Wydick et al., 2011; Zhang et al., 2012; Banerjee et al., 2013). For example Banerjee et al. (2013) found that information obtained from neighbours who participated in microfinance positively influences the decision on microfinance participation by households in India.

This essay explores the role of social networks in households' adoption of mobile money in Uganda. More specifically, we use unique social interactions dataset to analyse how information exchange within social networks affect the adoption of mobile money. In addition, we assess whether social network effects vary with poverty status of household. To the best of our knowledge, this has not been systematically analysed in previous studies.

Our results allow drawing some recommendations on whether mobile money technology could be diffused using social networks in Uganda. While our study focuses on mobile money, the results can be applied to other new technologies in developing countries, where information asymmetries limit household's adoption decisions. The remainder of this essay is organised as follows. In the next section we describe the conceptual framework and hypotheses. We then discuss the empirical model specification and estimation issues, followed by a description of 
survey data used for empirical analysis. Empirical results are presented and discussed. The last section concludes and discusses policy implications.

\subsection{Conceptual framework and hypotheses}

In developing countries, social networks are an important source of information because formal information institutions are underprovided. According to Maertens \& Barrett (2013) and Borgatti et al. (2009), social networks refer to individual members and the links among them through which information, money, goods or services flow. Our conceptual framework is guided by the social learning theory (Conley \& Udry, 2010; Maertens \& Barrett, 2013). Within this, we identify three social network theories that are relevant for our study: (i) Network size; (ii) Granovetter's strength of weak tie theory (Granovetter, 1973); and (iii) Social resources theory (Lin et al., 1981; Lin, 1999; Lai et al., 1998). The size of network contacts affects the quantity and quality of financial information a household can acquire (Zhang et al., 2012). Households may know someone in their social network but may not necessarily communicate with them about the use of mobile money. Without information exchange on mobile money, simply knowing a social network member may not produce the learning externality of social networks (Maertens \& Barrett, 2013), especially for mobile money which is highly unobservable. Hence, we use the size or number of adopters within the social network with whom the household communicates ${ }^{4}$ about mobile money (hereafter called exchange adopters) to capture information exchange. Households with more exchange adopters in their social network are likely to have better access to financial information and thus to adopt mobile money as well. From this, we develop the following testable hypothesis:

H1. Compared to households with fewer exchange adopters in their social network, those with more exchange adopters are more likely to adopt mobile money due to information benefits of a larger network.

\footnotetext{
${ }^{4}$ This encompasses all forms of communication e.g. word of mouth, sms or voice calls etc.
} 
Social network benefits may emanate from the specific type of network connections such as strong and weak ties. The strength of a tie is a combination of the amount of time, emotional intensity and reciprocal services that characterize a relationship (Granovetter, 1973). Tie strength can be measured by the type of relationship (Granovetter, 1973), the duration of acquaintanceship (Son \& Lin, 2012; Fu et al., 2013) and the frequency of contact (Fu et al., 2013). The classification based on the type of relationship considers the number of acquaintances (weak tie contacts) in one's social network relative to close friends and relatives (strong tie contacts). Frequent interactions between contacts represent a strong tie whereas infrequent contact captures weak ties. People with strong ties may meet regularly and in several contexts, while people with weak ties often meet irregularly and exchange diverse and often crucial information (Son \& Lin, 2012; Fu et al., 2013). The tie strength among households in a network has an impact on the quality of information transferred and shared. New financial information flows to individuals through weak ties rather than strong ties (Granovetter, 1973; Granovetter, 2005). Weak tie contacts know other contacts outside the household's circle of friends and possess diverse and heterogenous information that overlaps less with what one already knows. We therefore argue that when a household's social network contains a larger share of weak ties the household is more likely to access more diversified information about mobile money and other financial information which increases the chances of adopting mobile money (Granovetter, 2005). We expect that:

H2. A larger proportion of weak ties within a household's social network increase the likelihood of adopting mobile money.

The social resources theory considers the structural factors of social networks. The theory posits that social resources (e.g. wealth, socioeconomic status etc.) embedded in an individual's social network positively influence information access (Lin et al., 1981; Lai et al., 1998; Song \& Chang, 2012). For example, Song \& Chang (2012) found that education of network members is positively associated with frequency of health information seeking in USA. Households with more connections to network members with rich socioeconomic resources are more active in 
financial information seeking. People with more socioeconomic resources, in particular education, are more active in seeking financial information and are better informed about financial products from different information sources (Song \& Chang, 2012; Röper et al., 2009; Zhang et al., 2012). Hence, when connected to network members with higher socioeconomic status, individuals are more likely to be exposed to financial information and products from their network members, which can motivate them to utilize the respective products (Zhang et al., 2012). Using network education status and guided by the social resources theory of Lin et al. (1981), we expect:

H3. Compared to households with less educated social network members, those with welleducated network members are more likely to adopt mobile money due to more and better financial information.

Although social network is expected to be important for the adoption of mobile money, other factors are likely to influence the household's adoption decision. Previous studies indicate that factors such as age, education, gender, income and the distance to a mobile money agent can affect mobile money adoption by rural households (Kikulwe et al., 2014; Munyegera \& Matsumoto, 2014). Munyegera \& Matsumoto (2014) reported that distance to a mobile money agent had an inverse relationship with the adoption of mobile money. Wealth and asset ownership are also among the factors that have been found to explain adoption (Kikulwe et al., 2014). Generally, households with larger financial capacities are considered to be more prone to technology adoption.

\subsection{Econometric estimation}

The effect of social network variables on the likelihood of adopting mobile money is estimated using conditional (fixed-effects) logistic regression. The approach of estimating a probit model with village dummies to control for the correlated effects (Matuschke \& Qaim, 2009; LiverpoolTasie \& Winter-Nelson, 2012) may be inappropriate in this case. The approach introduces the 
incidental parameters problem which leads to biased and inconsistent results because the unobserved individual effects are replaced by sample estimates (Lancaster, 2000; Fernández-Val, 2009). We therefore use conditional logistic regression which does not suffer from incidental parameter bias (Allison \& Waterman, 2002; Greene, 2012). The conditional logistic regression model for a specified group (village), $k$, is expressed as (Yau Fu et al., 2005; Greene, 2012):

$$
\pi_{k}(x)=\frac{\exp \left(\beta_{0 k}+\beta_{x}^{\prime}\right)}{1+\exp \left(\beta_{0 k}+\beta_{x}^{\prime}\right)}
$$

Where, $\mathrm{k}$ is $1,2,3, \ldots, \mathrm{K} . \pi_{\mathrm{k}}(\mathrm{x})$ is the likelihood that household adopt mobile money. $\beta_{0 \mathrm{k}}$ is a nuisance or incidental (village specific) parameter, with constant contribution within the $k^{\text {th }}$ village. The village-specific parameters $\beta_{0 \mathrm{k}}(k=1,2, \ldots, K)$ are eliminated from the likelihood by conditioning on the number of positive outcomes in each village. For details on the conditional likelihood and log likelihood see Yau Fu et al. (2005) and Heinze \& Puhr (2010). $\beta^{\prime}=$ $\left(\beta_{1}, \beta_{2}, \beta_{3}, \ldots, \beta_{N}\right)$ are coefficients with respect to covariates, $x=\left(X_{1}, X_{2}, X_{3}, \ldots, X_{N}\right)$. The covariates of interest are the size of exchange adopters and structure of social network. The other covariates include household and contextual characteristics. We also accounted for access to other information sources by including the number of mobile phones owned by the household and contact with extension (community knowledge worker ${ }^{5}$ ).

Bias in the reported number of adopters within the social network could emerge if adopters are systematically better (or less) informed about the prevalence of adoption among the members of their network than non-adopters (Liverpool-Tasie \& Winter-Nelson, 2012). This bias may be quite substantial in this application, because mobile money use is not highly visible and households will not automatically be aware of adoption in their network. If a household is unaware of the adoption of mobile money by a network member, the contact is considered inactive and the measure will appropriately exclude the unobserved adopter from the measured

\footnotetext{
${ }^{5}$ Community knowledge workers are locally recruited peer farmers and trained to use android smart phones to disseminate agricultural and market information to fellow farmers in their respective villages.
} 
social network. We mitigate the bias from misreporting by accounting for particular household characteristics (like age and education) which could affect their ability to properly identify network characteristics. Furthermore, in addition to the reported mobile money adoption status we estimate a model based on actual adoption status in order to check whether misreporting bias is an issue. We discuss this in detail in the data section, where we describe social network measurement.

In any empirical analysis of social networks, identification is always an issue because the individual is also part of the group. Manski (1993) describes this as the reflection problem meaning that the group affects individual behaviour and at the same time individual behaviour contributes to some of the group behaviour. When behavioural effects of a group on an individual, who is a member of the group, are modelled, the results obtained are biased. This problem is usually mitigated through appropriate research designs. To tackle the identification problems associated with social networks, we implemented a random matching within sample sampling approach to collect social network data (Maertens \& Barrett, 2013). We randomly matched households to their potential network members and thus do not allow households to select their network member group. Such random assignment ensures that households do not choose network members of similar preferences and thus correlation between observed peer attributes and the error term in the mobile money adoption regression equation is limited by design (Richards et al., 2014).

Apart from the reflection problem, social networks typically have endogeneity problems. Manski (1993) highlights three categories as to why network members behave in a similar fashion: (1) correlated effects, which refer to the idea that peers may be similar in mobile money adoption choices because they face a similar environment or because of similar individual and institutional characteristics they self-select into a given social network; (2) exogenous effects, which are similarities with respect to the contextual factors such as similar demographics within a social 
network (e.g. background and cultural conditions), and (3) endogenous effects, which explain the existence of herd behaviour, in that members behave like other members in their social network rather than using their information. The two types of endogenous effects relevant for our context are instrumental and informational conformity (Wydick et al., 2011). Instrumental conformity refers to a scenario where members in a reference group use mobile money because it makes it easier for each of them to send group subscription fees to the treasurer. Informational conformity is based on a member seeing another member in the social network using mobile money. This is assumed to inform her that using mobile money yields a higher level of utility, making her eager to use mobile money. Furthermore, to control for exogenous effects, we included demographic information (in particular ethnicity and religion) to control for household level characteristics that could be correlated with adoption. Because our social network groups are exogenously determined, there is limited endogenous sorting into groups and thus endogenous effects are minimized due to our research design.

\section{$2.4 \quad$ Methodology}

\subsubsection{Household survey}

This study uses data collected from rural households in Mukono and Kasese districts in Uganda. We applied a multi-stage stratification approach to draw the sample. In the first stage, we randomly selected approximately 20 villages in each district. The selection of villages was such that they share similar agro-ecological characteristics. In each village, about 12 households were randomly selected for interview. Households were chosen from lists that were compiled in collaboration with the village administration, NGO workers and local extension staff. In total, we interviewed 482 households in 39 villages. For the analysis, we had to drop five households because of inconsistent data on the social network module, resulting in a total sample size of 477 households. From the mobile money module, we are able to distinguish between households using mobile money and those who are not, based on questions pertaining to the use of mobile 
money services. Our sampling strategy yielded a random sample of 273 mobile money adopters and 204 non-adopters across the two districts as shown in Table 2.1.

Table 2. 1. Sample differentiated by mobile money adoption status

\begin{tabular}{llll}
\hline & Non-Adopters & Adopters & Total \\
\hline Mukono & 92 & 147 & 239 \\
Kasese & 112 & 126 & 238 \\
\hline Total & 204 & 273 & $\mathbf{4 7 7}$ \\
\hline
\end{tabular}

The data were collected through personal interviews using a pre-tested questionnaire during November and December 2013. The questionnaires were administered to the household head and/or the spouse. The data collected includes information on household demographics, crop and livestock production, food and non-food consumption, income, mobile phone ownership and use, mobile money services, household assets and information sources including social networks. In this study, a household is classified as mobile money adopter (user) ${ }^{6}$ if any member of the household used mobile money services in the past 12 months prior to the survey. This classification is consistent with the definition used in literature (Kikulwe et al., 2014).

\subsubsection{Measuring social networks}

We used the random matching within sample approach to collect social network data (Maertens \& Barrett, 2013). According to Maertens \& Barrett (2013), this approach performs better compared to other techniques as it can capture both strong and weak network links. Each household was matched with five other households randomly drawn from the sample (matched households). Interviewed households where first asked whether they know each of the matched households. Conditional on knowing the matched household; we elicited the details of the relationship between the interviewed household and the matched household, whether they discuss about mobile money and the household's knowledge about the matched household's mobile money use. The matched households unknown to the interviewed household were excluded from

\footnotetext{
${ }^{6}$ Mobile money user and adopter are used interchangeably in this dissertation.
} 
the household's social network. In this study, the known matched households constitute the household's social network. Based on the household's social network we compute the number of adopters, exchange adopters and variables measuring the structure of social network.

Exchange adopters: As earlier discussed, this was computed as the number of mobile money adopters within the household's social network with whom the household communicated about mobile money over the past 12 months. In line with Maertens \& Barrett (2013), our measure captures the presence of information exchange within social networks. This variable is based on the reported mobile money adoption status. However, household members are often ill informed about their matched household's behaviour and outcomes. This is especially true for innovations, which are not highly visible, like mobile money. Because of this, Maertens \& Barrett (2013) recommend to use information on both the reported and actual behaviour and outcomes of network contacts. Since the households' social network is also part of the sample, we estimated another model based on network members' actual mobile money adoption in addition to the reported adoption status. This serves as a robustness check for misreporting bias.

In order to analyse how the structure of the social network affects the adoption of mobile money, we use two variables; weak ties and network education status:

Weak ties: During the interview, respondents were asked how frequently they talk with social network members $(1=$ everyday, $2=$ at least once a week, $3=$ once a month and $4=$ less often than once a month $)^{7}$. The frequency of contact was dichotomized by distinguishing between strong relations $(0=$ combining categories 1 and 2$)$ and weak ties $(1=$ combining categories 3 and 4). The share of weak ties was calculated as the number of weak ties in a household's social network relative to the total number of social network members.

\footnotetext{
${ }^{7}$ We also tried a different definition of weak ties based on the type of relationship but this did not change the results of our models.
} 
Network education status: This variable refers to the aggregate mean years of education completed by the household heads of the social network members. This variable serves to examine the effect of network socioeconomic status.

\subsubsection{Wealth and poverty measurement}

We constructed a wealth index to measure household wealth. The wealth index was constructed using factor analysis based on several variables related to housing quality (material of the main wall, floor, roof and type of cooking fuel), water and sanitation (type of toilet and drinking water source) and household physical and agricultural assets (ownership of motorcycle and/or car, bicycle, radio and/or TV, area cultivated, value of farm equipment and total livestock units (TLU)). Table 2.2 present the descriptive information of variables used to construct the wealth index and their factor loadings. One factor with eigenvalue greater than 1 was extracted explaining $94 \%$ of the total variation. Given that all the included variables are closely related to households' wealth status, the first factor explaining $94 \%$ of the total variation is assumed to be our measure of wealth (McKenzie, 2005; Sahn \& Stifel, 2000). Kaiser-Meyer-Olkin measure of sampling adequacy is 0.7 and Bartlett's test of sphericity has a value of 538.575 ( $\mathrm{df}=66, P<$ .000) indicating that the model fit is appropriate. Based on our wealth index variable, we categorized households into two poverty groups. Households who are below the $40^{\text {th }}$ percentile of the wealth index are categorized as poor and all others as non-poor. Sahn \& Stifel (2000) also applied the asset poverty approach and used the $40^{\text {th }}$ percentile as a cut off-point for poverty categories. 
Table 2. 2. Variables used in constructing wealth index and their factor loadings

\begin{tabular}{|c|c|c|c|c|c|}
\hline Dimension & Variable & Definition & Mean & SD & $\begin{array}{l}\text { Factor } \\
\text { loading }\end{array}$ \\
\hline \multirow[t]{4}{*}{ Housing quality } & Wall & Main house wall (mud, wood $=0 ;$ brick, stone $=1$ ) & 0.72 & 0.45 & 0.5447 \\
\hline & Floor & Main house floor $($ mud, wood $=0$; cement, tiles $=1)$ & 0.49 & 0.50 & 0.5888 \\
\hline & Roof & Main house roof $($ grass $=0 ;$ iron, tiles $=1)$ & 0.90 & 0.30 & 0.1218 \\
\hline & Light & $\begin{array}{l}\text { Source of lighting (paraffin, candle }=0 \text {; electricity, } \\
\text { solar, generator, gas }=1 \text { ) }\end{array}$ & 0.18 & 0.39 & 0.2735 \\
\hline \multirow[t]{2}{*}{$\begin{array}{l}\text { Water and } \\
\text { sanitation }\end{array}$} & Toilet & $\begin{array}{l}\text { Toilet system (bush }=0 \text {; flush, pit, ventilated latrine }= \\
\text { 1) }\end{array}$ & 0.99 & 0.11 & 0.1018 \\
\hline & Water & $\begin{array}{l}\text { Source of drinking water (unprotected well = } 0 \text {; tap, } \\
\text { borehole, protected well }=1 \text { ) }\end{array}$ & 0.71 & 0.45 & 0.1093 \\
\hline \multirow[t]{6}{*}{ Physical assets } & Motor/car & Own motorcycle and or car $($ no $=0 ;$ yes $=1)$ & 0.14 & 0.35 & 0.3758 \\
\hline & Bicycle & Own a bicycle $($ no $=0 ;$ yes $=1)$ & 0.60 & 0.49 & 0.3581 \\
\hline & Radio/TV & Household has radio and or $\mathrm{TV}($ no $=0 ;$ yes $=1)$ & 0.84 & 0.36 & 0.3210 \\
\hline & Land & Size of land cultivated (acres) & 3.78 & 3.12 & 0.4316 \\
\hline & Farmequip & Log value of farm equipment & 10.75 & 1.21 & 0.4530 \\
\hline & TLU & Total livestock units & 1.00 & 1.95 & 0.4065 \\
\hline
\end{tabular}

\subsection{Results and discussion}

\subsubsection{Results of descriptive analyses}

Overall, $57 \%$ of the households in our sample adopted mobile money (Table 2.3). Eighty three percent of the households in the sample own a mobile phone and on average, households own 2 mobile phones. Household heads in the sample have relatively low levels of education with an average of 6.4 years of schooling. Low literacy may be associated with difficulties in navigating through mobile phone menus, which are often written in English. Furthermore, 50 percent of the households in our sample have a household member who is engaged in off-farm activities. This variable is of relevance to our study, because most off-farm income activities are conducted outside the village and mobile money is one alternative channel for remitting money back to members in the village. 
Table 2. 3. Variable names, definitions and descriptive statistics

\begin{tabular}{|c|c|c|c|}
\hline Variable & Definition & Mean & SD \\
\hline \multicolumn{4}{|l|}{ Dependent variables } \\
\hline Mobile money adoption & Household adopted mobile money: dummy $(0 ; 1)$ & 0.57 & 0.50 \\
\hline \multicolumn{4}{|l|}{ Independent variables } \\
\hline \multicolumn{4}{|l|}{ Social network } \\
\hline Exchange adopters & Number of mobile money adopters household communicated about mobile money & 0.32 & 0.91 \\
\hline Weak ties & Number of weak ties relative to total number of social network members & 0.52 & 0.40 \\
\hline Network education & Years of schooling of social network members & 6.33 & 2.54 \\
\hline Group membership & Household member(s) belongs to any group: dummy $(0 ; 1)$ & 0.70 & 0.46 \\
\hline \multicolumn{4}{|l|}{ Access to information } \\
\hline Mobile phone & Number of mobile phones owned by household & 1.5 & 1.16 \\
\hline Extension contact & Household accesses information from community knowledge worker: dummy $(0 ; 1)$ & 0.50 & 0.50 \\
\hline \multicolumn{4}{|l|}{ Household characteristics } \\
\hline Age & Age of household head (years) & 49.54 & 13.59 \\
\hline Age squared & Squared age of household head (years) & 2639.47 & 1427.81 \\
\hline Gender & Gender of household head (1=Male) & 0.85 & 0.36 \\
\hline Education & Education of household head (years of schooling) & 6.42 & 4.36 \\
\hline Household size & Household size (number) & 7.00 & 2.80 \\
\hline Religion & Main religion of household $(1=$ Christianity; $0=$ Islam $)$ & 0.87 & 0.34 \\
\hline Ethnicity $^{8}$ & Household belongs to main ethnic group: dummy $(0 ; 1)$ & 0.77 & 0.42 \\
\hline \multicolumn{4}{|c|}{$e^{2}$} \\
\hline Wealth index & The first principal factor & $-1.30 \mathrm{e}-09$ & 0.83 \\
\hline Off farm income & Household member engaged in off-farm income : dummy $(0 ; 1)$ & 0.50 & 0.50 \\
\hline \multicolumn{4}{|l|}{ Location } \\
\hline MMA distance & Distance to mobile money agent (MMA) in km & 2.76 & 3.33 \\
\hline District & Household located in Mukono district: dummy $(0 ; 1)$ & 0.50 & 0.50 \\
\hline
\end{tabular}

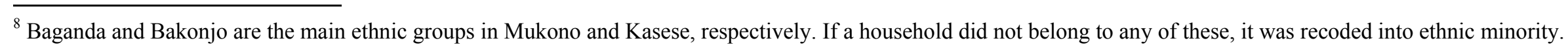


Table 2.4 shows the size of the households' social network. As discussed earlier this is the number of known matched households regardless of mobile money adoption status. Twenty two percent of the households in our sample had only one social network member. About $50 \%$ of the households had a social network size of 5. This implies that these households knew all the 5 households that they were randomly matched with.

Table 2. 4. Size of household's social network

\begin{tabular}{lll}
\hline Number & Frequency & Percent \\
\hline 1 & 22 & 4.61 \\
2 & 25 & 5.24 \\
3 & 70 & 14.68 \\
4 & 122 & 25.58 \\
5 & 238 & 49.90 \\
\hline Total & 477 & 100 \\
\hline
\end{tabular}

Table 2.5 shows the frequency distribution of adopters and exchange adopters in a household's social network. Seventy eight and eighty four percent of the households reported zero adopters and exchange adopters in their social network, respectively. About $22 \%$ of the households in the sample identified at least two mobile money adopters in their network. The number of actual adopters in the household's social network is shown in column 4. The fact that there are many more actual adopters than reported adopters is quite interesting. This confirms that households are indeed not well informed about mobile money use of their contacts. In this article, we use the reported adopters because this is what matters for social learning, i.e. if household does not know contact is using mobile money, obviously the contact will not influence his decision. Furthermore, we control for the effect of reporting bias by estimating different model specifications. Regarding exchange adopters, results indicate that only about $16 \%$ of the sampled households communicated and discussed about mobile money with one or more exchange adopters in their social network. This statistic is quite low, possibly because households have limited information about social network members' mobile money use. This is often the case with unobservable technologies such as mobile money. 
Table 2. 5. Frequency distribution of adopters within a household's social network

\begin{tabular}{lllllll}
\hline \multirow{2}{*}{ Number } & \multicolumn{2}{l}{ Adopters (reported) } & \multicolumn{2}{l}{ Adopters (actual) } & \multicolumn{2}{l}{ Exchange adopters (reported) } \\
\cline { 2 - 7 } & Frequency & Percent & Frequency & Percent & Frequency & Percent \\
\hline 0 & 370 & 77.57 & 125 & 26.21 & 403 & 84.49 \\
1 & - & - & - & - & 35 & 7.34 \\
2 & 43 & 9.01 & 133 & 27.84 & 19 & 3.98 \\
3 & 21 & 4.40 & 125 & 26.21 & 4 & 0.84 \\
4 & 27 & 5.66 & 75 & 15.72 & 11 & 2.31 \\
5 & 16 & 3.35 & 19 & 3.98 & 5 & 1.05 \\
\hline Total & 477 & 100 & 477 & 100 & 477 & 100 \\
\hline
\end{tabular}

Table 2.6 compares selected characteristics of mobile money adopters and non-adopters, presenting differences in means and t-test results. As evident, there are some notable differences between the two groups. Mobile money adopters have more exchange adopters in their social network than non-adopters. There is however no significant difference in terms of the share of weak-ties between the two groups. On average, mobile money adopters have a more educated social network than non-adopters. Furthermore, mobile money adopters live in closer proximity to mobile money agents compared to non-adopters.

Table 2. 6. Social network variables by adoption status

\begin{tabular}{lccc}
\hline & Adopters & Non-adopters & Differences \\
\hline Exchange adopters & 0.498 & 0.088 & $0.41^{* * *}$ \\
Weak ties & 0.54 & 0.50 & 0.04 \\
Network education & 6.560 & 6.027 & $0.53^{* *}$ \\
Group membership & 0.766 & 0.608 & $0.16^{* * *}$ \\
Distance to MMA & 2.315 & 3.366 & $-1.05^{* * *}$ \\
\hline Observations & 273 & 204 &
\end{tabular}

$*, * *, * * *$ indicates the corresponding differences are significant at the $10 \%, 5 \%$, and $1 \%$ levels, respectively (t-test).

One important question is how the adoption of mobile money is distributed across poverty levels, which will help us to identify whether the poor use mobile money. Figure 2.1 shows mobile money adoption differentiated by poverty status. Sixty seven percent of the wealthy households adopted mobile money, compared to only $43 \%$ of the poor households. Thus, in comparison to wealthier households, poor households appear to be lagging behind in the adoption of mobile 
money. Later in our econometric analysis, we split up the sample according to wealth category to identify heterogeneous social network effects.

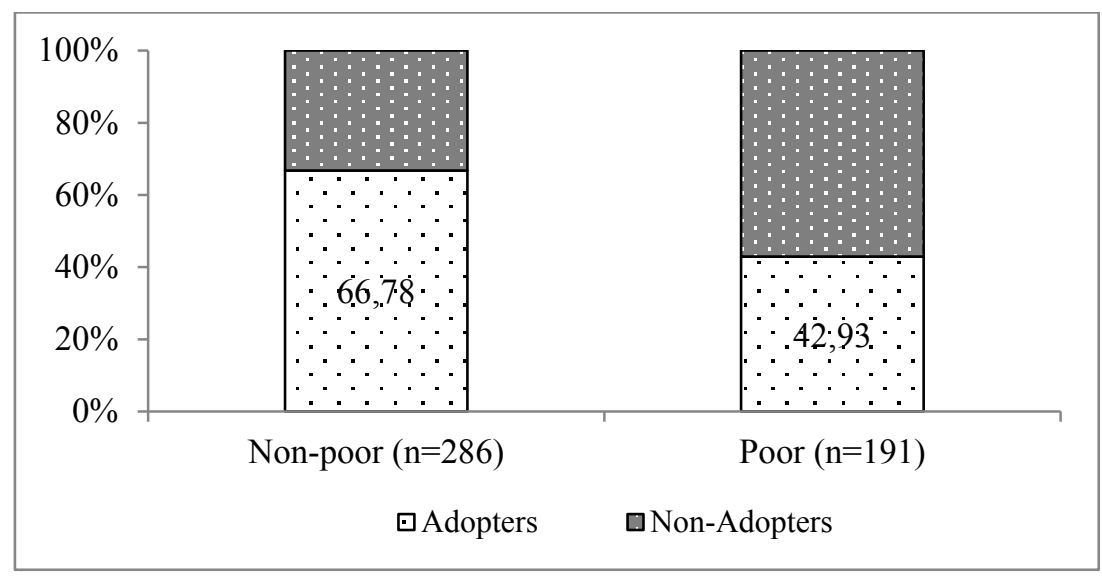

Figure 2. 1. Mobile money adoption differentiated by household poverty

Table 2.7 compares the social network and information access characteristics of poor and wealthy households, presenting differences in means and t-test results. Wealthy households have more exchange adopters in their social network than poor households. This suggests that wealthy households have better access to mobile money information. On the average, wealthy households also have more educated social network contacts than poor households. Based on the number of exchange adopters and network education status, we can argue that poor households are associated with information-poor networks. The descriptive statistics suggest that poor households are lagging behind in mobile money adoption highlighting the importance of improving information access especially for the poor.

Table 2. 7. Social network and information variables by poverty status

\begin{tabular}{lccc}
\hline & Poor & Non-poor & Differences \\
\hline Exchange adopters & 0.183 & 0.416 & $0.23^{* * *}$ \\
Weak ties & 0.492 & 0.542 & 0.05 \\
Network education & 5.996 & 6.557 & $0.56^{* *}$ \\
Group membership & 0.660 & 0.724 & 0.06 \\
Mobile phone & 1.152 & 1.755 & $0.60^{* * *}$ \\
Extension contact & 0.445 & 0.538 & $0.09^{* *}$ \\
Distance to MMA & 2.755 & 2.770 & 0.02 \\
\hline Observations & 191 & 286 & \\
\hline
\end{tabular}

$*, * *, * * *$ indicates the corresponding differences are significant at the $10 \%, 5 \%$, and $1 \%$ levels, respectively (t-test). 
Although the comparisons discussed above show some significant differences by adoption and poverty status, these descriptive statistics are not sufficient to explain adoption decisions across sample households, since they do not account for the effects of other household specific characteristics. In the next section, we use econometric techniques to estimate social network effects.

\subsubsection{Econometric results}

\subsubsection{Effect of social network on mobile money adoption}

Estimation results of the effects of social networks on adoption of mobile money are presented in Table 2.8. We estimate four different model specifications. In all models, we report the exponentiated coefficients (odds-ratios), which may be interpreted as the estimated odds of change in mobile money adoption as a result of a unit change in the independent variable (Gould, 2000). In the first specification, we estimate an ordinary logistic regression without controlling for correlated effects. In the second model, we estimate conditional logistic regression with cluster-correlated standard errors to control for correlated effects. The third model is similar to the second model, only that the wealth variable is excluded. The wealth variable could potentially be endogenous, if the adoption of mobile money leads to greater efficiency in households' business operations and accordingly to higher profits. We try to minimize the endogeneity of the wealth variable by choosing an asset index to measure wealth, which responds more slowly to changes in income flows (Howe et al., 2008). In addition, we explore how sensitive our results are to the exclusion of the wealth variable. While models 1 to 3 are based on reported network members' mobile money adoption status, model 4 uses actual network members' mobile money adoption status to control for misreporting bias. 
Table 2. 8. Determinants of mobile money adoption: Conditional logistic regression

\begin{tabular}{|c|c|c|c|c|c|c|c|c|}
\hline & \multicolumn{2}{|c|}{ Model 1: logit } & \multicolumn{2}{|c|}{ Model 2} & \multicolumn{2}{|c|}{ Model 3} & \multicolumn{2}{|c|}{ Model 4} \\
\hline & $\mathrm{EC}$ & Std. err. & $\mathrm{EC}$ & Std. err. & $\mathrm{EC}$ & Std. err. & $\mathrm{EC}$ & Std. err. \\
\hline \multicolumn{9}{|l|}{ Social network } \\
\hline Exchange adopters & $1.800^{* *}$ & 0.444 & $1.752^{* *}$ & 0.396 & $1.773^{* *}$ & 0.402 & $1.704^{*}$ & 0.472 \\
\hline Weak ties & 0.876 & 0.231 & 1.114 & 0.375 & 1.075 & 0.359 & 1.066 & 0.354 \\
\hline Network education & 1.015 & 0.045 & 0.964 & 0.068 & 0.969 & 0.068 & 0.973 & 0.068 \\
\hline Group membership & 1.215 & 0.344 & 1.329 & 0.398 & 1.404 & 0.415 & 1.432 & 0.421 \\
\hline \multicolumn{9}{|l|}{ Access to information } \\
\hline Mobile phone & $3.407^{* * *}$ & 0.810 & $2.944^{* * *}$ & 0.512 & $3.029^{* * *}$ & 0.522 & $3.054^{* * *}$ & 0.523 \\
\hline Extension contact & $1.475^{*}$ & 0.325 & & & & & & \\
\hline \multicolumn{9}{|l|}{ Household characteristics } \\
\hline Age & 1.052 & 0.062 & 1.009 & 0.064 & 1.010 & 0.064 & 1.026 & 0.065 \\
\hline Age squared & 1.000 & 0.001 & 1.000 & 0.001 & 1.000 & 0.001 & 1.000 & 0.001 \\
\hline Gender & 1.549 & 0.619 & 1.743 & 0.632 & $1.831^{*}$ & 0.658 & 1.791 & 0.640 \\
\hline Education & 1.037 & 0.029 & 1.030 & 0.033 & 1.035 & 0.033 & 1.034 & 0.033 \\
\hline Household size & 0.976 & 0.050 & 0.993 & 0.050 & 0.997 & 0.050 & 0.993 & 0.049 \\
\hline Religion & 1.295 & 0.454 & 1.434 & 0.511 & 1.451 & 0.516 & 1.482 & 0.526 \\
\hline Ethnicity & 0.999 & 0.274 & 1.237 & 0.412 & 1.288 & 0.425 & 1.238 & 0.406 \\
\hline \multicolumn{9}{|l|}{ Wealth } \\
\hline Wealth index & 1.289 & 0.240 & 1.222 & 0.225 & & & & \\
\hline Off farm income & $2.007^{* * *}$ & 0.472 & $2.007^{* * *}$ & 0.536 & $2.045^{* * *}$ & 0.545 & $2.064^{* * *}$ & 0.549 \\
\hline \multicolumn{9}{|l|}{ Location } \\
\hline Distance to MMA & $0.905^{* * *}$ & 0.034 & 0.934 & 0.047 & 0.937 & 0.048 & 0.941 & 0.048 \\
\hline District & $1.964^{* * *}$ & 0.489 & & & & & & \\
\hline Observations & 477 & & $465 t$ & & $465 \dagger$ & & $465 t$ & \\
\hline Pseudo $R^{2}$ & 0.324 & & 0.317 & & 0.314 & & 0.307 & \\
\hline Wald chi2(17)/LR chi2(15) & $135.51^{* * *}$ & & $146.10^{* * *}$ & & $144.91^{* * *}$ & & $141.47^{* * *}$ & \\
\hline Log likelihood & -220.14 & & -157.50 & & -158.10 & & -159.82 & \\
\hline
\end{tabular}

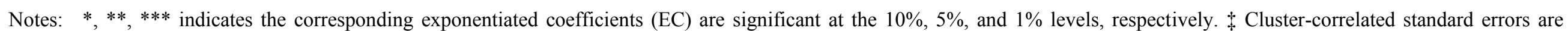

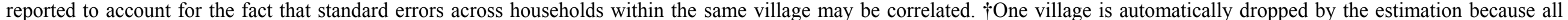

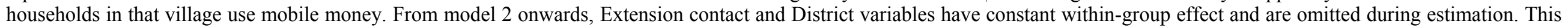
does not affect the estimation results (Gould, 2000). 
In models 1 and 2 the size of exchange adopters is positive and significant at the $5 \%$ level. The exponentiated coefficient decreases from 1.80 in first model to 1.75 when controlling for correlated effects in model 2 . The variables capturing social network structure, weak ties and network education status, remain insignificant in both models. Therefore the size of exchange adopters in the social network positively influences the adoption of mobile money. In the second and third models we control for correlated effects in social networks. The only difference is that in model 3, we exclude the wealth variable. Results in models 2 and 3 are quite similar in signs, and the magnitudes increase only slightly in model 3, suggesting that results are not sensitive to the exclusion of the wealth variable. Given that the wealth variable is not significant once we control for village fixed effects, we proceed excluding the wealth variable in our specifications.

The third and fourth models are quite similar in that we exclude the wealth variable and control for correlated effects. The only difference is that model 4 is based on the actual mobile money adoption status of network members instead of the reported adoption status used in model 3. Results show that the size of exchange adopters is positive and significant in both models. The exponentiated coefficient decreases from 1.77 in model 3 to 1.70 in model 4 , and the corresponding significance level changes from $5 \%$ to $10 \%$ level. The variables weak ties and network education status remain insignificant in both models. Other control variables, such as the number of mobile phones owned and off-farm income activity are all positive and significant at the $1 \%$ level in both models. The results in models 3 and 4 are qualitatively and quantitatively similar implying that misreporting bias is not a major issue in our study. In what follows, we thus interpret results based on the reported behaviour of network members (model 3).

The results confirm our first hypothesis that the size of exchange adopters affects mobile money adoption. The size of exchange adopters within a household's social network has a positive and significant effect on the adoption of mobile money with an exponentiated coefficient of 1.77 . This implies that adding one exchange adopter to the household social network increases the odds 
of adopting mobile money by $77 \%$. This result is plausible and emphasizes the crucial role of social learning for the diffusion of mobile money technology. Social networks increase access to information, so that the marginal costs of accessing information for an individual household decrease. This result is in line with other studies indicating that communication within social networks affects financial choices by improving the quantity of information available to the household (Zhang et al., 2012). When non-adopters interact and discuss about mobile money with adopters, they are better informed and can make their adoption decisions wisely. This shows that social learning may be effective in disseminating information on mobile money technology and may therefore promote the adoption of mobile money.

Furthermore, we hypothesized that a larger proportion of weak ties increases the likelihood of mobile money adoption. However, the results show that a larger proportion of weak ties have no influence on the adoption of mobile money. This is in contrast to Zhang et al. (2012) who found that weak ties improve the diversity of financial information that a household acquires. Finally, our last hypothesis that households who have a network with higher average educational status are more likely to adopt mobile money is not confirmed either. Similar results are found by Röper et al. (2009) who report that the socio-economic status of network members did not influence the likelihood of finding a home. Our results are at odds with other studies (Song \& Chang, 2012; Lin, 1999; Lai et al., 1998). For example, Song \& Chang (2012) find that education of network members positively influences the frequency of health information seeking. Model results suggest that mobile money adoption is influenced by the size of exchange adopters in the social network and not by the structure of social network. Therefore the effects of social network structure depend upon the type of technology under study and should not be generalized.

Furthermore, besides social network variables, there are other household and contextual characteristics that influence the adoption of mobile money. For example, results reveal that the number of mobile phones owned and gender of head affect the adoption decision positively. This 
implies that in addition to social networks, households are informed about the existence of mobile money through other information channels, such as mobile phone communication. Mobile phone is positive and highly significant with an odds ratio of 3 , which means that the odds of adopting mobile money are 3 times higher for households with more mobile phones. This is expected as households can transact mobile money on their own mobile phones as long as the mobile money account is registered. Our results show that male headed households have a higher likelihood of adopting mobile money compared to female headed households. Off-farm income activity is positive and significant at the $1 \%$ level. In particular, households with members engaged in offfarm income activities have a 2-fold greater odds of adopting mobile money compared to those with no off-farm income. This is plausible, as most off-farm income activities are conducted outside the village and mobile money is used as one of the channels for remitting money to household members in the village.

\subsubsection{Social network effects by household poverty status}

Chang (2005) highlights that wealthier households rely less on social networks and consult different sources of financial information, e.g. newspapers, internet and radio. The poorer oftentimes depend much stronger on social networks as their sole source of information. Even though social networks may be the sole source of information, they may not have an effect on poor households if they are associated with an information-poor network (Liverpool-Tasie \& Winter-Nelson, 2012). To formally test the differential impacts of social networks, we estimate conditional logistic regression models separately for poor and non-poor households. The regression results are shown in Table 2.9. 
Table 2. 9. Social network effects differentiated by poverty status

\begin{tabular}{lcccc}
\hline & \multicolumn{2}{c}{ Poor households } & \multicolumn{2}{c}{ Non-poor households } \\
& EC & Std. err. & EC & Std. err. \\
\hline Exchange adopters & 1.677 & 0.856 & $1.802^{* *}$ & 0.477 \\
Weak ties & 0.678 & 0.456 & 1.856 & 0.870 \\
Network education & 0.949 & 0.118 & 0.902 & 0.091 \\
Group membership & 1.882 & 1.143 & 1.233 & 0.493 \\
Mobile phone & $3.851^{* * *}$ & 1.393 & $2.316^{* * *}$ & 0.498 \\
Age & 1.257 & 0.189 & 0.961 & 0.087 \\
Age squared & 0.998 & 0.001 & 1.000 & 0.001 \\
Gender & 1.679 & 1.293 & 1.672 & 0.883 \\
Education & 1.014 & 0.067 & 1.051 & 0.048 \\
Household size & 0.847 & 0.086 & 1.032 & 0.067 \\
Religion & 0.884 & 0.651 & $2.619^{* *}$ & 1.250 \\
Ethnicity & $4.823^{*}$ & 3.942 & 0.838 & 0.387 \\
Off farm income & $3.993^{* *}$ & 2.245 & $2.370^{* * *}$ & 0.910 \\
Distance to MMA & 0.798 & 0.114 & 0.995 & 0.052 \\
\hline Observations & 179 & & 271 & \\
Pseudo $R^{2}$ & 0.478 & & 0.298 & \\
LR chi2(14) & $69.96^{* * *}$ & & $67.63^{* * *}$ & -79.68 \\
Log likelihood & -38.19 & & & \\
\hline & & & & \\
\hline
\end{tabular}

$*, * * * * *$ indicates the corresponding exponentiated coefficients (EC) are significant at the $10 \%, 5 \%$, and $1 \%$ levels, respectively.

For non-poor households, the number of exchange adopters within a household's social network is positive and significant at the $5 \%$ level with an exponentiated coefficient of 1.8 . In contrast, this variable is insignificant for poor households. The other variables capturing network structure: weak ties and network education status are insignificant for both poverty categories. Our results show that the effects of size of exchange adopters is stronger in the case of non-poor households, a finding that is not in line with (Chang, 2005) who studied the influence of social networks on sources of financial information. In our study context, poor households may potentially benefit less from social network effects because they are associated with information-poor networks, as shown earlier in Table 2.7. This interpretation is in line with the findings of Liverpool-Tasie \& Winter-Nelson (2012). 
Other control variables, including the number of mobile phones owned and off-farm income activity are positive and significant in both categories. Ethnicity is positive and significant only in the case of poor households indicating that for poor households belonging to the major ethnic group is critical for mobile money adoption. On the other hand, religion is positive and highly significant for non-poor households.

\subsection{Conclusion and policy implications}

This article examines the influence of social networks on the adoption of mobile money among rural households in Uganda. We estimate conditional logistic regression to control for household characteristics, correlated effects, and other possible information sources without introducing the incidental parameter bias. Empirical results show that the size of exchange adopters positively influence the adoption of mobile money. This suggests that information exchange within social networks helps disseminate information about mobile money and increases its adoption. In contrast, the structure of the social network is found to have no significant influence on the adoption of mobile money. In addition to social network effects, the number of mobile phones owned and the existence of off-farm income activities positively affect the adoption of mobile money. Our results also show that social network effects, and in particular the size of exchange adopters appear to be more pronounced for non-poor households.

Study findings have important policy implications for the diffusion of mobile money in developing countries, where formal information institutions are lacking. They suggest that exchange within social networks help disseminate information about mobile money. The adoption of mobile money is likely to be increased if promotion programs reach more social networks. Furthermore, mobile money promotion programs need to reach the poor, because our evidence suggests that the poor may be trapped in information-poor networks and thus social network multiplier effects will most likely not automatically work in their case. Therefore, there is need to target mobile money promotion programs to reach the poor. One possible promotion 
strategy is the provision of mobile money education and awareness campaigns in rural areas. Making rural households more aware about mobile money, its use and advantages is likely to improve adoption. In particular, mobile money service providers should be at the forefront of rolling out mobile money promotion programs because they stand to benefit financially if more households adopt mobile money. From a policy perspective, there is a need for policy makers, mobile money service providers and extension to strengthen and utilize informal institutions to disseminate information about mobile money.

Mobile money is a relatively new technology in developing countries and many research questions remain unexplored. This study adds to the emerging literature on mobile money, and in particular on the influence of social networks on the adoption decision. We use only two variables to measure the structure of the social network. Future studies could enhance the analysis by using additional measures of social network structure, for example difference in educational attainment level, age and distance of network members relative to interviewed household. In addition, other drivers of adoption, for example: household perception of fraud and security associated with mobile money are not accounted in this study. Our study uses cross-section data which is static and relates to current effect. Such a static analysis fails to account for the dynamic nature of social networks. Further research might need to build on panel data to explore the effects of social networks over time. 


\title{
3 Mobile money and household food security in Uganda'
}

\begin{abstract}
.
Mobile money technology is growing rapidly in developing countries. However, empirical studies of the broader welfare effects of the technology on rural households are limited. Using household survey data, we analyse the effect of mobile money on household food security in Uganda. Unlike previous studies that rely on a single measure of food security, we measure food security using two indicators - food insecurity index and food expenditure. To account for selection bias in mobile money use, we estimate treatment effects and instrumental variables regression. The use of mobile money reduces food insecurity by 0.20 index points. In the food expenditure model, results show that the use and intensity of using mobile money increase food consumption by $9 \%$ points and $1 \%$ points respectively. Our results confirm that mobile money improves household food security. Policy interventions and strategies to improve household food security should consider the promotion of mobile money among rural households in Uganda and other developing countries.
\end{abstract}

\subsection{Introduction}

Mobile money is spreading rapidly in developing countries. Mobile money refers to the use of mobile phones to perform financial and banking functions (Donovan, 2012; IFC, 2011). Mobile money offers various benefits which are especially useful in developing countries where financial access is limited (Donovan, 2012; Kikulwe et al., 2014). One key benefit is improving access to financial services for the poor and those with no bank accounts. Mobile money facilitates financial transactions through affordable payment systems, which is of particular importance in developing countries where households rely on remittances from family members (Donovan,

\footnotetext{
9 This chapter is co-authored by Meike Wollni. The following roles were performed by me: designing of the study, data analysis, and interpretation of the research results in cooperation with Meike Wollni; writing of the paper. This paper has been presented at the World Food System Conference in Ascona, Switerzland on 21-26 June 2015.
} 
2012; IFC, 2011; Jack et al., 2013). The affordability of mobile money also emanates from modest and proportionate withdrawal fees. The proportionate withdrawal fees are usually not a barrier to poor households who transact in small amounts. The other benefit is associated with reduced security risk of moving with cash and faster transfer of money into rural areas (Kikulwe et al., 2014). Savings and insurance products are also now being offered through mobile money. This is particularly valuable for poor households as it offers the possibility for protection against vulnerabilities such as illness and to smooth consumption (Jack \& Suri, 2014).

A growing number of studies document the positive effect of financial access on savings behaviour (Karlan et al., 2014), consumption and productive investment (Dupas \& Robinson, 2013; Adams \& Cuecuecha, 2013). Mobile money is one innovation that has the potential to improve financial access especially for rural households with no bank accounts. Rural households could gain from using mobile money through faster transfer of money from various sources (e.g. remittances, payment from traders, wage etc), lower financial transaction costs and availability of other financial instruments for example savings and insurance. Mobile money is expected to bridge the financial access gap, thus allowing for food security and broader welfare improvements especially among the financially excluded rural communities in developing countries. To date there are few studies that have analysed the welfare effects of mobile money on rural household's in developing countries (Jack \& Suri, 2014; Jack et al., 2013; Kikulwe et al., 2014; Munyegera \& Matsumoto, 2014). Most of these studies find positive effects of mobile money on household income (Kikulwe et al., 2014), consumption smoothing (Jack \& Suri, 2014) and per capita consumption (Munyegera \& Matsumoto, 2014).

The above mentioned studies provide new empirical evidence of the broader welfare effects of mobile money. However, little is known about the effects of mobile money on food security of the rural poor. This article fills this gap by analysing the effect of mobile money on household food security in Uganda, where the use of mobile money has grown rapidly in recent years. Our 
paper contributes to the emerging literature on mobile money in several ways. First, to the best of our knowledge this is the first paper that analyse the effects of mobile money on food security in a developing country context. Second, unlike studies that use one measure of food security, we contribute methodologically by using two measures as food security is multidimensional (Maxwell et al., 2014). In addition to food expenditure (an objective and monetary measure), we use a subjective and non-monetary measure: the Household Food Insecurity Access Scale (HFIAS). The advantage of the HFIAS is that it includes many facets of food security and also captures subjectively perceived risks of food insecurity. In addition, measurement errors are minimal, in particular in comparison to consumption indicators (Kabunga et al., 2014). The use of two measures adds to the robustness of results. Our study is relevant in the context that we study the effects of mobile money (a new financial innovation) on food security - an issue high on the global policy agenda. Our study is also unique in that we use two alternative specifications of the treatment variable (use and intensity of use).

The remainder of this article is organised as follows. In the next section we describe the conceptual framework. We then discuss the methodology - description of survey data and food security measures used for empirical analysis, followed by the estimation strategy employed. Empirical results are presented and discussed and the last section concludes and discusses policy implications. 


\subsection{Conceptual framework}

In our framework, we follow Munyegera \& Matsumoto (2014) and consider the same rural household in two time periods: prior and after the introduction of mobile money (Figure 3.1). The rural household is located a remote village where financial institutions are not available. This household receives money from various sources (e.g. remittances, payment from traders, wage or pension) in both periods. The only difference is on the money transfer or payment method which affects the overall disposable income. In period one, cash is transferred physically through slow and insecure informal methods (e.g person, bus, taxi) between the sender working in urban area and receiver in the rural village (Kikulwe et al., 2014; Munyegera \& Matsumoto, 2014). In addition, household members have to travel to distant business centres to receive payments for their agricultural produce from traders as well as access other financial services, for example pension. This is associated with high costs of accessing finance both in terms of transport fare and opportunity cost of travel time between the two locations. The high transaction cost reduces household disposable income and reduces household investment in food, health, education and agricultural inputs. Subsequently, overall household welfare is reduced. Therefore, money transfer channels that are accessible in remote areas, relatively cheap, fast and secure may facilitate smooth flow of money into the rural households.

In period two, mobile money is introduced which makes it possible for rural households in remote areas to access funds remitted by their working members, traders and pension organizations. In period two, there is high probability of increased flow of cash into rural households because of the introduction of a relatively faster and safer financial innovation. The benefits realized through using mobile money have the potential to contribute to household food security and poverty reduction through various pathways. First, the household is able to receive cash faster from various sources (e.g. remittances, payment from traders, wage or pension payment). Mobile money is now among the major channels used by household members working 
in urban areas to send money to rural households in Uganda. Jack et al. (2013) show that mobile money positively increased the volume of internal remittances in Kenya. Kikulwe et al. (2014) and Munyegera \& Matsumoto (2014) show that mobile money is associated with higher remittances received by households. The remittances received can be used for household productive and consumptive purposes (Adams \& Cuecuecha, 2013). This has roots in exchange theory that demonstrates that inter-household exchange of resources can generate improved household welfare (Becker, 1982). The faster transfer of money associated with mobile money enhances the time value of money and is associated with a faster liquidity effect on rural households.

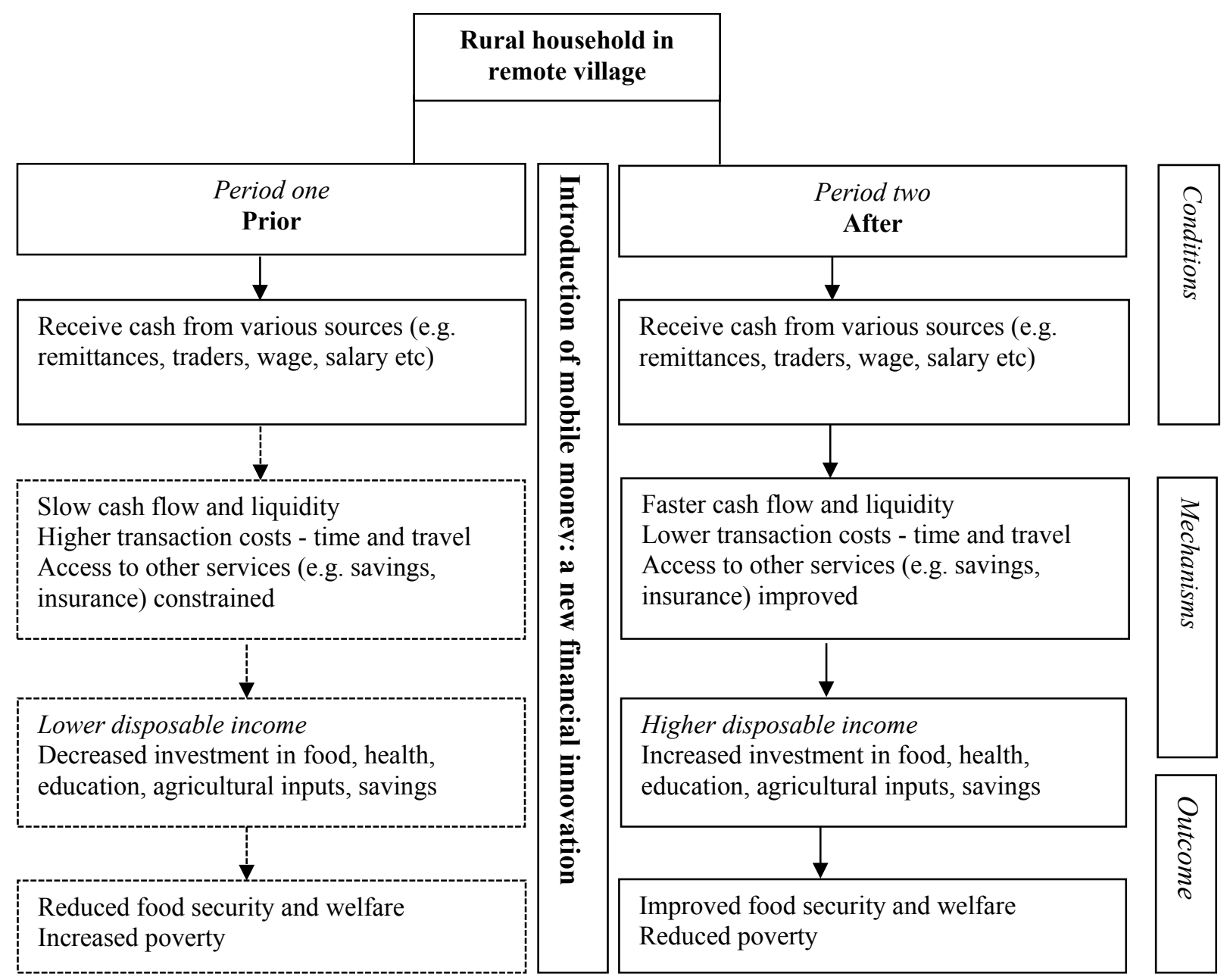

Figure 3. 1. Pathways through which mobile money affect household food security and poverty

The second pathway through which mobile money can affect household welfare and poverty is through lower transaction costs. Mobile money can be an accessible, convenient and cheap 
medium for the delivery of financial services and more reliable than traditional and informal methods (Kikulwe et al., 2014). In many countries, mobile money is a relatively cheaper means of money transfer than other alternatives (Donovan, 2012) and users benefit from the reduced time and monetary costs of accessing financial services. The lower transaction costs associated with sending money via mobile money services can directly translate into more money available to households for various expenditures, for example food, health, education and agricultural inputs. With access to finance through mobile money services, households can investment in productivity enhancing agricultural inputs and technologies, for example improved seeds, fertilizers, crop chemicals, livestock feeds and hired labour (Kikulwe et al., 2014). There is a growing body of empirical studies linking the use of new and improved technologies (e.g. fertilizers, improved varieties etc) to productivity and household welfare in developing countries. Increased crop and livestock productivity contributes positively to household food stocks. Recent studies show the positive effect of improved maize adoption (Bezu et al., 2014; Kassie \& Jaleta et al., 2014), improved wheat adoption (Shiferaw et al., 2014) on productivity and household welfare in Africa. In addition, higher agricultural productivity may result in marketable surplus. The revenue obtained from marketable surplus may be used to purchase food and agricultural inputs or saved.

Third, it is now possible to extend the range of financial services offered by mobile money beyond basic payment and withdrawal to other financial products, for example savings and insurance (IFC, 2011). With access to savings or insurance services, households can efficiently manage risks and invest in improving agricultural production. Jack \& Suri (2014) found that remittances received via mobile money enabled households in Kenya to smooth consumption, thus offering a form of risk insurance. In this section, we demonstrated that mobile money potentially lowers the economic and opportunity costs of transferring money and enhances liquidity through faster transfer of cash. Through these pathways, we therefore hypothesize that mobile money improves welfare and reduces poverty among rural households. However, it 
should be kept in mind that other mechanisms may be at work when interpreting the observed household welfare effects.

\subsection{Methodology}

\subsubsection{Data}

This essay uses data collected from rural households in Mukono and Kasese districts in Uganda. Details of the data collection and sampling strategy are explained earlier in Section 2.4.1. From the sample shown in Section 2.4.1, one non-adopting household was dropped because of missing information on consumption. Our analysis is based on 476 households in 39 villages consisting of 273 mobile money users and 203 non-users. Data on socioeconomic characteristics, including food consumption and expenditure, were collected at the household level. Details on food consumption were collected using 7-day recall period for food, beverages and tobacco. A 30-day recall period was used to capture purchases that are undertaken by households only once per month (Deaton \& Zaidi, 2002). The HFIAS module consisted of nine questions, representing different experiences of food insecurity over the last 30 days (Coates et al., 2007).

A household is defined as a mobile money user if any member of the household used mobile money services in the past 12 months prior to the survey (Kikulwe et al., 2014). We measure the intensity of using mobile money as the number of times a household sent and received money via mobile phone in the past 12 months, with zero values indicating mobile money has not been used. This is similar to the approach used by Kirui et al. (2012).

\subsubsection{Food security measurement}

According to the World Food Summit in 1996, food security exists when all people, at all times, have physical and economic access to sufficient safe and nutritious food to meet their dietary needs and food preferences for a healthy and active life (FAO, 1996). Food security is multidimensional and this makes its measurement quite complex. There are several indicators 
that are used to measure food security. Barrett (2010) gives an overview of objective measures of food security, e.g. dietary intake, expenditure, and health indicators as well as subjective measures, e.g. perceived adequacy of consumption, exposure to risk and the cultural acceptability of foods. However most of the approaches based on dietary intake and anthropometric indicators are expensive and data intensive (de Haen et al., 2011). Maxwell et al. (2014) provide a review of the subjective indicators often used by agencies working on food security for example World Food Program. These include: a) dietary diversity and food frequency, e.g. Household Dietary Diversity Score and Food Consumption Score; b) consumption behaviours, e.g. Coping Strategies Index; c) experiential measures, e.g. the Household Food Insecurity Access Scale and the Household Hunger Scale; and d) self-assessment measures. The subjective measures are simple and easy to use but their main disadvantage is that they focus only on measuring food access and do not account for food intake and availability. Maxwell et al. (2014) highlight that food security is a multidimensional livelihood outcome which should ideally be measured by multiple indicators. Hence, we use HFIAS and food expenditure to measure food security. We describe these measures separately in the next subsections.

\subsubsection{HFIAS}

The HFIAS measures the degree of food (access) insecurity (Coates et al., 2007). According to Coates et al. (2007) and Maxwell et al. (2014), the HFIAS is a simple, cost effective and scientifically valid indicator which captures household experiences in terms of insufficient quality, quantity and uncertainty over insecure food access. The HFIAS is widely used in international contexts and its recent applications to Sub-Saharan Africa include: Cock et al. (2013) for South Africa, Kabunga et al. (2014) and Keino et al. (2014) for Kenya and Maxwell et al. (2014) for Ethiopia.

The HFIAS consists of asking household heads to respond to nine questions, which represent universal domains of the experience of insecure access to food. The nine questions (sub-domains) 
are grouped into three main domains (Cock et al., 2013; Keino et al., 2014; Kabunga et al., 2014; Coates et al., 2007). The details of the domains and subdomains are shown further in Table 3.1. Domain I represents anxiety and uncertainty about household food supply. Domain II represents insufficient food quality, while domain III represents insufficient food quantity intake and physical consequences. Respondents answered each sub-domain using a score from 0 to 3 , depending on whether the particular problem described occurred. Non-occurrence was coded as never, rarely (1-2 times), sometimes (3-10 times), or often over the last 30 days. For each individual household, the HFIAS score is computed by aggregating the sub-domain scores and ranges from 0 to 27 . The higher the score, the greater the food insecurity the household experienced whereas a lower score represents a more food-secure household (Coates et al., 2007).

\subsection{Food insecurity index}

Creating the dependent variable by summing the HFIAS scores (Cock et al., 2013; Keino et al., 2014) has the disadvantage of assigning equal weight to each item, regardless of its value or utility. For impact analysis this may not be informative because the sub-domains capture different aspects of food insecurity (Kabunga et al., 2014). One approach to address this weakness involves using factor analysis (FA) to create composite scores that capture the common patterns in the data (Kabunga et al., 2014). We therefore created Food Insecurity Index (FIN) from HFIAS using weights obtained from FA. Kabunga et al. (2014) highlights that the food insecurity index computed from FA represents relative food insecurity within the sample and is suitable for impact evaluations because it compares the extent to which one household differs from the other. FA determines and assigns weights mathematically to capture relative importance of multiple indicators and maximize the variance explained by the linear composites. The use of FA is a well-established method that has been applied in numerous studies (Sahn \& Stifel, 2000; McKenzie, 2005). 
FA was conducted on the nine questions to determine a combination that yielded the best accuracy performance for the FIN. For the FIN, eight subdomains loaded highly on the first principal factor. The first factor explaining $77 \%$ of the variation is assumed to be our measure of food insecurity (Sahn \& Stifel, 2000). The factor loadings are shown further in Table 3.1. Positive factor loadings indicate a positive correlation of the variable with relative food insecurity and vice versa. Higher positive values of the index reflect higher levels of food insecurity.

The appropriateness of the method of factor analysis to extract FIN was confirmed by the KaiserMeyer-Olkin (KMO) measure of sampling adequacy and Bartlett test of sphericity. The KMO yielded a value of 0.85 and Field (2013) recommends accepting KMO values above 0.6. The Bartlett test of sphericity tests the null hypothesis that the original correlation matrix is an identity matrix. The Bartlett test yielded $\chi^{2}=2896.03(\mathrm{p}=0.000)$, hence we reject the null hypothesis and conclude there are some relationships between the variables used for the index. The KMO and Bartlett test signify the data's adequacy for factor analysis. The scale reliability is expressed via the Cronbach's alpha statistic. The corresponding statistics of 0.88 shows the scale achieved the advisable minimum of 0.7 and therefore it consistently reflect the construct that it is measuring (Field, 2013; Keino et al., 2014). The scale's consistency was assessed by correlating the individual sub-domains with the total scale score. The sub-domains are highly correlated with the total score, a reflection of internal consistency.

\subsection{Binary food insecurity}

We also used the binary food insecurity as an alternative to food insecurity index - a continuous variable. This approach enables us to get absolute food insecurity levels. To define a cut-off for absolute food insecurity, we used the Household Food Insecurity Access Prevalence (HFIAP) developed by Coates et al. (2007) to categorize households into four levels of food insecurity. The four categories of food insecurity are: $1=$ food secure, $2=$ mildly food insecure, $3=$ moderately food insecure and $4=$ severely food insecure. Households are categorized as 
increasingly food insecure as they respond affirmatively to more severe conditions and/or experience those conditions more frequently (Coates et al., 2007). In the analysis, we merge categories 1 and 2 into food-secure households, and categories 3 and 4 into food-insecure households (Kassie \& Ndiritu et al., 2014).

\subsubsection{Food expenditure}

A 7-day recall period was used for expenditure on food, beverages and tobacco and a 30-day recall period was used in the case of household food expenditure on frequently purchased services. We collected expenditure data on an item-by item basis. These expenditures were aggregated to the household level according to the recall period used. Conversion factors were used to change food consumption expenditures to a 30-day monthly basis. Thereafter all the expenditures were aggregated to derive the food consumption expenditures at household level. Home-produced food consumption is valued at local market prices for those food items. The food consumption expenditure was expressed in monthly per adult equivalent (AE) basis. We use the OECD adult equivalent scale which is given by: $1+0.7(\mathrm{~A}-1)+0.5 \mathrm{C}$, where $\mathrm{A}$ and $\mathrm{C}$ represent the number of adults and children in a household, respectively (Deaton \& Zaidi, 2002). The monthly food expenditure per AE was normalized by log transformation.

\subsection{Estimation strategy}

Mobile money is expected to have significant effect on food security. We examine the effect of mobile money on food security using the following specification:

$F S=\beta \boldsymbol{X}+\delta M M+\varepsilon$

Where FS is one of the food security outcome variable (food insecurity index, binary food insecurity, food expenditure). $\boldsymbol{X}$ is a vector of regressors influencing the outcome variable. $M M$ is the treatment variable (use or intensity of use). The parameter $\delta$ measures the effect of mobile money on food security and, $\beta$ is a vector of parameters to be estimated. 
When analysing food security, mobile money might be subject to selection bias resulting from unobservable factors influencing not only household's use of mobile money, but also food security. Mobile money users are more likely to be technical literate, have family members in the capital city or abroad who send remittances. Therefore mobile money users are more likely to have higher average levels of income and human capital as well as lower average levels of food insecurity. Due to potential self-selection bias, mobile money users and non-users are not directly comparable, which implies that an estimation method needs to correct for this bias to obtain unbiased estimates of the effect of mobile money.

In this study, we use the size of exchange social network ${ }^{10}$ and mobile phone network connectivity as instruments. For mobile network connectivity, we asked how many network bars are displayed by mobile phones at the homestead ranging from 0 to 4 ( 0 equals no network and 4 excellent network connectivity). We classified 0 to 2 network bars into poor network connectivity and 3 to 4 network bars into good network connectivity. The size of exchange social network is likely to positively influence household adoption of mobile money through improved information access. Network connectivity enables households to use their mobile phones to transact mobile money. These instruments are correlated with mobile money use and do not affect household food security directly. We also tested other potential instruments for example the proportion of households using mobile money and owning mobile phone at the village level (Kikulwe et al., 2014). Unfortunately these turn out not valid for our case.

\footnotetext{
${ }^{10}$ We used the random matching within sample approach to collect social network data proposed by Maertens \& Barrett (2013). Each household was matched with five other households randomly drawn from the sample. Conditional on knowing the matched household; we asked whether they discuss about mobile money. The known matched households constitute the household's social network. The number of households within social network the interviewed household communicates with about mobile money is then referred to as the size of exchange social network.
} 


\subsubsection{Continuous outcome variables: food insecurity index and food expenditure}

We use treatment effects models for estimating the effect of mobile money on food insecurity index and food expenditure to control for both observed and unobserved heterogeneity. Using this econometric technique to control for potential selection bias is appropriate in this context because our treatment variable is binary (Greene, 2012; StataCorp, 2013). In the mobile money intensity specification, we use Instrumental Variables (IV) regression to account for the continuous treatment variable. In the absence of endogeneity, we rely on OLS regression for estimation (Greene, 2012; StataCorp, 2013).

\subsubsection{Binary food insecurity}

As mentioned earlier, the four categories are combined into two: food-insecure (combining moderately food insecure and severely food insecure) and food-secure (combining food secure and mildly food insecure). We did not detect problems of selection bias, when using the binary food insecurity measure and therefore used probit regression for estimation.

\subsubsection{Control variables}

The choice of most control variables used for estimation is guided by the emerging literature on mobile money use (Kikulwe et al., 2014; Kirui et al., 2013; Jack \& Suri, 2014) and the broader literature on technology adoption and food security (Kassie \& Ndiritu et al., 2014; Kabunga et al., 2014; Shiferaw et al., 2014). These variables are shown later in Table 3.2.

\subsection{Results and discussion}

\subsubsection{Use of mobile money}

The activities to which households used mobile money are shown in Figure 3.2, as percentage by activity. Around $96 \%$ of the mobile money users stated that they withdraw money from their mobile account. This may be money coming from various sources (e.g. remittances or payments 
by traders). This money could be used for various household activities - for example purchasing agricultural inputs and food purchases among others. Fifty seven percent of the households stated that they use their mobile money accounts as a savings account. About $53 \%$ of the households stated that they also transferred money to other relatives and friends, while $25 \%$ of the households use mobile money to buy airtime for their mobile phones. Eighteen percent used mobile services to transfer money to business partners and a similar proportion $(18 \%)$ used mobile services to pay school fees.

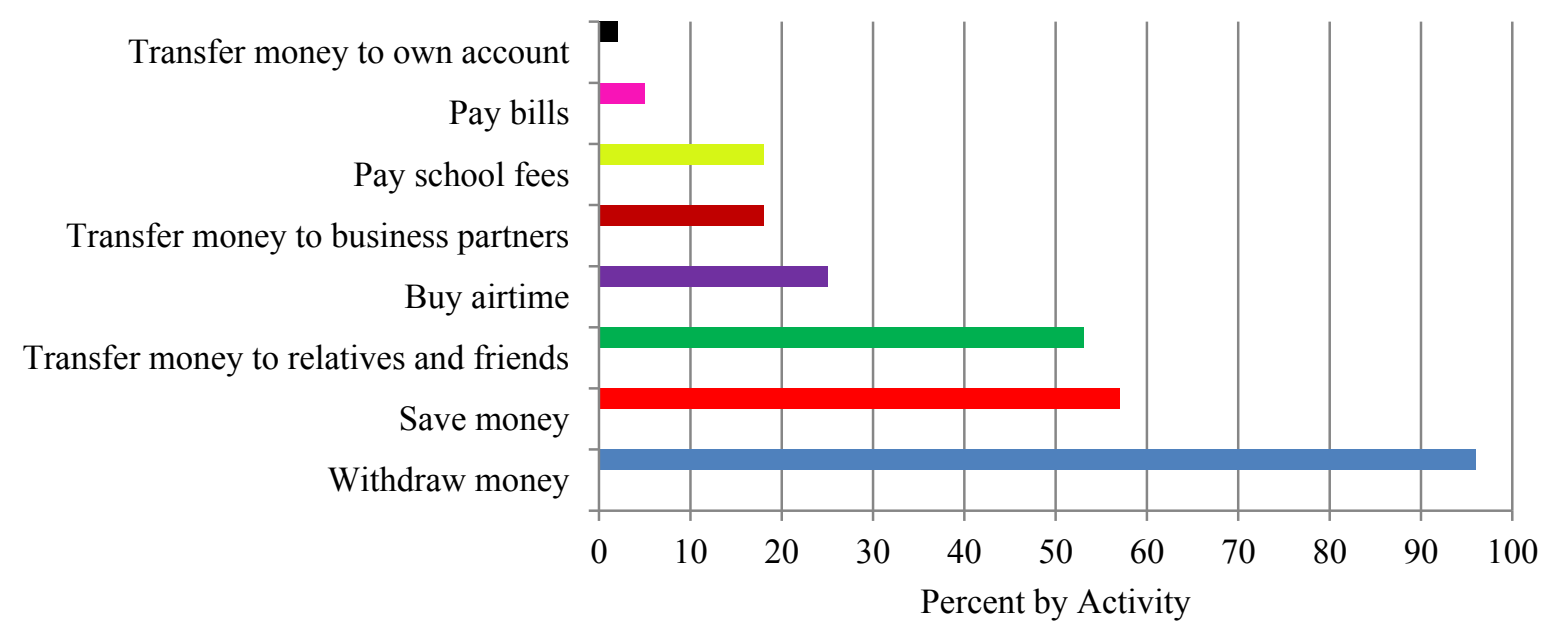

Figure 3. 2. Activity household performed with mobile money

\subsubsection{Results of descriptive analysis}

The sample statistics for the HFIAS sub-domains are shown in Table 3.1. The proportion of households responding 'never' in the first sub-domain is about $48 \%$, implying that $52 \%$ of the sampled households were anxious and uncertain about their food supply. In domain II, the average proportion of 'never' responses of the three sub-domains was $35 \%$. This means that roughly $65 \%$ of the households have insufficient food quality. Based on domain III, the average proportion of 'never' responses of the five sub-domains was $79 \%$, implying that about $21 \%$ have insufficient food quantity intake due to physical unavailability. 
Table 3. 1. Sample statistics for the sub-domains (Percentage response on occurrences in the last 30 days)

\begin{tabular}{|c|c|c|c|c|c|}
\hline & $\begin{array}{l}\text { Never } \\
(0 \\
\text { times })\end{array}$ & $\begin{array}{l}\text { Rarely } \\
(1-2 \\
\text { times })\end{array}$ & $\begin{array}{l}\text { Sometimes } \\
\text { (3-10 times) }\end{array}$ & $\begin{array}{l}\text { Often } \\
(>10 \\
\text { times }) \\
\end{array}$ & $\begin{array}{l}\text { Factor } \\
\text { loadings }\end{array}$ \\
\hline \multicolumn{6}{|l|}{ Domain I. Anxiety and uncertainty about household food supply } \\
\hline $\begin{array}{l}\text { 1. Did you worry that your household would not have enough } \\
\text { food? (Anxiety) }\end{array}$ & 47.90 & 16.39 & 27.10 & 8.61 & 0.778 \\
\hline \multicolumn{6}{|l|}{$\begin{array}{l}\text { Domain II. Insufficient quality (includes food variety and } \\
\text { preferences) }\end{array}$} \\
\hline $\begin{array}{l}\text { 2. Were you or any household member not able to eat the kinds } \\
\text { of foods you preferred because of a lack of resources? (Kinds) }\end{array}$ & 34.66 & 12.18 & 38.87 & 14.29 & 0.825 \\
\hline $\begin{array}{l}\text { 3. Did you or any household member have to eat a limited } \\
\text { variety of foods due to a lack of resources? (Variety) }\end{array}$ & 37.61 & 11.76 & 36.76 & 13.87 & 0.817 \\
\hline $\begin{array}{l}\text { 4. Did you or any household member have to eat some foods } \\
\text { that you really did not want to eat because of a lack of resources }\end{array}$ & 33.61 & 12.61 & 39.08 & 14.71 & 0.779 \\
\hline to obtain other types of food? (Not want) & & & & & \\
\hline Domain III. Insufficient food intake and physical consequences & & & & & \\
\hline $\begin{array}{l}\text { 5. Did you or any household member have to eat a smaller meal } \\
\text { than you felt you needed because there was not enough food? } \\
\text { (Smaller) }\end{array}$ & 57.37 & 10.71 & 27.52 & 4.41 & 0.786 \\
\hline $\begin{array}{l}\text { 6. Did you or any household member have to eat fewer meals in } \\
\text { a day because there was not enough food? (Fewer) }\end{array}$ & 61.34 & 7.98 & 25.63 & 5.04 & 0.767 \\
\hline $\begin{array}{l}\text { 7. Was there ever no food to eat of any kind in your household } \\
\text { because of a lack of resources to get food? (No Food) }\end{array}$ & 86.76 & 3.15 & 9.03 & 1.05 & 0.525 \\
\hline $\begin{array}{l}\text { 8. Did you or any household member go to sleep at night } \\
\text { hungry because there was not enough food? (Sleep) }\end{array}$ & 92.02 & 2.31 & 5.46 & 0.21 & 0.465 \\
\hline $\begin{array}{l}\text { 9. Did you or any household member go a whole day and night } \\
\text { without eating anything because there was not enough food? } \\
\text { (Whole day) }\end{array}$ & 95.80 & 2.31 & 1.89 & 0.00 & 0.306 \\
\hline
\end{tabular}

Fifty seven percent of the sampled household use mobile money. The mean frequency or intensity of using mobile money among users was 7 (minimum 1 and maximum 10). Figure 3.3 shows the food insecurity categories based on HFIAP classification. The proportion of food secure and mildly food insecure households are higher among mobile money users, while the proportion of moderately and severely food-insecure households is higher among non-users. 


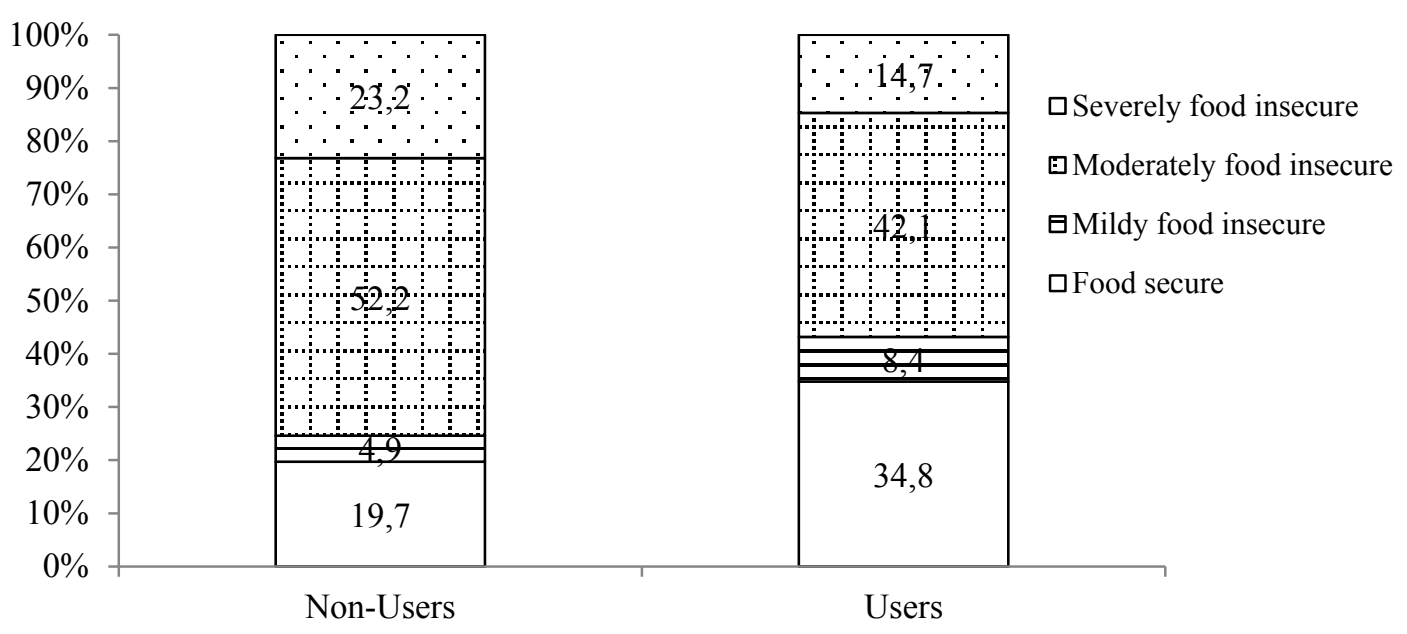

Figure 3. 3. Food insecurity categories

Mobile money users have lower food insecurity, with a food insecurity index of -0.20 compared to 0.27 for non-users. The mean difference of 0.47 is statistically significant at the $1 \%$ level using t-test. The monthly food expenditure per AE for users $\left(82860.49 \mathrm{UGX}^{11}\right)$ is higher than for nonusers (76 479.18UGX) at the $10 \%$ level. These results suggest that users are more likely to be food secure than non-users. The discussion above on mean comparisons has shown significant differences between users and non-users in terms of food insecurity and food consumption expenditure. While the differences cannot be interpreted as effects, they provide an indication that there are potentially structural differences in food security between mobile money users and non-users. In section 3.5.3 and the other sections that follow, we use econometric techniques to isolate the effect of mobile money.

The descriptive statistics for explanatory variables differentiated by mobile money use are shown in Table 3.2. There are significant differences with respect to some of the variables. On average, mobile money users have better access to information captured by group membership and number of mobile phones owned. In particular, we include the variable "number of mobile phones owned" to control for other benefits derived from mobile phones, such as information access. Controlling for this, we make sure that our variable of interest mobile money really captures the use of that specific service (as opposed to more general benefits of mobile phones).

\footnotetext{
${ }^{11}$ The exchange rate was 2500 Uganda Shillings $($ UGX) $=1$ USD at the time of survey.
} 
In addition, we included contact to extension (CKW contact). The extension program is a mobilephone based extension program that uses locally recruited peer farmers known as Community Knowledge Workers. CKWs are local farmers recruited by the NGO, and trained to use android smart phones to disseminate agricultural and market information to fellow farmers in their respective villages. Access to agricultural information is expected to improve agricultural productivity and subsequently boost food security and reduce poverty.

There are also significant differences with respect to education levels, land holdings and livestock ownership. Better educated mobile money users and those with larger land holdings are more likely to have higher agricultural productivity and be food secure. Users are more likely to be involved in off-farm income activities, suggesting that household members engaged in off-farm activities may possibly sent remittances using mobile money. Off-farm income activities increases household cash which might be used either to purchase sufficient food or invest in agriculture to increase agricultural productivity and production to meet household food security needs. Earlier studies show the importance of off-farm income for food security (Mabiso et al., 2014; Sinyolo et al., 2014). Considering land, assets, off-farm income activity and livestock as proxies of wealth, results suggest that mobile money users are wealthier than non-users. Significantly more of the mobile money users also have own means of transportation. This gives them advantage in mobility and transporting agricultural inputs and outputs. In addition, they can earn additional income from transport hiring, especially those who own motorcycle or car. The income can be used to purchase agricultural inputs or food supplies. 
Table 3. 2. Differences between mobile money users and non-users

\begin{tabular}{|c|c|c|c|c|c|}
\hline \multirow[b]{2}{*}{ Variable } & \multirow[b]{2}{*}{ Description } & \multicolumn{2}{|c|}{ Users } & \multicolumn{2}{|c|}{ Non-users } \\
\hline & & Mean & Std & Mean & Std \\
\hline \multicolumn{6}{|l|}{ Treatment variables } \\
\hline Mobile money & Household used mobile money (dummy) & 0.57 & 0.50 & - & - \\
\hline Mobile money intensity & Times household used mobile money & 7.22 & 2.77 & - & - \\
\hline \multicolumn{6}{|l|}{ Control variables } \\
\hline Group membership & $\begin{array}{l}\text { Household member(s) belongs to any group } \\
\text { (dummy) }\end{array}$ & $0.766^{* * *}$ & 0.42 & 0.606 & 0.49 \\
\hline Mobile phones & Number of mobile phones owned by household & $2.018^{* * *}$ & 1.06 & 0.842 & 0.93 \\
\hline Extension contact & $\begin{array}{l}\text { Household access information from CKW } \\
\text { (dummy) }\end{array}$ & $0.564^{* * *}$ & 0.50 & 0.419 & 0.50 \\
\hline Age & Age of household head (years) & 49.377 & 12.85 & 49.897 & 14.48 \\
\hline Gender & Gender of household head (1=Male) & $0.897^{* * *}$ & 0.30 & 0.788 & 0.41 \\
\hline Education & Education of household head (years) & $7.414^{* * *}$ & 4.46 & 5.064 & 3.85 \\
\hline Farming experience & Years of farming experience & 25.597 & 16.06 & 25.330 & 15.71 \\
\hline Household size & Household size (number) & $7.326^{* * *}$ & 2.64 & 6.596 & 2.93 \\
\hline Dependency ratio & $\begin{array}{l}\text { Dependents ( } 15 \& \text { below, } 65 \text { plus) to workforce } \\
(16-64)\end{array}$ & 1.362 & 1.10 & 1.499 & 1.26 \\
\hline Adult equivalent & Adult equivalent & $4.603^{* * *}$ & 1.51 & 4.165 & 1.67 \\
\hline Land size & Size of land owned in acres & $5.153^{* * *}$ & 5.43 & 3.619 & 3.25 \\
\hline Ln(Farmequipment) & Value of farm equipment $(\log )$ & $10.943^{* * *}$ & 1.26 & 10.502 & 1.09 \\
\hline Off farm income & $\begin{array}{l}\text { Household member(s) engaged in off-farm } \\
\text { income activity (dummy) }\end{array}$ & $0.619^{* * *}$ & 0.49 & 0.355 & 0.48 \\
\hline Credit access & Household accessed credit (dummy) & $0.546^{* * *}$ & 0.50 & 0.345 & 0.48 \\
\hline $\mathrm{TLU}^{12}$ & Total livestock units & $1.242^{* * *}$ & 2.21 & 0.671 & 1.50 \\
\hline Motorcyclelcar & Household own motorcycle and or car (dummy) & $0.201^{* * *}$ & 0.40 & 0.059 & 0.24 \\
\hline MMA & Distance to mobile money agent $(\mathrm{km})$ & 2.315 & 2.54 & $3.380^{* * *}$ & 4.10 \\
\hline District & $\begin{array}{l}\text { Household is located in Mukono district } \\
\text { (dummy) }\end{array}$ & 0.538 & 0.50 & 0.453 & 0.50 \\
\hline \multicolumn{6}{|l|}{ Instruments } \\
\hline $\begin{array}{l}\text { Size of exchange social } \\
\text { network }\end{array}$ & $\begin{array}{l}\text { Number of network members household } \\
\text { communicates with about mobile money }\end{array}$ & $0.498^{* * *}$ & 1.13 & 0.089 & 0.39 \\
\hline Connectivity & Mobile phone network connectivity $(1=$ good $)$ & $0.780^{* * *}$ & 0.41 & 0.507 & 0.50 \\
\hline Observations & & 273 & & 203 & \\
\hline
\end{tabular}

$* * *$ indicates the corresponding mean differences are significant at the $1 \%$ level (t-tests).

\footnotetext{
${ }^{12} \mathrm{TLU}$ is calculated using the numbers of livestock owned by the household using the Storck (1991) conversion factors: cows, oxen, bulls $=1$; heifers $=0.75$; calves $=0.25$; donkey $=0.5$; goat, sheep $=0.1 ;$ pig $=0.2$; chickens $=$ 0.01 .
} 


\subsubsection{Effect of mobile money on food insecurity}

As discussed earlier, we expressed food insecurity in two forms: food insecurity index (continuous) and binary food insecurity. The effects of mobile money on the continuous and binary food insecurity are discussed separately in the next sub-sections.

\subsubsection{Effect of mobile money on food insecurity index}

The estimation results on the effects of mobile money use and intensity of use on food insecurity index are shown in Table 3.3. The results for mobile money use specification are based on treatment effects regression. The endogeneity test in IV model in the intensity of use specification shows no evidence of selection bias ( $p$-value of 0.798 ). We therefore rely on OLS regression for estimation. Mobile money turns out significant only in the mobile money use specification. The other control variables are qualitatively similar in both specifications of the treatment variable. In what follows, we discuss results from the mobile money use specification.

In the treatment effects regression, we instrumented mobile money with size of exchange social network and mobile phone network connectivity. The parameter $\operatorname{ath}(\rho)$ is significant in the treatment effects model; we therefore reject the null hypothesis and conclude that the instrumented variable is endogenous. The parameter $\operatorname{ath}(\rho)^{13}$ in treatment effects model shows the inverse hyperbolic tangent of the correlation between the error terms in the selection and outcome equations (Miyata et al., 2009; StataCorp, 2013; Kabunga et al., 2014). When this parameter is significant it exhibits the presence of selection bias which is controlled for by instrument(s). Our outcome variable is food insecurity and therefore the parameter ath $(\rho)$ indicates negative selection bias which is controlled by using the treatment effects model (Kabunga et al., 2014). Therefore the OLS model underestimates the effects of mobile money on food insecurity. Negative selection bias in our case implies that households with lower food

\footnotetext{
${ }^{13}$ The model does not estimate $\rho$ directly but rather $\operatorname{ath}(\rho)$ the inverse hyperbolic tangent of $\rho$. However the test of the hypothesis that $\operatorname{ath}(\rho)=0$ is equivalent to the test that $\rho=0$, which tests for the presence of correlation of the error terms thus selection bias.
} 
insecurity (food secure) are more likely to adopt mobile money. Unobservables that decrease food insecurity tend to occur with unobservables that increase mobile money use, for example innate ability. Our result that food secure households are more likely to adopt the innovation is consistent with Kabunga et al. (2014) who found that food secure households were more likely to adopt tissue culture.

In what follows, we thus interpret results based on the treatment effects model (Table 3.3, column 4). For interpretation, our dependent variable is food insecurity; therefore negative coefficient estimates imply a reduction in food insecurity and vice versa. For better interpretation the food insecurity index is normalized. In the treatment effects model there is no interaction between treatment variable and outcome covariates, so the treatment effects model estimates the Average Treatment Effects (ATE) directly (StataCorp, 2013). Our findings show that use of mobile money significantly reduces household food insecurity. The use of mobile money reduces relative food insecurity by 0.20 index points. The sample mean for food insecurity index computed by factor analysis is zero, therefore percentage interpretations relative to sample mean is not possible (Kabunga et al., 2014). The index has a standard deviation of one and therefore the estimated effects can be considered relatively large. The ATE of mobile money on food insecurity underscores the importance of mobile money for enhancing food security.

The regression coefficients for land size and means of transport are of interest. Land size has a negative and significant effect on food insecurity. Households with large land holdings are more food secure. One additional acre of land reduces relative food insecurity by 0.01 index points. Ownership of means of transport reduces food insecurity by 0.09 index points. Our result which is also supported by Kassie \& Ndiritu et al. (2014) confirm the importance of transport on improving household food security. Results show that household characteristics do not seem to have significant effects on reducing food insecurity. Our result that education is insignificant in reducing food insecurity is similar to findings by Kassie \& Ndiritu et al. (2014), but contradicts 
other studies. For example, earlier studies have shown that human capital is an important determinant of food security (Cock et al., 2013; Kabunga et al., 2014). Group membership has a negative coefficient but is insignificant. This result is not in line with other studies, e.g. Kassie \& Ndiritu et al. (2014) who found that group membership reduced chronic and transitory food insecurity among smallholder farmers in Kenya.

Table 3. 3. Estimated effects of mobile money on food insecurity index

\begin{tabular}{|c|c|c|c|c|c|c|c|c|}
\hline & \multicolumn{4}{|c|}{ Use (dummy) } & \multicolumn{4}{|c|}{ Intensity of use } \\
\hline & \multicolumn{2}{|c|}{ OLS } & \multicolumn{2}{|c|}{ Treatment effects } & \multicolumn{2}{|c|}{ IV } & \multicolumn{2}{|c|}{ OLS } \\
\hline & Coeff & $\mathrm{SE}$ & Coeff & $\mathrm{SE}^{*}$ & Coeff & $\mathrm{SE}$ & Coeff & $\mathrm{SE}^{\sharp}$ \\
\hline Mobile money & $-0.063^{* *}$ & 0.026 & $-0.201^{* * *}$ & 0.074 & 0.003 & 0.019 & -0.002 & 0.003 \\
\hline \multicolumn{9}{|l|}{ Control variables } \\
\hline CKW contact & $-0.063^{* *}$ & 0.026 & 0.006 & 0.022 & 0.001 & 0.029 & 0.006 & 0.022 \\
\hline Group membership & 0.009 & 0.022 & -0.037 & 0.026 & -0.034 & 0.026 & -0.034 & 0.027 \\
\hline Mobile phones ${ }^{/ a}$ & -0.037 & 0.027 & 0.001 & 0.010 & -0.113 & 0.071 & $-0.097^{* * *}$ & 0.035 \\
\hline Age & -0.004 & 0.011 & 0.001 & 0.001 & 0.001 & 0.001 & 0.001 & 0.001 \\
\hline Gender & 0.001 & 0.001 & -0.012 & 0.032 & -0.012 & 0.032 & -0.010 & 0.033 \\
\hline Education & -0.007 & 0.033 & -0.002 & 0.003 & -0.003 & 0.004 & -0.002 & 0.003 \\
\hline Household size & -0.003 & 0.003 & $0.008^{*}$ & 0.004 & $0.008^{*}$ & 0.004 & $0.008^{*}$ & 0.004 \\
\hline Dependency ratio & $0.008^{*}$ & 0.005 & 0.006 & 0.010 & 0.011 & 0.012 & 0.010 & 0.010 \\
\hline Land size & 0.006 & 0.011 & $-0.008^{* * *}$ & 0.002 & $-0.009^{* * *}$ & 0.003 & $-0.008^{* * *}$ & 0.002 \\
\hline Ln(Farmequipment) & $-0.008^{* * *}$ & 0.002 & -0.012 & 0.009 & -0.015 & 0.011 & -0.014 & 0.010 \\
\hline Off farm income & -0.013 & 0.009 & -0.037 & 0.024 & -0.044 & 0.030 & -0.039 & 0.024 \\
\hline Access to credit & -0.038 & 0.024 & -0.016 & 0.023 & -0.023 & 0.027 & -0.019 & 0.023 \\
\hline TLU & -0.019 & 0.023 & -0.004 & 0.005 & -0.004 & 0.006 & -0.004 & 0.005 \\
\hline Motorcyclelcar & -0.004 & 0.005 & $-0.092^{* * *}$ & 0.029 & $-0.099^{* *}$ & 0.041 & $-0.093^{* * *}$ & 0.029 \\
\hline Output market & $-0.092^{* * *}$ & 0.030 & 0.001 & 0.002 & 0.002 & 0.002 & 0.001 & 0.002 \\
\hline District & 0.001 & 0.002 & 0.011 & 0.026 & 0.015 & 0.030 & 0.019 & 0.027 \\
\hline Constant & 0.016 & 0.027 & $0.557^{* * *}$ & 0.114 & $0.555^{* * *}$ & 0.139 & $0.534^{* * *}$ & 0.113 \\
\hline Observations & 476 & & 476 & & 476 & & 476 & \\
\hline $\operatorname{ath}(\rho)$ & & & $0.400^{* *}$ & 0.204 & & & & \\
\hline $\ln (\sigma)$ & & & $-1.429^{* * *}$ & 0.045 & & & & \\
\hline Endogeneity test ( $p$-value) & & & & & 0.798 & & & \\
\hline Wald test $\left(\right.$ Prob $\left.>\chi^{2}\right)$ & & & 0.032 & & & & & \\
\hline Wald/F statistic & $6.31 * * *$ & & $84.93^{* * *}$ & & $5.14 * * *$ & & $6.46^{* * *}$ & \\
\hline Adjusted R-square & 0.12 & & & & & & 0.13 & \\
\hline
\end{tabular}

$*, * *, * * *$ indicates the corresponding coefficients are significant at the $10 \%, 5 \%$, and $1 \%$ levels, respectively. ${ }^{*}$ Robust standard errors are reported. ${ }^{/ a}$ Dummy variable is used in the intensity specification. 


\subsubsection{Effect of mobile money on binary food insecurity}

Here, we estimated probit models using different specifications of the treatment variable. The results are shown in Table 3.4. The use of mobile money reduces the likelihood being food insecure by $10 \%$ points. The intensity of using mobile money turns out insignificant in determining food insecurity. The other control variables are quite similar across the different specifications of the treatment variable. The variables land size and means of transport are negative and significant in both models. Large land holdings and owning means of transport reduces the likelihood of being food insecure. The results on land size and means of transport are consistent with the estimates obtained in the treatment effects model for food insecurity index.

Table 3. 4. Estimated effects of mobile money on binary food insecurity: probit model

\begin{tabular}{|c|c|c|c|c|}
\hline & \multicolumn{2}{|c|}{ Use (dummy) } & \multicolumn{2}{|c|}{ Intensity of use } \\
\hline & AME & $\mathrm{SE}^{*}$ & AME & $\mathrm{SE}^{+}$ \\
\hline Mobile money & $-0.104^{*}$ & 0.055 & 0.003 & 0.007 \\
\hline CKW contact & 0.054 & 0.046 & 0.042 & 0.047 \\
\hline Group membership & $-0.116^{* *}$ & 0.053 & $-0.110^{* *}$ & 0.053 \\
\hline Mobile phones/dummy for intensity & 0.001 & 0.024 & $-0.172^{* * *}$ & 0.061 \\
\hline Age & 0.000 & 0.002 & 0.000 & 0.002 \\
\hline Gender & -0.028 & 0.068 & -0.037 & 0.068 \\
\hline Education & -0.003 & 0.006 & -0.003 & 0.006 \\
\hline Household size & 0.012 & 0.010 & 0.013 & 0.009 \\
\hline Dependency ratio & 0.001 & 0.023 & 0.008 & 0.022 \\
\hline Land size & $-0.011^{*}$ & 0.006 & $-0.011^{*}$ & 0.006 \\
\hline Ln(Farmequipment) & -0.027 & 0.020 & -0.028 & 0.020 \\
\hline Off farm income & -0.075 & 0.049 & -0.077 & 0.049 \\
\hline Access to credit & 0.001 & 0.050 & -0.003 & 0.050 \\
\hline TLU & $-0.031^{* *}$ & 0.013 & $-0.029^{* *}$ & 0.012 \\
\hline Motorcyclelcar & $-0.216^{* * *}$ & 0.073 & $-0.226^{* * *}$ & 0.073 \\
\hline Output market & 0.004 & 0.005 & 0.005 & 0.005 \\
\hline District & 0.078 & 0.055 & 0.074 & 0.055 \\
\hline Observations & 476 & & 476 & \\
\hline Wald statistic & $70.11^{* * *}$ & & $66.95^{* * *}$ & \\
\hline Pseudo R-square & 0.111 & & 0.115 & \\
\hline
\end{tabular}

$*, * *, * * *$ indicates the corresponding average marginal effects are significant at $10 \%, 5 \%$, and $1 \%$ levels, respectively. ${ }^{*}$ Robust standard errors are reported. Marginal effects are for discrete change of dummy variable from 0 to 1 . 


\subsubsection{Effect of mobile money on food expenditure}

The regression results for the effect of mobile money use on food expenditure based on treatment effects and OLS models are shown in Table 3.5. As in section 3.5.3.1, the size of exchange social network and mobile phone network connectivity are used as instruments in the treatment effects model. In the treatment effects model, the parameters ath $(\rho)$ and Wald test of independent equations are insignificant, indicating that there is no selection on unobservables. The last two columns in Table 3.5 shows the estimated treatment effects based on the intensity of using mobile money. We first estimated IV regression and found no evidence of selection bias. In the absence of endogeneity, performing IV based estimations is not appropriate as it inflates the asymptotic variance of the estimators (Wooldridge, 2010). We therefore interpret results of OLS model for both specifications of the treatment variable.

The result of OLS model shows that mobile money use is positive and significant at the $10 \%$ level. The result suggests a $9 \%$ point increase in monthly food expenditure per adult equivalent given the use of mobile money innovation. For the intensity of use, regression results reveal the significant effect of higher intensity of using mobile money on food expenditure. A unit increase in the number of times of using mobile money increases food expenditure per AE by $1.4 \%$ points. The coefficients of some of the control variables are quite similar in the mobile money use and intensity of use specification. We therefore only discuss results for the mobile money use specification. Larger households are associated with lower food consumption. An additional member in the household reduces food consumption per adult equivalent by $4.4 \%$ points. A similar result based on per capita food consumption is reported by Shiferaw et al. (2014). Land size, value of farm equipment and TLU are all positive and highly significant. An additional acre of land results in $0.7 \%$ point increase in food consumption per AE. A $1 \%$ increase in the value of farm equipment is associated with a 5\% point increase in food expenditure per AE. An increase in TLU by a unit results in $2.3 \%$ points increase in food consumption. Shiferaw et al. (2014) also found similar result that livestock ownership increased per capita consumption expenditure in 
Ethiopia. Livestock is important for food security in Uganda and programs that promote livestock production should be promoted. Owning means of transport is also positive and significant at the $10 \%$ level.

Table 3. 5. Estimated effects of mobile money on monthly food expenditure per AE $(\log )$

\begin{tabular}{|c|c|c|c|c|c|c|}
\hline & \multicolumn{4}{|c|}{ Use (dummy) } & \multirow{2}{*}{\multicolumn{2}{|c|}{$\frac{\text { Intensity of use }}{\text { OLS }}$}} \\
\hline & \multicolumn{2}{|c|}{ Treatment effects } & \multicolumn{2}{|c|}{ OLS } & & \\
\hline & Coeff & SE $\$$ & Coeff & SE & Coeff & SE + \\
\hline Treatment variable & & & & & & \\
\hline Mobile money & $0.225^{*}$ & 0.125 & $0.091^{*}$ & 0.048 & $0.014^{* *}$ & 0.006 \\
\hline Control variables & & & & & & \\
\hline CKW contact & 0.027 & 0.042 & 0.026 & 0.042 & 0.015 & 0.043 \\
\hline Group membership & 0.053 & 0.052 & 0.054 & 0.053 & 0.052 & 0.054 \\
\hline Mobile phones/dummy for intensity & $-0.041^{*}$ & 0.021 & $-0.036^{*}$ & 0.021 & 0.004 & 0.069 \\
\hline Age & 0.001 & 0.002 & 0.001 & 0.002 & 0.001 & 0.002 \\
\hline Gender & 0.029 & 0.063 & 0.025 & 0.064 & 0.020 & 0.063 \\
\hline Education & 0.007 & 0.005 & 0.008 & 0.005 & 0.005 & 0.005 \\
\hline Household size & $-0.044 * * *$ & 0.008 & $-0.044 * * *$ & 0.009 & $-0.049^{* * *}$ & 0.008 \\
\hline Dependency ratio & 0.025 & 0.017 & 0.025 & 0.018 & $0.032^{*}$ & 0.017 \\
\hline Land size & $0.007^{*}$ & 0.004 & $0.007 *$ & 0.004 & 0.005 & 0.004 \\
\hline Ln(Farmequipment) & $0.049^{* *}$ & 0.020 & $0.050^{* *}$ & 0.020 & $0.047^{* *}$ & 0.021 \\
\hline Off farm income & -0.012 & 0.046 & -0.011 & 0.047 & -0.029 & 0.046 \\
\hline Access to credit & 0.021 & 0.044 & 0.023 & 0.045 & 0.012 & 0.045 \\
\hline TLU & $0.023^{* *}$ & 0.011 & $0.023^{* *}$ & 0.011 & $0.021^{*}$ & 0.011 \\
\hline Motorcyclelcar & $0.103^{*}$ & 0.054 & $0.104 *$ & 0.055 & 0.089 & 0.055 \\
\hline Output market & 0.005 & 0.003 & 0.005 & 0.004 & 0.005 & 0.004 \\
\hline District & 0.022 & 0.052 & 0.018 & 0.053 & 0.010 & 0.054 \\
\hline Constant & $10.561 * * *$ & 0.241 & $10.636^{* * *}$ & 0.237 & $10.681^{* * *}$ & 0.242 \\
\hline Observations & 476 & & 476 & & 476 & \\
\hline $\operatorname{ath}(\rho)$ & -0.201 & 0.177 & & & & \\
\hline $\ln (\sigma)$ & $-0.805 * * *$ & 0.036 & & & & \\
\hline Wald statistic/F statistic & $98.90 * * *$ & & $6.02 * * *$ & & $5.90^{* * *}$ & \\
\hline Adjusted R-square & & & 0.116 & & 0.12 & \\
\hline $\begin{array}{l}\text { Wald test of independent equations } \\
\left(\text { Prob }>\chi^{2}\right)\end{array}$ & 0.2485 & & & & & \\
\hline
\end{tabular}

$*, * *, * * *$ indicates the corresponding coefficients are significant at the $10 \%, 5 \%$, and $1 \%$ levels, respectively. $\$$ Robust standard errors are reported. 


\subsection{Conclusion and policy implications}

Our present study complements and adds to the limited literature on the broader welfare effects of mobile money on households in developing countries. We analysed the effect of mobile money on food security among rural households in Uganda. We use a recent household survey to estimate these effects. Treatment effects regression is employed for estimating the food insecurity index model to account for bias stemming from both observed and unobserved heterogeneity in mobile money use. In addition, we expressed food insecurity as a binary variable and used probit model for estimation. In the food expenditure specification an OLS model is used as we detect no evidence of selection bias.

Empirical results are consistent across two food security specifications (food insecurity and food expenditure) and indicate that using mobile money improve household food security. While the magnitude of estimated effects varies across estimation methods, the effects remain significant. The use of mobile money reduces household relative food insecurity by 0.20 index points. Our results are robust to different specifications of the food insecurity outcome variable and suggest that mobile money use reduces food insecurity. Turning to food expenditure per AE, we realize that use of mobile money increases food consumption by $9 \%$ points. We also found that the intensity of using mobile money has a positive and significant effect on food security. A unit increase in the number of times of using mobile money increases food expenditure per AE by $1.4 \%$ points. These study results provide evidence for the positive effect of mobile money on improving food security among rural households in Uganda. Results of this study have important food policy implications, in particular that mobile money play a role in ensuring household food security. Policy interventions and strategies to improve household food security should consider the promotion of mobile money among rural households in Uganda and other developing countries.

Over and above mobile money, other estimated coefficients have important policy implications. 
Results show that land size and ownership of transport are consistently significant in the food insecurity and food expenditure specifications. These findings confirm the welfare enhancing effect of these variables. Focusing on land area expansion is infeasible because of land scarcity in Uganda. Instead policy makers could look at how to promote the adoption of sustainable intensification practices among rural households. Sustainable intensification practices that aim to increase productivity and food security per unit of input resource (e.g. land area, fertilisers etc.) while conserving the natural resource base include for example modern high-yielding varieties, intercropping practices, and soil and water conservation (Smith, 2013; The Montpellier Panel, 2013). The effect of ownership of transport on food security may be through enhanced input and output marketing. Market participation is usually associated with high agricultural productivity and farm income, which in turn help in increasing food security. Therefore, there is a need for investment in improving transport network in rural areas of Uganda.

Finally, though results of this study are consistent with our expectations, there are limitations worth mentioning. The study uses cross-section data which is static and relates to current effect. The effects of mobile money might be different in the long run, for example due to changes in expenditure and seasonal variability in food supply. Therefore, further research might need to build on panel data to explore the effect of mobile money on food security over time. 


\section{Mobile money, household welfare and poverty in Uganda ${ }^{14}$}

Abstract.

Mobile money is a financial innovation that has the potential to improve household welfare in developing countries. This study uses household survey data to analyse the effect of mobile money on household welfare and poverty in Uganda. We measured welfare using household consumption expenditure. Poverty was measured using consumption poverty and multidimensional poverty index. We estimate instrumental variable and endogenous switching probit regressions to control for the potential endogeneity of mobile money. Model results show that use and intensity of using mobile money increases consumption expenditure by $10 \%$ and $2 \%$ points respectively. Based on consumption poverty, our model estimates highlight that use of mobile money reduces the probability of being poor among users by $10 \%$ points. Furthermore, among non-users the probability of being poor could be reduced by $5 \%$ points if they were to use mobile money. In addition, higher intensity of using mobile money reduces the likelihood of being poor by $1 \%$ point. The use of mobile money reduces multidimensional poverty by 0.67 index points. We find that a unit increase in the intensity of using mobile money reduces multidimensional poverty by 0.07 index points. Our results for the effects of mobile money are robust to alternative specifications of the treatment and poverty outcome variables. The results confirm that mobile money is welfare-enhancing and reduces household poverty. Policy interventions to improve household welfare and reduce poverty should also embrace the promotion of mobile money among rural households in Uganda.

\subsection{Introduction}

Worldwide, about 2.5 billion adults do not have a bank account or use other formal financial services (World Bank, 2014). In developing countries, about 59 percent of the adults have no bank account. Furthermore, and of concern is that the majority of households living in extreme

\footnotetext{
${ }^{14}$ This chapter is co-authored by Meike Wollni. The following roles were performed by me: designing of the study, data analysis, and interpretation of the research results in cooperation with Meike Wollni; writing of the paper.
} 
poverty and women are largely excluded from formal financial institutions (World Bank, 2014). There has been tremendous effort by financial institutions to increase the range of financial services, for example payment cards, microfinance products, money gramme and other electronic instruments. However, these still remain out of reach for majority of poor households. The majority of households in developing countries are financially excluded because of the costs, travel distance, and other barriers associated with maintaining an account. Because of these circumstances, most of these households rely on informal money transfer services (bus, taxi etc) (Kikulwe et al., 2014), use cash and often save under mattresses, in informal groups, and/or in jewellery and livestock (Karlan et al., 2014). Most of these informal mechanisms are oftentimes expensive, insecure and offer no instant liquidity. Because of the liquidity trap, most poor households remain in persistent poverty.

Empirical evidence suggest that providing individuals access to savings instruments increases savings (Karlan et al., 2014), consumption and productive investment (Dupas \& Robinson, 2013). There is a general consensus that access and use of appropriate financial services for saving, sending, and borrowing money is critical for poverty reduction in developing countries, where financial institutions are lacking (UNCDF, 2015; Dupas \& Robinson, 2013). Over the past decade, mobile money has proliferated rapidly in developing countries and is emerging as one potential innovation that can enhance financial inclusion even for poor households in remote areas (UNCDF, 2015; Donovan, 2012). As discussed earlier, mobile money refers to the use of mobile phones to perform financial and banking functions, for example airtime purchases, peerto-peer money transfers, school fees payments and mobile banking (Donovan, 2012). Mobile money has the potential to ameliorate some of the challenges faced by poor people in accessing financial services such as long physical distance to financial institutions, high fees and minimum bank balances (Diniz et al., 2012; Donovan, 2012). Mobile money might play a role in improving poor people access to finance by delivering sustainable financial services to distant and underserved locations, charging lower and proportionate transaction fees (Donovan, 2012; 
Kikulwe et al., 2014; Morawczynski, 2009). In addition, some mobile money products allow lowincome people to accumulate capital through savings and affordable credit. This is crucial considering the fact that poor households have no collateral to borrow credit and usually deal with small transactions which are costly for financial institutions (Beck \& Demirguc-Kunt, 2008).

Previous research has analysed the welfare effects of mobile money on rural households (Jack et al., 2013; Jack \& Suri, 2014; Kikulwe et al., 2014; Kirui et al., 2013; Munyegera \& Matsumoto, 2014). These studies found positive effects of mobile money on household income (Kikulwe et al., 2014), farm income (Kirui et al., 2013), consumption smoothing (Jack \& Suri, 2014) and per capita consumption (Munyegera \& Matsumoto, 2014) among rural households. Access to financial services through mobile money could enhance household financial liquidity through remittances received (Giuliano \& Ruiz-Arranz, 2009; Kikulwe et al., 2014) and lower financial transaction costs thereby improving household welfare. This can help poor households move out of the vicious cycle of poverty. Despite the relative importance of mobile money among rural households, less is known about its welfare effects. Specifically, there is scanty empirical evidence on whether mobile money reduces poverty among rural households in developing countries.

The empirical contribution of this study to literature is threefold: First, we analyse the effect of mobile money on poverty - an issue that has not been researched so far. Uganda offers an interesting case to study the causal link between mobile money and poverty. Uganda has one of the fast growing mobile money industry in East Africa. About $27 \%$ of the total adult population is already using mobile money within five years of inception in Uganda (Gutierrez \& Choi, 2014). On the other hand, about 40 percent of the Ugandan population live below the poverty line of 1.25 USD a day (Gutierrez \& Choi, 2014). Furthermore, UNDP (2015) reveal that about 70 
percent of the population in Uganda is multidimensionally poor and this is reflected by the country's categorization into a Low Human Development Index.

Second, and in comparison to previous studies on mobile money, our study is unique in that we use two alternative specifications of the treatment variable (a dummy variable for use and intensity of use). Third, most recent closely related studies rely on a single measure of poverty for example the consumption poverty (Foster et al., 1984; Khonje et al., 2015; Meyer \& Sullivan, 2012) and multidimensional poverty index (Ayuya et al., 2015; Alkire \& Santos, 2014). Unlike most studies, we use both approaches to measure poverty and benefit from their strengths and complementarities. Poverty measures based on consumption data reflects effective consumption (Deaton \& Zaidi, 2002; Meyer \& Sullivan, 2012), while multidimensional poverty index reflects human development (Alkire \& Santos, 2014).

The remainder of this article is organised as follows. In the next section we describe the conceptual framework. We then discuss the methodology, followed by the estimation strategy employed. Empirical results are presented and discussed and the last section concludes and discusses policy implications.

\subsection{Conceptual framework}

The rapid penetration of mobile money in the developing world has important socioeconomic implications. The use of mobile money could contribute to poverty reduction and improve household welfare through different pathways. Please refer to Section 3.2 for the detailed conceptual framework on the welfare and poverty effects of mobile money. Here, we briefly summarize the impact pathways. The first pathway is through cash received faster (e.g. remittances, payment from traders, wage or salary payment etc), which might provide an alternative way to finance investment and help households overcome liquidity constraints

(Giuliano \& Ruiz-Arranz, 2009; Kikulwe et al., 2014; Jack et al., 2013). Kikulwe et al. (2014) 
found that the use of mobile money is associated with significantly higher remittances received by households in Kenya. In another study, Jack et al. (2013) found that mobile money positively increased the volume of internal remittances in Kenya. The cash received through mobile money increases household disposable income, which can be invested in food and non-food consumption. Kikulwe et al. (2014) found that mobile money had a positive effect on household income in Kenya, while Munyegera \& Matsumoto (2014) found that mobile money increased monthly per capita consumption for households in Uganda. Furthermore, the cash received can be saved and offer insurance to households. For Kenya, Jack \& Suri (2014) found that mobile money had a significant effect on the ability of households to smooth consumption. In other closely related studies, Adams \& Cuecuecha (2013) and Gupta et al. (2009) demonstrates that remittances are crucial for poverty reduction in Africa.

The second pathway through which mobile money affects household welfare is through lowered transactions costs. As discussed earlier in Section 3.2, mobile money is a relatively cheap, faster and safer medium of transferring money to remote households compared to the traditional and informal methods. Mobile money is associated with lower travel and time costs as well as low withdrawal fees. The cost saved increases household financial liquidity which can be invested in food, health, education and agricultural inputs. Furthermore, the travel time saved by the household members can be released into labour for productive purposes, for example agricultural labour. 


\subsection{Methodology}

\subsubsection{Data}

This essay uses data collected from rural households in Mukono and Kasese districts in Uganda during November and December 2013. Details of the data collection and sampling strategy are explained earlier in Section 2.4.1. From the sample discussed in Section 2.4.1, one non-adopting household was dropped because of missing information on consumption. Our analysis for this essay is based on 476 households in 39 villages consisting of 273 mobile money users and 203 non-users. Data on socioeconomic characteristics, including food and non-food consumption and expenditure, were collected at the household level. In line with literature, different recall periods were used to capture information on different sub-components of household expenditures (Deaton \& Zaidi, 2002; Levine, 2012). A 7-day recall period was used for expenditure on food, beverages and tobacco and a 30-day recall period was used in the case of household consumption expenditure on non-durable goods and frequently purchased services. For the semi-durable and durable goods and services, and non-consumption expenditures a 365-day recall period was used (Deaton \& Zaidi, 2002).

We collected expenditure data on an item-by item basis. During analysis, these expenditures were aggregated to the household level according to the recall period used and by broader subcomponents of expenditures. Given the different recall periods used in the survey to collect household expenditure data, conversion factors were applied to change expenditures to a 30-day monthly basis. Thereafter all the different sub-components of the expenditures were aggregated to derive the food, non-food and total consumption expenditures at household level.

As in the previous essay, a household is defined as a mobile money user if any member of the household used mobile money services in the past 12 months prior to the survey (Kikulwe et al., 2014). Following Kirui et al. (2012), the intensity of use refers to the number of times a 
household sent and received money via mobile phone in the past 12 months, with zero values indicating mobile money has not been used.

\subsubsection{Poverty measurement}

There are two broad methods to measure poverty - the consumption poverty (Foster et al., 1984; Meyer \& Sullivan, 2012) and multidimensional poverty index (Alkire \& Foster, 2011). These methods have been extensively applied in literature. In measuring poverty, the present study used both methods which we describe below.

\subsubsection{Consumption poverty}

Our aim is to measure poverty levels at the household level. We therefore created a dummy variable to capture consumption poverty. Households whose consumption falls below the poverty line were classified as consumption poor and the others as non-poor ${ }^{15}$. The study used the international poverty line of US\$1.25/day, which was converted to 28310 UGX per adult equivalent (or capita) per month using purchasing power parity ${ }^{16}$ (Levine, 2012). The consumption expenditure data which included food and non-food consumption items were used because they give a better measure of welfare than income (Deaton \& Zaidi, 2002; Ravallion et al., 2009).

\subsubsection{Multidimensional poverty}

The multidimensional poverty approach which is also called the direct method reveals whether people satisfy a set of specified basic needs and rights (Alkire \& Santos, 2014). The method of multidimensional poverty index (MPI) was developed by Alkire \& Foster (2011). The dimensions and indicators used to measure multidimensional poverty captured various components of human development, including the Millennium Development Goals, derived from

\footnotetext{
${ }^{15}$ The use of headcount index, which is an aggregate measure of poverty in a reference population (Foster et al., 1984; Mathenge et al., 2014), is not appropriate at the household level.

${ }^{16}$ The PPP exchange rate is 744.62 Uganda shillings (UGX) per dollar. At the time of survey, the official market exchange rate was around 2,500 UGX per US dollar.
} 
previous studies (Alkire \& Santos, 2014; Ayuya et al., 2015; Vijaya et al., 2014). The indicators used fall into the broad dimensions of education, standard of living, assets and health.

Alkire \& Foster (2011) and Alkire \& Santos (2014) used the "nested weights structure", where each indicator in each dimension were equally weighted. The dimensions are weighted equally and within each dimension, all indicators are assigned equal weights. The multidimensional poverty index as in any poverty measure involves a number of decisions on the indicator's choice and definition, deprivation cut-offs, weights, and the poverty cut-off which affect both identification and aggregation (Alkire \& Foster, 2011; Alkire \& Santos, 2014). As a departure from these studies, we created the multidimensional poverty index as a continuous variable using weights obtained from factor analysis instead of the "nested weights structure" by Alkire \& Foster (2011).

\subsection{Estimation strategy}

If we are to accurately measure the effect of mobile money, households should be randomly assigned to user and non-user groups (Jack et al., 2013; Kikulwe et al., 2014). As in many impact evaluation studies based on non-experimental observations our problem is that we cannot observe the outcome variable for users, in the case that they did not use and for non-users had they used. This problem is easily addressed in experimental studies by randomly assigning households to treatment and control groups, which assures that users and non-users are not systemically different (Khonje et al., 2015). The use of mobile money is not randomly distributed to the two groups of households, but rather households self-select themselves into use, therefore users and non-users may be systemically different. In our case, the unobservable characteristics that influence household mobile money use decision are likely to correlate with unobservable characteristics that influence welfare and poverty. Ignoring the endogeneity of mobile money would result in biased estimated parameters. We use various econometric models which accounts for the correlation in the unobserved characteristics in the mobile money use decision and 
outcome variables. Specifically, we use instrumental variable and endogenous switching probit regressions to account for the endogeneity of mobile money. The proportion of households owning mobile phones and using mobile money at the village level are used as instrument(s) (Kikulwe et al., 2014).

\subsubsection{Consumption expenditure and multidimensional poverty index}

To analyse the effect of mobile money on household welfare and multidimensional poverty index, we specify the following model:

$y_{i}=\delta M M_{i}+\gamma X_{i}+\varepsilon_{i}$

where $y_{i}$ is one of the continuous outcome variables (consumption expenditure or multidimensional poverty index), $M M$ is the treatment variable for mobile money (use or intensity of use). $X$ is a vector of regressors influencing the outcome variable. The parameter $\delta$ measures the effect of mobile money on the outcome variable. $\gamma$ is a vector of parameters to be estimated, and $\varepsilon$ is the error term. To control both observed and unobserved heterogeneity, we use Instrumental variables regression (IV) (Greene, 2012). We use the instruments discussed above: alone or in combination to control for the potential endogeneity of mobile money. For estimation, we used the IV estimator developed by Baum \& Schaffer (2007). 


\subsubsection{Consumption poverty}

Following Lokshin \& Sajaia (2011), consider a model with a binary outcome (whether household is poor or not) and a treatment variable, $M M_{i}$ denoting whether the household used mobile money or not. The treatment and the outcome can take one of the two potential values:

$M M_{i}=1$ if $\gamma Z_{i}+\mu_{i}>0$

$M M_{i}=0$ if $\gamma Z_{i}+\mu_{i} \leq 0$

$y_{1 i}^{*}=\beta_{1} X_{1 i}+\varepsilon_{1 i} \quad y_{1 i}=I\left(y_{1 i}^{*}>0\right)$

$y_{0 i}^{*}=\beta_{0} X_{0 i}+\varepsilon_{0 i} \quad y_{0 i}=I\left(y_{0 i}^{*}>0\right)$

Observed $y_{i}$ is defined as

$$
\begin{aligned}
& y_{i}=y_{1 i} \text { if } M M_{i}=1 \\
& y_{i}=y_{0 i} \text { if } M M_{i}=0
\end{aligned}
$$

Where $y_{1 i}^{*}$ and $y_{0 i}^{*}$ are latent variables (household poverty status) that defines the observed poverty status $y_{1}$ and $y_{0}$ (whether household is poor or not, respectively); $Z_{i}$ and $X_{i}$ are vectors of observables generating the selection equation and the poverty equation; $\gamma, \beta_{1}$ and $\beta_{0}$ are the vector of parameters to be estimated. $\mu_{i}$ is the error term for the selection equation, $\varepsilon_{1 i}$ and $\varepsilon_{0 i}$ are the regime-specific error terms. Assume that $\mu_{i}, \varepsilon_{1 i}$ and $\varepsilon_{0 i}$ are jointly normally distributed, with a mean-zero vector and correlation matrix:

$\Omega=\left(\begin{array}{ccc}1 & \rho_{0} & \rho_{1} \\ & 1 & \rho_{01} \\ & & 1\end{array}\right)$

where $\rho_{0}$ and $\rho_{1}$ are the correlations between $\varepsilon_{0}, \mu_{i}$ and $\varepsilon_{1}, \mu_{i}$, and $\rho_{01}$ is the correlation between $\varepsilon_{0}$ and $\varepsilon_{1}$. To ensure that estimated $\rho_{0}$ and $\rho_{1}$ are bounded between -1 and 1 , the model directly estimates $\operatorname{ath}(\rho)$ - the inverse hyperbolic tangent of the correlation coefficients (Lokshin \& Sajaia, 2011). 
Recent studies on binary endogenous regressors in the context of binary outcomes highlights the advantages of using a switching probit model over alternative econometric techniques (Lokshin \& Glinskaya, 2009; Floro \& Bali Swain, 2013; Ayuya et al., 2015; Aakvik et al., 2005). The endogenous switching probit model offers the possibility of deriving probabilities in counterfactual cases for household's poverty status on mobile money use. In particular, it enables controlling for endogeneity of mobile money use and estimating an average treatment effect (ATE), treatment effect on the treated (ATT), treatment effect on the untreated (ATU) and marginal treatment effects. Following Aakvik et al. (2005) and Lokshin \& Sajaia (2011) the effect of the treatment on the treated, or the expected effect of the treatment on individuals with observed characteristics $x$ who used mobile money (TT) is calculated as:

$$
\begin{gathered}
\operatorname{TT}(x)=\operatorname{Pr}\left(y_{1}=I \mid M M=1, X=x\right)-\operatorname{Pr}\left(y_{0}=I \mid M M=1, X=x\right) \\
=\frac{\Phi_{2}\left(X_{1} \beta_{1}, Z_{\gamma} \rho_{1}\right)-\Phi_{2}\left(X_{0} \beta_{0}, Z_{\gamma} \rho_{0}\right)}{F\left(Z_{\gamma}\right)}
\end{gathered}
$$

where $F$ is a cumulative function of the univariate normal distribution. The $(T T)$ is the difference between the predicted probability of being poor for households using mobile money and the probability of being poor for household had they not used mobile money. The average treatment effect on the treated (ATT) is obtained by computing the average of (TT) on households using mobile money. The effect of the treatment on the untreated, $(T U)$ which is the expected effect on poverty status if non-users had used mobile money, is derived from:

$$
\begin{gathered}
T U(x)=\operatorname{Pr}\left(y_{1}=I \mid M M=0, X=x\right)-\operatorname{Pr}\left(y_{0}=I \mid M M=0, X=x\right) \\
=\frac{\Phi_{2}\left(X_{1} \beta_{1}-Z_{\gamma}-\rho_{1}\right)-\Phi_{2}\left(X_{0} \beta_{0}-Z_{\gamma}-\rho_{0}\right)}{F\left(-Z_{\gamma}\right)}
\end{gathered}
$$


Computing the average of $T U(x)$ of households that did not use mobile money results in the average treatment effect on the untreated $(A T U)$ (Lokshin \& Sajaia, 2011). The treatment effect (TE), which is the expected effect of the treatment for the person with observed characteristics $x$ randomly drawn from the total sample is specified as:

$$
T E(x)=\operatorname{Pr}(M M=1, X=x)-\operatorname{Pr}(M M=0, X=x)=F\left(X_{1} \beta_{1}\right)-F\left(X_{0} \beta_{0}\right)
$$

The average treatment effects (ATE) can be calculated by averaging $T E(x)$ on all observations in the sample (Lokshin \& Sajaia, 2011; Aakvik et al., 2005). The endogenous switching probit model is identified by nonlinearities of its functional form (Lokshin \& Sajaia, 2011). Hence, to improve on identification an exclusion restriction was used, where $Z_{i}$ in Eqns. (4.2) contained at least one variable not in $X_{i}$, in Eqns. (4.3) and (4.4) (Lokshin \& Sajaia, 2011; Wooldridge, 2010). The selection instrument we used is the proportion of households using mobile money at the village level (Kikulwe et al., 2014). The explanatory variables were selected based on past studies on mobile money (Jack et al., 2013; Kikulwe et al., 2014) and poverty (Ali \& Abdulai, 2010; Asfaw et al., 2012; Ayuya et al., 2015).

\subsection{Results and discussion}

\subsubsection{Descriptive analysis}

In our sample about 29 percent of households are identified as multidimensionally poor. The dimensions, indicators, and deprivation cut-offs used to measure multidimensional poverty are presented in Table 4.1. The multidimensional poverty index derived from factor analysis is appropriate for impact evaluation because the index represent relative multidimensional poverty within the sample thus can be used to compare the extent to which one household differs from the other (Kabunga et al., 2014). Higher positive values reflect higher levels of multidimensional poverty. The Kaiser-Meyer-Olkin (KMO) measure of sampling adequacy and Bartlett test of 
sphericity were used to test the data's adequacy for factor analysis. The KMO yielded a value of 0.63 which is equal to the advisable minimum value of 0.6 . The Bartlett test yielded $\chi^{2}=501.263$ $(p=0.000)$, hence we reject the null hypothesis and conclude there are some relationships between variables used and the multidimensional poverty index.

Table 4. 1. Dimensions, indicators and deprivation cut-offs used in multidimensional poverty measurement

\begin{tabular}{|c|c|c|}
\hline Dimension and indicator & Description of deprivation cut-offs & $\begin{array}{l}\text { Factor } \\
\text { loadings }\end{array}$ \\
\hline \multicolumn{3}{|l|}{ Education } \\
\hline $\begin{array}{l}\text { Ever attended school/ } \\
\text { School attendance }\end{array}$ & Deprived if household head has never attended any formal schooling & 0.32 \\
\hline \multicolumn{3}{|l|}{ Standard of living } \\
\hline Drinking water & $\begin{array}{l}\text { Deprived if the household water source is unprotected/not safe (MDG } \\
\text { guidelines) }\end{array}$ & 0.07 \\
\hline Sanitation & $\begin{array}{l}\text { Deprived if the household has no descent pit latrine/use bush (MDG } \\
\text { guidelines) }\end{array}$ & 0.11 \\
\hline Main wall & Deprived if the household main wall is earth or wood & 0.52 \\
\hline Main floor & Deprived if the household main floor is earth or wood & 0.54 \\
\hline \multicolumn{3}{|l|}{ Assets } \\
\hline Phone & Deprived if the household does not own a mobile phone & 0.44 \\
\hline Radio and/or television & Deprived if the household does not own at least radio & 0.35 \\
\hline Vehicle & Deprived if the household does not own at least bicycle & 0.34 \\
\hline \multicolumn{3}{|l|}{ Health } \\
\hline Nutrition 1 & $\begin{array}{l}\text { Deprived if there was ever no food to eat of any kind in household } \\
\text { because there was not enough food in past } 4 \text { weeks }\end{array}$ & 0.39 \\
\hline Nutrition 2 & $\begin{array}{l}\text { Deprived if any member ate fewer meals in a day because there was not } \\
\text { enough food in past } 4 \text { weeks }\end{array}$ & 0.44 \\
\hline
\end{tabular}

Based on consumption poverty, about 34 percent of households are poor, with their monthly real gross expenditures below the poverty line. This result computed from consumption per capita are in line with findings of Gutierrez \& Choi (2014) who estimate that $40 \%$ of the population in Uganda live below the poverty line. The consumption poverty computed from consumption per adult equivalency show that 11 percent of households are poor, with their monthly real gross expenditures below the poverty line. Table 4.2 compares the outcome indicators and socioeconomic characteristics of users and non-users. Mobile money users have higher monthly 
consumption per adult equivalent compared to non-users. Users are less poor than non-users based on the consumption poverty. The multidimensional poverty index (MPI) for mobile money users is lower compared to non-users. These results suggests that users are more likely to be nonpoor compared to non-users. These results show that mobile money use is associated with lower poverty. However, to establish the causal effects we turn to econometric analysis in the next section. The correlation coefficient between multidimensional poverty and consumption poverty estimated using per capita consumption was positive (0.26) and significant at $0.01 \%$ level. For consumption poverty based on per adult equivalent the correlation was also positive $(0.27)$ and significant at the $0.01 \%$ level. The correlations of the two different poverty measures are positive and significant. This shows that they mostly identify the same household as being poor.

Mobile money users have better access to information through membership in farmer organizations and extension contact. Access to agricultural information is crucial for agricultural productivity and subsequently boosts food security and reduces poverty. There are also significant differences with respect to education levels, land holdings, livestock ownership and off-farm activities with users having higher figures for each variable compared to non-users. Using land, assets, off-farm income activity and livestock as proxies of wealth, our results reveal that mobile money users are wealthier than non-users. Better educated and wealthier users are more likely to have higher agricultural productivity and low poverty levels. 
Table 4. 2. Outcome indicators and socio-economic differences between mobile money users and non-users

\begin{tabular}{|c|c|c|c|c|c|}
\hline \multirow[b]{2}{*}{ Variable } & \multirow[b]{2}{*}{ Description } & \multicolumn{2}{|c|}{ Users } & \multicolumn{2}{|c|}{ Non-Users } \\
\hline & & Mean & Std & Mean & Std \\
\hline \multicolumn{6}{|l|}{ Outcome indicators } \\
\hline Consumption & Monthly consumption per AE & $66688.287^{* * *}$ & 35320.24 & 53790.80 & 33474.92 \\
\hline $\begin{array}{l}\text { Consumption } \\
\text { poverty }\end{array}$ & $\begin{array}{l}\text { Consumption poor }(1=\text { yes }) \text { (computed from } \\
\text { consumption per } \mathrm{AE})\end{array}$ & 0.077 & 0.27 & $0.153^{* * *}$ & 0.36 \\
\hline MPI & Multidimensional poverty scores & -0.280 & 0.61 & $0.376^{* * *}$ & 0.89 \\
\hline \multicolumn{6}{|l|}{ Treatment variable } \\
\hline Mobile money & Household used mobile money (dummy) & 0.57 & 0.50 & - & - \\
\hline $\begin{array}{l}\text { Mobile money } \\
\text { intensity }\end{array}$ & Times household used mobile money & 7.22 & 2.77 & - & - \\
\hline \multicolumn{6}{|l|}{ Control variables } \\
\hline $\begin{array}{l}\text { Mobile phone } \\
\text { (dummy) }\end{array}$ & Household own mobile phone & $1.000^{* * *}$ & 0.00 & 0.611 & 0.49 \\
\hline Mobile phones & Number of mobile phones owned & $2.018^{* * *}$ & 1.06 & 0.842 & 0.93 \\
\hline $\begin{array}{l}\text { Group } \\
\text { membership }\end{array}$ & $\begin{array}{l}\text { Household member(s) belongs to any group } \\
\text { (dummy) }\end{array}$ & $0.766^{* * *}$ & 0.42 & 0.606 & 0.49 \\
\hline Extension & $\begin{array}{l}\text { Household access information from CKW } \\
\text { (dummy) }\end{array}$ & $0.564^{* * *}$ & 0.50 & 0.419 & 0.50 \\
\hline Age & Age of household head (years) & 49.377 & 12.85 & 49.897 & 14.48 \\
\hline Gender & Gender of household head (1=Male) & $0.897^{* * *}$ & 0.30 & 0.788 & 0.41 \\
\hline Education & Education of household head (years) & $7.414^{* * *}$ & 4.46 & 5.064 & 3.85 \\
\hline Literacy & Household head literate (dummy) & $0.868^{* * *}$ & 0.34 & 0.719 & 0.45 \\
\hline Household size & Household size (number) & $7.326^{* * *}$ & 2.64 & 6.596 & 2.93 \\
\hline Land size & Size of land owned in acres & $5.153^{* * *}$ & 5.43 & 3.619 & 3.25 \\
\hline $\begin{array}{l}\text { Log farm } \\
\text { equipment }\end{array}$ & Log value of farm equipment & $10.943^{* * *}$ & 1.26 & 10.502 & 1.09 \\
\hline Off farm income & $\begin{array}{l}\text { Household member(s) engaged in off-farm } \\
\text { income activity (dummy) }\end{array}$ & $0.619^{* * *}$ & 0.49 & 0.355 & 0.48 \\
\hline Credit access & Household accessed credit (dummy) & $0.546^{* * *}$ & 0.50 & 0.345 & 0.48 \\
\hline TLU $^{17}$ & Total livestock units & $1.242^{* * *}$ & 2.21 & 0.671 & 1.50 \\
\hline Transport & $\begin{array}{l}\text { Household own motorcycle and or car } \\
\text { (dummy) }\end{array}$ & $0.201^{* * *}$ & 0.40 & 0.059 & 0.24 \\
\hline VMOB & $\begin{array}{l}\text { Households owning mobile phones at } \\
\text { village }(\%)\end{array}$ & $0.869^{* * *}$ & 0.12 & 0.787 & 0.14 \\
\hline VMMS & $\begin{array}{l}\text { Households using mobile money at village } \\
(\%)\end{array}$ & $0.639^{* * *}$ & 0.18 & 0.485 & 0.18 \\
\hline District & $\begin{array}{l}\text { Household is located in Mukono district } \\
\text { (dummy) }\end{array}$ & 0.538 & 0.50 & 0.453 & 0.50 \\
\hline Observations & & 273 & & 203 & \\
\hline
\end{tabular}

$*, * *, * * *$ indicates the corresponding mean differences are significant at the $10 \%, 5 \%$ and $1 \%$ level (t-tests). Nominal consumption values are reported here for ease of interpretation. In the regressions, we use the natural logarithm of consumption.

\footnotetext{
${ }^{17}$ TLU is calculated using the numbers of livestock owned by the household using Storck (1991) conversion factors: cows, oxen, bulls $=1$; heifers $=0.75 ;$ calves $=0.25$; donkey $=0.5$; goat, sheep $=0.1 ;$ pig $=0.2 ;$ chickens $=0.01$.
} 


\subsubsection{Econometric results}

\subsubsection{Effect of mobile money on household welfare}

Table 4.3 shows the effect of mobile money use and intensity on household consumption expenditure per AE. As discussed earlier, intensity indicates the number of times a household sent and received money via mobile phone in the past 12 months. In the IV model, we instrumented mobile money use and intensity with the proportion of households owning mobile phones and using mobile money at the village level (Kikulwe et al., 2014). In both specifications of the treatment variable, the p-value of the endogeneity test in the IV models is insignificant. This indicates absence of endogeneity between mobile money and consumption expenditure. Therefore, the OLS estimated coefficients presented in Table 4.3, which we discuss are unbiased, consistent and efficient.

The results indicate that mobile money plays a positive role in influencing household welfare. The use of mobile money increases consumption expenditure by $10 \%$ points. Munyegera \& Matsumoto (2014) also report similar findings for Uganda. Furthermore, results show that the intensity of using mobile money has a positive and significant effect on consumption expenditure. A unit increase in the number of times of using mobile money increases consumption expenditure per $\mathrm{AE}$ by $2 \%$ points. These findings demonstrate the positive role of mobile money on household welfare. This is consistent with the other studies that show that mobile money can improve household welfare in developing countries (Kikulwe et al., 2014; Munyegera \& Matsumoto, 2014; Jack \& Suri, 2014). 
Table 4. 3. Effect of mobile money use and intensity on monthly consumption per AE (UGX $\log$ )

\begin{tabular}{|c|c|c|c|c|}
\hline & \multicolumn{2}{|c|}{ Use (dummy) } & \multicolumn{2}{|c|}{ Intensity } \\
\hline & IV & OLS & IV & OLS \\
\hline \multirow[t]{2}{*}{ Mobile money } & 0.232 & $0.098^{* *}$ & 0.028 & $0.021^{* * *}$ \\
\hline & $(0.197)$ & $(0.049)$ & $(0.023)$ & $(0.006)$ \\
\hline \multirow[t]{2}{*}{ Group membership } & $0.087^{*}$ & $0.093^{*}$ & $0.096^{*}$ & $0.096^{*}$ \\
\hline & $(0.051)$ & $(0.053)$ & $(0.049)$ & $(0.053)$ \\
\hline \multirow[t]{2}{*}{ Mobile phones } & -0.027 & -0.005 & -0.026 & -0.016 \\
\hline & $(0.039)$ & $(0.023)$ & $(0.036)$ & $(0.023)$ \\
\hline \multirow[t]{2}{*}{ Extension } & 0.059 & 0.067 & 0.048 & 0.054 \\
\hline & $(0.043)$ & $(0.042)$ & $(0.046)$ & $(0.042)$ \\
\hline \multirow[t]{2}{*}{ Age } & $0.003^{* *}$ & $0.003^{*}$ & $0.004^{* *}$ & $0.004^{*}$ \\
\hline & $(0.002)$ & $(0.002)$ & $(0.002)$ & $(0.002)$ \\
\hline \multirow[t]{2}{*}{ Sex } & 0.009 & 0.019 & 0.020 & 0.022 \\
\hline & $(0.062)$ & $(0.064)$ & $(0.059)$ & $(0.065)$ \\
\hline \multirow[t]{2}{*}{ Education } & $0.014^{* *}$ & $0.015^{* * *}$ & $0.011^{*}$ & $0.012^{* *}$ \\
\hline & $(0.006)$ & $(0.005)$ & $(0.007)$ & $(0.006)$ \\
\hline \multirow[t]{2}{*}{ Household size } & $-0.044^{* * *}$ & $-0.044^{* * *}$ & $-0.043^{* * *}$ & $-0.044^{* * *}$ \\
\hline & $(0.008)$ & $(0.008)$ & $(0.008)$ & $(0.008)$ \\
\hline \multirow[t]{2}{*}{ Dependency ratio } & -0.023 & -0.024 & -0.022 & -0.022 \\
\hline & $(0.019)$ & $(0.018)$ & $(0.019)$ & $(0.018)$ \\
\hline \multirow[t]{2}{*}{ Land size } & $0.016^{* * *}$ & $0.016^{* * *}$ & $0.014^{* * *}$ & $0.015^{* * *}$ \\
\hline & $(0.005)$ & $(0.005)$ & $(0.005)$ & $(0.005)$ \\
\hline \multirow[t]{2}{*}{ Log farm equipment } & $0.071^{* * *}$ & $0.072^{* * *}$ & $0.067^{* * *}$ & $0.069^{* * *}$ \\
\hline & $(0.019)$ & $(0.019)$ & $(0.019)$ & $(0.019)$ \\
\hline \multirow[t]{2}{*}{ Off farm income } & -0.043 & -0.026 & -0.035 & -0.030 \\
\hline & $(0.051)$ & $(0.049)$ & $(0.047)$ & $(0.048)$ \\
\hline \multirow[t]{2}{*}{ Credit Access } & $0.080^{*}$ & $0.092^{* *}$ & $0.083^{*}$ & $0.087^{* *}$ \\
\hline & $(0.048)$ & $(0.042)$ & $(0.046)$ & $(0.042)$ \\
\hline \multirow[t]{2}{*}{ TLU } & 0.017 & 0.016 & 0.017 & 0.017 \\
\hline & $(0.012)$ & $(0.015)$ & $(0.012)$ & $(0.016)$ \\
\hline \multirow[t]{2}{*}{ Transport } & $0.152^{* *}$ & $0.163^{* * *}$ & $0.139^{* *}$ & $0.147^{* * *}$ \\
\hline & $(0.065)$ & $(0.057)$ & $(0.068)$ & $(0.057)$ \\
\hline \multirow[t]{2}{*}{ District } & -0.028 & -0.008 & -0.019 & -0.012 \\
\hline & $(0.057)$ & $(0.053)$ & $(0.053)$ & $(0.053)$ \\
\hline \multirow[t]{2}{*}{ Constant } & $9.914^{* * *}$ & $9.899^{* * *}$ & $9.955^{* * *}$ & $9.938^{* * *}$ \\
\hline & $(0.212)$ & $(0.217)$ & $(0.215)$ & $(0.215)$ \\
\hline Observations & 476 & 476 & 476 & 476 \\
\hline Log likelihood & -286.362 & -282.712 & -279.579 & -278.896 \\
\hline Anderson canon. corr. LM statistic (p-value) & 0.00 & & 0.00 & \\
\hline Cragg-Donald Wald F statistic & 15.53 & & 17.91 & \\
\hline Sargan statistic & 0.19 & & 0.20 & \\
\hline Endogeneity test ( $p$-value) & 0.48 & & 0.74 & \\
\hline Adjusted R-square & & 0.236 & & 0.249 \\
\hline
\end{tabular}

$*, * *, * * *$ indicates the corresponding coefficients are significant at the $10 \%, 5 \%$, and $1 \%$ levels, respectively. Standard errors are shown in parenthesis.

The other explanatory factors are quite similar in signs and magnitudes in the two specifications of the treatment variable. We proceed and interpret the econometric results based on the OLS model for intensity treatment variable. The variables education, land size, farm assets, credit access and ownership of means of transport are positive and highly significant in explaining household consumption expenditure. Kikulwe et al. (2014) also found similar results that education and land owned positively influenced household welfare for Kenya. The positive role 
of credit in improving household welfare is well documented (Roodman \& Morduch, 2013; Swain \& Floro, 2012). Ownership of means of transport is important for movement of people, household goods and services critical for human development as well as it acts as a source of income (transport hiring). This result confirms the importance of transport infrastructure on improving household welfare in Uganda.

\subsubsection{Effect of mobile money on consumption poverty}

We used an endogenous switching probit model, which relaxes the assumption of equality of coefficients of the consumption poverty equations in two regimes and thus is more efficient than the bivariate probit estimation (Lokshin \& Glinskaya, 2009; Lokshin \& Sajaia, 2011). In our sample, the Chow test rejected the assumption of equality of coefficients for users and non-users at a $0.01 \%$ significance level $\mathrm{X}^{2}(15)=2.01$ for consumption poverty, indicating that mobile money user-specific coefficient estimates are likely to be more informative. This demonstrates the appropriateness of the endogenous switching probit model. A pooled regression (a dummy regression where a binary mobile money use variable is used) may not be appropriate in assessing the effect of mobile money on consumption poverty. This is because a pooled regression model estimation assumes that the set of covariates have the same impact on users and non-users (i.e., a common slope coefficient for both regimes) (Khonje et al., 2015). This means that there is no interaction between the mobile money variable and other explanatory variables, indicating that mobile money only has an intercept effect or a parallel shift effect, which is always the same irrespective of the values taken by other covariates that determine consumption poverty.

Table 4.4 presents the determinants of mobile money use on consumption poverty estimated using endogenous switching probit regression. The proportion of households using mobile money at the village level is used as an instrument (Kikulwe et al., 2014). Before presenting results of our variable of interest, we discuss few variables that turn out significant in influencing the probability of consumption poverty. Education and land size have poverty-reducing effects for 
both users and non-users. Education enables households to be informed about various inputs and productivity enhancing technologies appropriate for different farm enterprises. This enables households to make rational and informed decisions on various enterprises in an effort to maximize returns, which might be spent on food expenditure and other human development investments. Farm assets reduce poverty among users only. Farm assets are important for boosting agricultural production and productivity. Higher agricultural productivity may enhance commercialization, which in turn improve household liquidity which is crucial for building household human development indicators. The result that off-farm income increases the probability of consumption poverty among non-users is unexpected. This may suggest non-users are engaged in off-farm income activities that yield lower returns.

Table 4. 4. Effect of mobile money use on consumption poverty - endogenous switching probit model

\begin{tabular}{|c|c|c|c|c|}
\hline & \multicolumn{2}{|c|}{ Users } & \multicolumn{2}{|c|}{ Non-users } \\
\hline & Coef & Std. err. & Coef & Std. err \\
\hline Group membership & 0.090 & 0.310 & -0.103 & 0.278 \\
\hline Mobile phones & 0.086 & 0.170 & 0.189 & 0.234 \\
\hline Extension & -0.103 & 0.259 & -0.032 & 0.266 \\
\hline Age & 0.005 & 0.011 & -0.004 & 0.009 \\
\hline Sex & 0.670 & 0.525 & -0.416 & 0.316 \\
\hline Education & $-0.056^{*}$ & 0.033 & $-0.062^{*}$ & 0.037 \\
\hline Household size & 0.024 & 0.053 & 0.076 & 0.048 \\
\hline Land size & $-0.091^{*}$ & 0.054 & $-0.195^{* *}$ & 0.092 \\
\hline Log farm equipment & $-0.258^{* *}$ & 0.120 & -0.102 & 0.147 \\
\hline Off farm income & 0.147 & 0.308 & $0.553^{* *}$ & 0.278 \\
\hline Credit access & -0.293 & 0.282 & -0.398 & 0.299 \\
\hline TLUC & 0.047 & 0.060 & -0.087 & 0.123 \\
\hline Output market & -0.006 & 0.031 & -0.035 & 0.031 \\
\hline District & 0.163 & 0.319 & 0.063 & 0.314 \\
\hline Constant & 0.808 & 1.576 & 0.927 & 1.602 \\
\hline $\operatorname{ath}(\rho 1), \operatorname{ath}(\rho 0)$ & -0.106 & 0.563 & 0.169 & 0.515 \\
\hline LR test of indep. eqns & 0.93 & & & \\
\hline Observations & 476 & & & \\
\hline Log likelihood & -351.447 & & & \\
\hline
\end{tabular}

$*, * *, * * *$ indicates the corresponding coefficients are significant at the $10 \%, 5 \%$, and $1 \%$ levels, respectively. Monthly consumption per adult equivalent is used in the computation of consumption poverty. The first stage results are not shown, since our interest is on the second stage only. 
Table 4.5 shows the effect of mobile money on the likelihood of being poor. The treatment effects were estimated by equations 4.6 to 4.8 following Lokshin \& Sajaia (2011). In the second column, consumption poverty was calculated based on monthly consumption per adult equivalent. The average treatment effect on the treated (ATT) was -0.10 . This implied that among users, the use of mobile money reduces the likelihood of being poor by about $10 \%$ points compared to the counterfactual case (not using mobile money). The average treatment effect on the untreated (ATU) suggests that non-users could potentially improve their welfare if they were to use mobile money. Among non-users, the probability of being poor would be reduced by $5 \%$ points if they were to use mobile money. Based on the average treatment effects (ATE) our econometric results show that use of mobile money reduces the probability of being poor by $8 \%$ points.

We also calculated consumption poverty based on the monthly consumption per capita. The mean treatment effects of mobile money on consumption poverty computed on per capita basis are shown Table 4.5, column 4. An endogenous switching probit model is used and the proportion of households using mobile money at the village level is used as an instrument. The average treatment effects show that use of mobile money reduces the probability that household falls below the poverty line by $4 \%$ points. The ATE is consistent with results based on consumption poverty computed from monthly consumption per adult equivalent.

Table 4. 5. Mean treatment effect of mobile money use on consumption poverty

\begin{tabular}{|c|c|c|c|c|}
\hline \multirow[b]{2}{*}{ Treatment effects } & \multicolumn{2}{|c|}{ Per adult equivalent } & \multicolumn{2}{|c|}{ Per capita } \\
\hline & Estimate & Std. err. & Estimate & Std. err. \\
\hline Average treatment effect on the treated (ATT) & -0.100 & 0.009 & -0.147 & 0.007 \\
\hline Average treatment effect on the untreated (ATU) & -0.046 & 0.009 & 0.111 & 0.008 \\
\hline Average treatment effect (ATE) & -0.077 & 0.006 & -0.036 & 0.006 \\
\hline
\end{tabular}

In Table 4.6, we found no endogeneity between intensity of using mobile and consumption poverty. We therefore present probit estimates on the effect of intensity of using mobile money on poverty among rural households in Uganda. Results show that the intensity of using mobile 
money has a significant effect on poverty. A unit increase in the intensity of using mobile money reduces the probability of consumption poverty by about $1 \%$ point. The other covariates; education, land size, farm assets and credit access are negative and significant implying they are crucial in reducing the probability of poverty among sample households. Larger land sizes and farm assets might lead to increased agricultural production and productivity. This may potentially enhance consumption and boost farm incomes through increased commercialization activities. Higher farm incomes may increase total household income thereby reducing poverty. Access to credit is important and enables households to purchase yield enhancing inputs, food and other household goods and services that contribute to poverty reduction. Imai et al. (2010) also report similar findings for India. The result that off-farm income increases the probability of consumption poverty is quite surprising as we expected the opposite. The major off-farm income activities undertaken by households in our sample include personal business (retail trade, brickmaking and boda boda - motorcycle hiring) and wage employment outside the farm. Our results suggest that the returns from these off-farm activities are too low.

Table 4. 6. Effect of intensity of using mobile money on consumption poverty

\begin{tabular}{lcc}
\hline & AME & Std. err. \\
\hline Mobile money intensity & $-0.009^{* * *}$ & 0.003 \\
Group membership & 0.000 & 0.024 \\
Mobile phones & 0.014 & 0.010 \\
Extension & -0.003 & 0.020 \\
Age & -0.000 & 0.001 \\
Sex & -0.008 & 0.028 \\
Education & $-0.006^{*}$ & 0.003 \\
Household size & 0.005 & 0.004 \\
Land size & $-0.014^{* * *}$ & 0.004 \\
Log farm equipment & $-0.023^{*}$ & 0.012 \\
Off farm income & $0.045^{* *}$ & 0.023 \\
Credit access & $-0.041^{*}$ & 0.023 \\
TLUC & 0.004 & 0.006 \\
Output market & -0.002 & 0.002 \\
District & 0.007 & 0.026 \\
\hline Observations & 476 & \\
Wald chi2(15) & $52.33^{* * *}$ & 0.160 \\
Pseudo R2 & -137.892 & \\
Log likelihood & & \\
\hline
\end{tabular}

$*, * *, * * *$ indicates the corresponding marginal effects are significant at the $10 \%, 5 \%$, and $1 \%$ levels, respectively. Marginal effects for dummy variable are discrete change from 0 to 1 . 


\subsubsection{Effect of mobile money on multidimensional poverty}

Table 4.7 presents the estimation results of effect of mobile money use and intensity of use on multidimensional poverty index. We used IV models for estimation. We instrumented mobile money with the proportion of households using mobile money at the village level (Kikulwe et al., 2014). This instrument is correlated with mobile money use and does not affect poverty directly. The test statistics for checking the relevance and validity of our instrument are shown in the bottom panel of table. The Anderson LM statistic of whether the excluded instrument is relevant and the equations are identified has a p-value of 0.00 . This indicates that we can reject the null hypothesis that the equations are under-identified and conclude that the instrument is relevant (Baum \& Schaffer, 2007; Bascle, 2008). The estimated Cragg-Donald F statistics for the two models is above the value of 10 , implying that the chosen instrument is relevant and sufficiently strong. Our equations are exactly identified as shown by the Sargan statistic of overidentification. The endogeneity test statistics of mobile money (Baum \& Schaffer, 2007; Bascle, 2008) are significant with p-values of 0.03 and 0.04 , hence, we reject the null hypothesis and conclude that the instrumented variable is endogenous. Hence, unobserved factors (e.g. risk aversion, innate ability etc) affect both mobile money and multidimensional poverty.

For interpretation, our dependent variable is multidimensional poverty; therefore negative coefficient estimates imply a reduction in multidimensional poverty and vice versa. Our variable of interest: mobile money is negative and highly significant in both models. The use of mobile money reduces multidimensional poverty by 0.67 index points. On the other hand, a unit increase in the intensity of using mobile money reduces multidimensional poverty by 0.07 index points. These results highlight the importance of mobile money on poverty reduction among rural households in Uganda, and support our earlier findings based on consumption poverty. Our results are robust to different specification of the treatment variable and poverty outcome variables. 
Table 4. 7. Effect of mobile money use and intensity on multidimensional poverty index

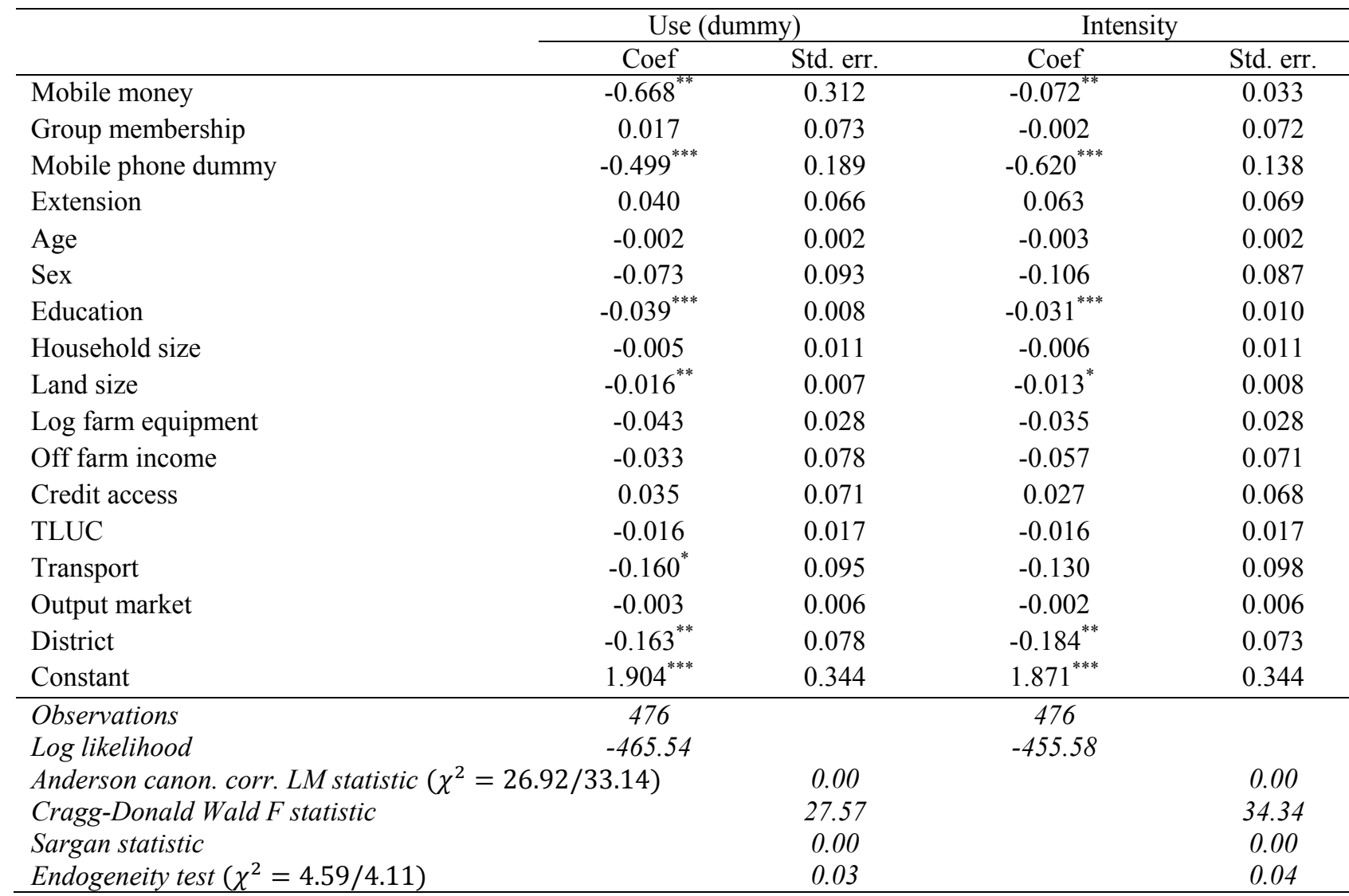

$*, * *, * * *$ indicates the corresponding coefficients are significant at the $10 \%, 5 \%$, and $1 \%$ levels, respectively

The other explanatory variables mobile phone, education, land and location are negative and significant in reducing multidimensional poverty in both specifications of the treatment variable.

Our model results show that ownership of mobile phone reduce multidimensional poverty by 0.50 and 0.62 index points respectively. This captures the other benefits of using mobile phones beyond transferring mobile money, for example information access. Access to information through mobile phones is welfare enhancing. An additional year of schooling reduces multidimensional poverty by 0.04 and 0.03 index points in the use and intensity specification respectively. The variable land size has negative and significant regression coefficient in the two model specifications. Households with larger land sizes are likely to have more agricultural produce which when sold could lead to higher farm incomes. Higher farm incomes could in turn facilitate households to build their human development indicators. Ayuya et al. (2015) found a similar result that land size reduces multidimensional poverty in Kenya. 


\subsection{Conclusion and policy implications}

This essay analyses the effect of mobile money on welfare and poverty among rural households in Uganda. In particular, we analyse the effect of mobile money use and intensity of use on household welfare and poverty using data obtained from a sample of 476 households. The paper is unique in three dimensions. First, we examine the effects of mobile money on poverty - an area not yet explored. Second, we use two alternative specifications of the treatment variable (use and intensity of using mobile money). Third, at the methodological level, we use two measures of poverty: consumption poverty and multidimensional poverty index, unlike most previous studies that rely on a single measure. The analysis of poverty using alternative measures acts as a robustness check of our results.

We measured household welfare with consumption per adult equivalent. Based on OLS models, our results show that the use and intensity of using mobile money increases consumption expenditure by $10 \%$ and $2 \%$ points respectively. Further, we utilized different econometric model specifications to estimate the effects of mobile money on poverty. Specifically, the study used endogenous switching probit and IV models to control for potential endogeneity of mobile money use. We find consistent evidence that use of mobile money as well as the intensity of using mobile money have significant poverty-reducing effects among households in Uganda. Although the magnitude of the estimated effects varies across the two poverty measures and different econometric models, the qualitative results are similar.

With regards to consumption poverty, our model estimates presents an interesting story. Among users, the use of mobile money reduces the probability of being poor by about $10 \%$ points compared to the counterfactual case. The average treatment effect on the untreated (ATU) is quite interesting from a policy perspective, suggesting that non-users could potentially improve their welfare if they were to use mobile money. Among non-users, the probability of poverty would be reduced by $5 \%$ points if they were to use mobile money. The average treatment effects (ATE) 
show that use of mobile money reduces the likelihood of being poor by $8 \%$ points. The result on the intensity of using mobile money also shows significant effects. A unit increase in the intensity of using mobile money reduces the probability of consumption poverty by $1 \%$ point. Based on the multidimensional poverty measure, our model results reveal that use of mobile money significantly reduces multidimensional poverty by 0.67 index points. A unit increase in the intensity of using mobile money reduces multidimensional poverty by 0.07 index points.

Our results are robust to different specifications of the outcome and treatment variables and consistently confirm the poverty-reducing effects of mobile money. Hence, mobile money promotion could complement other poverty reduction strategies in Uganda. Other poverty reduction strategies could include investment in education, land intensification, farm assets and transport infrastructure which are shown to have poverty-reducing effects based on our econometric estimates. Our findings have important policy implications for the use of mobile money on household welfare and poverty reduction. In particular, they suggest that policy interventions to improve household welfare and reduce poverty should embrace the promotion of mobile money among rural households in Uganda. Furthermore, the promotion of mobile money should be in tandem with other policy efforts that aim to improve education, road and transport infrastructure in Uganda. The promotion of mobile money could be achieved by enhancing access to information through extension, social networks and increasing the number of mobile money agents in rural areas.

Our study presents interesting findings. However, there are limitations worth mentioning. The study uses cross-section data which relates to current effect. The effects of mobile money might be different in the long run, for example due to changes in expenditure and seasonal variability in food supply. Further research might need to build on panel data to understand the long-term effects of mobile money on poverty. 


\section{$5 \quad$ General Conclusion}

\subsection{Main findings}

In this study, we have contributed to the existing literature in many ways. In developing countries, households often rely on social networks to get information on new innovations because financial information services are underprovided. In the first essay, we contribute to literature by using unique social interactions data to analyse how social networks affect mobile money adoption among rural households. A conditional logistic regression model is estimated controlling for household characteristics, correlated effects, and other possible information sources. We find that information exchange within social networks helps disseminate information about mobile money and has enhanced its adoption. An increase in the exchange adopters within household social network increases the odds of adopting mobile money by $77 \%$ points. However, the structure of social network appears to have no effect on mobile money adoption. We also analyse the effect of social networks, separately for poor and non-poor households. Our results show that social network effects, and in particular the size of exchange adopters appear to be more pronounced for non-poor households.

In the second essay, we analyse the effect of mobile money on household food security. We contribute to limited literature on the implications of mobile money in many ways. First, we analyse the food security implications of mobile money - an area not yet researched. Second, we contribute methodologically by using two measures of food security (a subjective and objective measure). Third, and unlike previous studies, we use two alternative specifications of the treatment variable (dummy for use of mobile money and intensity of using mobile money). We account for potential endogeneity of mobile money by using treatment effects and instrumental variable regression techniques. We have shown that use of mobile money decreases household relative food insecurity. Furthermore, we find that use of mobile money and intensity of using 
mobile money increases monthly food expenditure. We conclude that mobile money positively affects food security.

In the third essay, we analyse the effect of mobile money on household welfare and poverty. We measured welfare using household consumption expenditure. Poverty was measured using consumption poverty and multidimensional poverty index. We have contributed to the emerging literature on mobile money by analysing the welfare and poverty implications of mobile money. Furthermore, we contribute methodologically by using two alternative specifications of the treatment variable and outcome variable. We estimate instrumental variable and endogenous switching probit regressions to control for the potential endogeneity of mobile money. Our econometric results show that use and intensity of using mobile money both increases consumption expenditure, thus improves household welfare. In terms of consumption poverty, we find that use of mobile money reduces the probability of being poor among users. Among nonusers, the probability of being poor could be reduced if they were to use mobile money. Furthermore, the intensity of using mobile money reduces the likelihood of being poor. The use and intensity of using mobile money reduces multidimensional poverty. Our results for the effects of mobile money are robust to alternative specifications of the treatment and poverty outcome variables. These results confirm that mobile money is welfare-enhancing and reduces household poverty.

Our general conclusion is that exchange within social networks positively and significantly influences the adoption the mobile money. Furthermore, mobile money improves food security and welfare as well as reduces poverty among rural households in Uganda. 


\subsection{Policy implications}

Our study findings from the first essay have important policy implications for the diffusion of mobile money in developing countries, where formal information institutions are lacking. In particular, they suggest that informal institutions such as social networks help disseminate information about mobile money. The adoption of mobile money is likely to be increased if promotion programs reach more social networks. From a policy perspective, there is a need for policy makers, mobile money service providers and extension to strengthen and utilize informal institutions to disseminate information about mobile money. Furthermore, our evidence suggests that the poor may be trapped in information-poor networks and thus social network multiplier effects will most likely not automatically work in their case. Therefore, there is need to target mobile money promotion programs to reach the poor. One possible promotion strategy is the provision of mobile money education and awareness campaigns in rural areas. Making rural households more aware about mobile money, its use and advantages is likely to improve adoption. In particular, mobile money service providers should be at the forefront of rolling out mobile money promotion programs because they stand to benefit financially if more households adopt mobile money.

Results from essay 2 and 3 are quite interesting for policy making. Our research has shown that rural households can improve their welfare and food security as well as reduce poverty through using mobile money. Of particular interest is the potential of mobile money to contribute to sustainable development goals 1 and 2: of ending poverty; and ending hunger and achieving food security and improved nutrition respectively. These results suggest that mobile money is welfareenhancing and its promotion will be beneficial for rural households. Policy interventions to improve household food security and welfare and reduce poverty in Uganda and other developing countries should consider promotion of mobile money. For these reasons, donors, policy makers, 
mobile money service providers, public and private sector should continue promoting mobile money in developing countries.

\subsection{Limitations of the study}

Our study offers interesting evidence on the adoption and welfare effects of mobile money in a developing country context. The study has limitations that are worth mentioning. In the first essay, we use only two variables to measure the structure of the social network. Future studies could enhance the analysis by using additional measures of social network structure, for example difference in educational attainment level, age and distance of network members relative to interviewed household. In addition, other drivers of adoption, for example: household perception of fraud and security associated with mobile money are not accounted in this study. Our study uses cross-section data which is static and relates to current effect. Such a static analysis fails to account for the dynamic nature of social networks. For welfare analysis, the limitation is that static analysis does not account for the long run effects, for example due to changes in expenditure and seasonal variability in food supply. Therefore, further research might need to build on panel data to explore the effect of mobile money on food security and poverty over time. 


\section{References}

Aakvik, A., Heckman, J. J., \& Vytlacil, E. J. (2005). Estimating treatment effects for discrete outcomes when responses to treatment vary: an application to Norwegian vocational rehabilitation programs. Journal of Econometrics, 125, 15-51.

Adams, R. H., \& Cuecuecha, A. (2013). The Impact of Remittances on Investment and Poverty in Ghana. World Development, 50, 24-40.

Ali, A., \& Abdulai, A. (2010). The Adoption of Genetically Modified Cotton and Poverty Reduction in Pakistan. Journal of Agricultural Economics, 61, 175-192.

Alkire, S., \& Foster, J. (2011). Counting and multidimensional poverty measurement. Journal of Public Economics, 95, 476-487.

Alkire, S., \& Santos, M. E. (2014). Measuring Acute Poverty in the Developing World: Robustness and Scope of the Multidimensional Poverty Index. World Development, $59,251-274$.

Allison, P. D., \& Waterman, R. P. (2002). Fixed-Effects Negative Binomial Regression Models. Sociological Methodology, 32, 247-265.

Anzoategui, D., Demirgüç-Kunt, A., \& Martínez Pería, María Soledad (2014). Remittances and Financial Inclusion: Evidence from El Salvador. World Development, 54, 338-349.

Asfaw, S., Kassie, M., Simtowe, F., \& Lipper, L. (2012). Poverty Reduction Effects of Agricultural Technology Adoption: A Micro-evidence from Rural Tanzania. Journal of Development Studies, 48, 1288-1305.

Ayuya, O. I., Gido, E. O., Bett, H. K., Lagat, J. K., Kahi, A. K., \& Bauer, S. (2015). Effect of Certified Organic Production Systems on Poverty among Smallholder Farmers: Empirical Evidence from Kenya. World Development, 67, 27-37.

Banerjee, A., Chandrasekhar, A. G., Duflo, E., \& Jackson, M. O. (2013). The diffusion of microfinance. Science (New York, N.Y.), 341, 1236498.

Barrett, C. B. (2010). Measuring Food Insecurity. Science, 327, 825-828.

Bascle, G. (2008). Controlling for endogeneity with instrumental variables in strategic management research. Strategic Organization, 6, 285-327.

Baum, C. F., \& Schaffer, M. E. (2007). Enhanced routines for instrumental variables/generalized method of moments estimation and testing. The Stata Journal, 7, 465-506.

Beck, T., \& Demirguc-Kunt, A. (2008). Access to Finance: An Unfinished Agenda. The World Bank Economic Review, 22, 383-396.

Becker, G. S. (1982). A Theory of Social Interactions. Journal of Political Economy, 82, 10631093.

Bezu, S., Kassie, G. T., Shiferaw, B., \& Ricker-Gilbert, J. (2014). Impact of Improved Maize Adoption on Welfare of Farm Households in Malawi: A Panel Data Analysis. World Development, 59, 120-131.

Borgatti, S. P., Mehra, A., Brass, D. J., \& Labianca, G. (2009). Network Analysis in the Social Sciences. Science, 323, 892-895.

Chang, M. L. (2005). With a Little Help from My Friends (and My Financial Planner). Social Forces, 83, 1469-1497. 
Coates, J., Swindale, A., \& Bilinsky, P. (2007). Household Food Insecurity Access Scale (HFIAS) for measurement of food access: Indicator guide. (Version 3). Washington, $\mathrm{DC}$.

Cock, N., D’Haese, M., Vink, N., Rooyen, C. J., Staelens, L., Schönfeldt, H. C., \& D’Haese, L. (2013). Food security in rural areas of Limpopo province, South Africa. Food Security, 5, 269-282.

Conley, T. G., \& Udry, C. R. (2010). Learning about a New Technology: Pineapple in Ghana. American Economic Review, 100, 35-69.

de Haen, H., Klasen, S., \& Qaim, M. (2011). What do we really know? Metrics for food insecurity and undernutrition. Food Policy, 36, 760-769.

Deaton, A., \& Zaidi, S. (2002). Guidelines for constructing consumption aggregates for welfare analysis. LSMS working paper, no. 135. Washington, DC: World Bank.

Diniz, E., Birochi, R., \& Pozzebon, M. (2012). Triggers and barriers to financial inclusion: The use of ICT-based branchless banking in an Amazon county. Poverty, Technology and Microfinance, 11, 484-494.

Donovan, K. (2012). Mobile Money for Financial Inclusion. In Information and Communications for Development 2012 (pp. 61-73): The World Bank.

Dupas, P., \& Robinson, J. (2013). Savings Constraints and Microenterprise Development: Evidence from a Field Experiment in Kenya. American Economic Journal: Applied Economics, 5, 163-192.

FAO (1996). The Rome Declaration on World Food Security. The World Food Summit. FAO, Rome.

Fernández-Val, I. (2009). Fixed effects estimation of structural parameters and marginal effects in panel probit models. Journal of Econometrics, 150, 71-85.

Field, A. P. (2013). Discovering statistics using IBM SPSS statistics: And sex and drugs and rock'n'roll. (4. ed). Los Angeles, Calif. [u.a.]: SAGE.

Floro, M. S., \& Bali Swain, R. (2013). Food Security, Gender, and Occupational Choice among Urban Low-Income Households. World Development, 42, 89-99.

Foster, J., Greer, J., \& Thorbecke, E. (1984). A Class of Decomposable Poverty Measures. Econometrica, 52, 761-766.

Fu, Y.-c., Ho, H.-C., \& Chen, H. M. (2013). Weak ties and contact initiation in everyday life: Exploring contextual variations from contact diaries. Social Networks, 35, 279-287.

Giuliano, P., \& Ruiz-Arranz, M. (2009). Remittances, financial development, and growth. Journal of Development Economics, 90, 144-152.

Gould, W. (2000). sg124: Interpreting logistic regression in all its forms. Stata Technical Bulletin, 53, 19-21.

Granovetter, M. (2005). The Impact of Social Structure on Economic Outcomes. Journal of Economic Perspectives, 19, 33-50.

Granovetter, M. S. (1973). The Strength of Weak Ties. American Journal of Sociology, 78, 1360 1380 .

Greene, W. H. (2012). Econometric analysis. (7th ed). Boston: Prentice Hall. 
GSMA (2014). Mobile Money for the Unbanked: How MTN Uganda communicates to its network of 15,000 agents. http://www.gsma.com/mobilefordevelopment/how-mtnuganda-communicates-to-its-network-of-15000-agents. Accessed 12.05.2014.

GSMA (2015). State of the Industry 2014: Mobile Financial Services for the Unbanked. London.

Gupta, S., Pattillo, C. A., \& Wagh, S. (2009). Effect of Remittances on Poverty and Financial Development in Sub-Saharan Africa. World Development, 37, 104-115.

Gutierrez, E., \& Choi, T. (2014). Mobile Money Services Development: The Cases of the Republic of Korea and Uganda: Policy Research Working Paper 6786. Washington, D.C.

Heinze, G., \& Puhr, R. (2010). Bias-reduced and separation-proof conditional logistic regression with small or sparse data sets. Statistics in medicine, 29, 770-777.

Howe, L. D., Hargreaves, J. R., \& Huttly, Sharon R A (2008). Issues in the construction of wealth indices for the measurement of socio-economic position in low-income countries. Emerging themes in epidemiology, 5, 3.

IFC (2011). Mobile Money Study: Summary Report. Washington, DC.

Imai, K. S., Arun, T., \& Annim, S. K. (2010). Microfinance and Household Poverty Reduction: New Evidence from India. World Development, 38, 1760-1774.

InterMedia (2012). Mobile Money in Uganda: Use, Barriers and Opportunities. Washington, D.C.

Jack, W., Ray, A., \& Suri, T. (2013). Transaction Networks: Evidence from Mobile Money in Kenya. American Economic Review, 103, 356-361.

Jack, W., \& Suri, T. (2014). Risk Sharing and Transactions Costs: Evidence from Kenya's Mobile Money Revolution †. American Economic Review, 104, 183-223.

Kabunga, N. S., Dubois, T., \& Qaim, M. (2014). Impact of tissue culture banana technology on farm household income and food security in Kenya. Food Policy, 45, 25-34.

Karlan, D., Ratan, A. L., \& Zinman, J. (2014). Savings by and for the poor: a research review and agenda. The Review of income and wealth, 60, 36-78.

Kassie, M., Jaleta, M., \& Mattei, A. (2014). Evaluating the impact of improved maize varieties on food security in Rural Tanzania: Evidence from a continuous treatment approach. Food Security, 6, 217-230.

Kassie, M., Ndiritu, S. W., \& Stage, J. (2014). What Determines Gender Inequality in Household Food Security in Kenya? Application of Exogenous Switching Treatment Regression. World Development, 56, 153-171.

Keino, S., Plasqui, G., \& van den Borne, Bart (2014). Household food insecurity access: a predictor of overweight and underweight among Kenyan women. Agriculture \& Food Security, 3, 2.

Khonje, M., Manda, J., Alene, A. D., \& Kassie, M. (2015). Analysis of Adoption and Impacts of Improved Maize Varieties in Eastern Zambia. World Development, 66, 695-706.

Kikulwe, E. M., Fischer, E., \& Qaim, M. (2014). Mobile money, smallholder farmers, and household welfare in Kenya. PloS one, 9, e109804.

Kirui, O. K., Okello, J. J., \& Njiraini, G. W. (2013). Impact of mobile phone-based money transfer services in agriculture: evidence from Kenya. Quarterly Journal of International Agriculture, 52, 141-162. 
Kirui, O. K., Okello, J. J., \& Nyikal, R. A. (2012). Determinants of use and intensity of use of mobile phone-based money transfer services in smallholder agriculture: case of Kenya. Paper prepared for the International Association of Agricultural Economists (IAAE) Triennial Conference, Foz do Iguaçu, Brazil, 18-24 August, 2012.

Lai, G., Lin, N., \& Leung, S.-Y. (1998). Network resources, contact resources, and status attainment. Social Networks, 20, 159-178.

Lancaster, T. (2000). The incidental parameter problem since 1948. Journal of Econometrics, 95 , $391-413$.

Levine, S. (2012). Exploring Differences in National and International Poverty Estimates: Is Uganda on Track to Halve Poverty by 2015? Social Indicators Research, 107, 331349 .

Lin, N. (1999). Social Networks and Status Attainment. Annual Review of Sociology, 25, 467487.

Lin, N., Ensel, W. M., \& Vaughn, J. C. (1981). Social Resources and Strength of Ties: Structural Factors in Occupational Status Attainment. American Sociological Review, 46, 393 405.

Liverpool-Tasie, L. S. O., \& Winter-Nelson, A. (2012). Social Learning and Farm Technology in Ethiopia: Impacts by Technology, Network Type, and Poverty Status. Journal of Development Studies, 48, 1505-1521.

Lokshin, M., \& Glinskaya, E. (2009). The Effect of Male Migration on Employment Patterns of Women in Nepal. The World Bank Economic Review, 23, 481-507.

Lokshin, M., \& Sajaia, Z. (2011). Impact of interventions on discrete outcomes: Maximum likelihood estimation of the binary choice models with binary endogenous regressors. The Stata Journal, 11, 368-385.

Mabiso, A., Cunguara, B., \& Benfica, R. (2014). Food (In)security and its drivers: insights from trends and opportunities in rural Mozambique. Food Security, 6, 649-670.

Maertens, A., \& Barrett, C. B. (2013). Measuring Social Networks' Effects on Agricultural Technology Adoption. American Journal of Agricultural Economics, 95, 353-359.

Manski, C. F. (1993). Identification of endogenous social effects: the reflection problem. Review of Economic Studies, 60, 531-542.

Mathenge, M. K., Smale, M., \& Olwande, J. (2014). The impacts of hybrid maize seed on the welfare of farming households in Kenya. Food Policy, 44, 262-271.

Matuschke, I., \& Qaim, M. (2009). The impact of social networks on hybrid seed adoption in India. Agricultural Economics, 40, 493-505.

Maxwell, D., Vaitla, B., \& Coates, J. (2014). How do indicators of household food insecurity measure up? An empirical comparison from Ethiopia. Food Policy, 47, 107-116.

McKenzie, D. J. (2005). Measuring inequality with asset indicators. Journal of Population Economics, 18, 229-260.

Meyer, B. D., \& Sullivan, J. X. (2012). Identifying the Disadvantaged: Official Poverty, Consumption Poverty, and the New Supplemental Poverty Measure. Journal of Economic Perspectives, 26, 111-136.

Miyata, S., Minot, N., \& Hu, D. (2009). Impact of Contract Farming on Income: Linking Small Farmers, Packers, and Supermarkets in China. World Development, 37, 1781-1790. 
Morawczynski, O. (2009). Exploring the usage and impact of "transformational" mobile financial services: the case of M-PESA in Kenya. Journal of Eastern African Studies, 3, 509525.

MTN (2014). Mobile Banking. http://www.mtn.co.ug/mtn-services/mobile-banking.aspx.

Munyegera, G. K., \& Matsumoto, T. (2014). Mobile Money, Rural Household Welfare and Remittances: Panel Evidence from Uganda. National Graduate Institute for Policy Studies, Tokyo Japan.

Ravallion, M., Chen, S., \& Sangraula, P. (2009). Dollar a Day Revisited. The World Bank Economic Review, 23, 163-184.

Richards, T. J., Hamilton, S. F., \& Allender, W. J. (2014). Social Networks and New Product Choice. American Journal of Agricultural Economics, 96, 489-516.

Roodman, D., \& Morduch, J. (2013). The Impact of Microcredit on the Poor in Bangladesh: Revisiting the Evidence. The Journal of Development Studies, 50, 583-604.

Röper, A., Völker, B., \& Henk, F. (2009). Social networks and getting a home: Do contacts matter? Social Networks, 31, 40-51.

Sahn, D. E., \& Stifel, D. C. (2000). Poverty Comparisons Over Time and Across Countries in Africa. World Development, 28, 2123-2155.

Shiferaw, B., Kassie, M., Jaleta, M., \& Yirga, C. (2014). Adoption of improved wheat varieties and impacts on household food security in Ethiopia. Food Policy, 44, 272-284.

Sinyolo, S., Mudhara, M., \& Wale, E. (2014). Water security and rural household food security: empirical evidence from the Mzinyathi district in South Africa. Food Security, 6, 483499.

Smith, P. (2013). Delivering food security without increasing pressure on land. Global Food Security, 2, 18-23.

Son, J., \& Lin, N. (2012). Network diversity, contact diversity, and status attainment. Social Networks, 34, 601-613.

Song, L., \& Chang, T.-Y. (2012). Do resources of network members help in help seeking? Social capital and health information search. Social Networks, 34, 658-669.

StataCorp (2013). Stata: Release 13. Statistical Software. College Station, TX: StataCorp LP.

Storck, H. (1991). Farming systems and farm management practices of smallholders in the Haraghe Highlands: A baseline survey. Farming systems and resource economics in the tropics, vol. 11. Kiel: Wiss.-Verl. Vauk.

Swain, R. B., \& Floro, M. (2012). Assessing the Effect of Microfinance on Vulnerability and Poverty among Low Income Households. Journal of Development Studies, 48, 605618.

The Montpellier Panel (2013). Sustainable Intensification: A New Paradigm for African Agriculture. Imperial College London, London.

UNCDF (2015). Inclusive finance. Increasing access to financial services. New York, USA.

UNDP (2015). Human Development Reports. International Human Development Indicators. http://hdr.undp.org/en/countries. Accessed 13.01.2015.

Vijaya, R. M., Lahoti, R., \& Swaminathan, H. (2014). Moving from the Household to the Individual: Multidimensional Poverty Analysis. World Development, 59, 70-81. 
Wooldridge, J. M. (2010). Econometric analysis of cross section and panel data. (2nd ed.). Cambridge, Mass.: MIT Press.

World Bank (2014). Financial Inclusion Data: Uganda country dashboard. http://datatopics.worldbank.org/financialinclusion/country/uganda. Accessed 12.05.2014.

Wydick, B., Karp Hayes, H., \& Hilliker Kempf, S. (2011). Social Networks, Neighborhood Effects, and Credit Access: Evidence from Rural Guatemala. World Development, 39, 974-982.

Yau Fu, C., Hung, J.-H., Liu, S.-H., \& Chien, Y.-L. (2005). A new algorithm for solving binary discrimination in conditional logistic regression, with two choices of strata. Computational Statistics \& Data Analysis, 49, 85-97.

Zhang, Y., Lin, N., \& Li, T. (2012). Markets or networks: Households' choice of financial intermediary in Western China. Social Networks, 34, 670-681. 


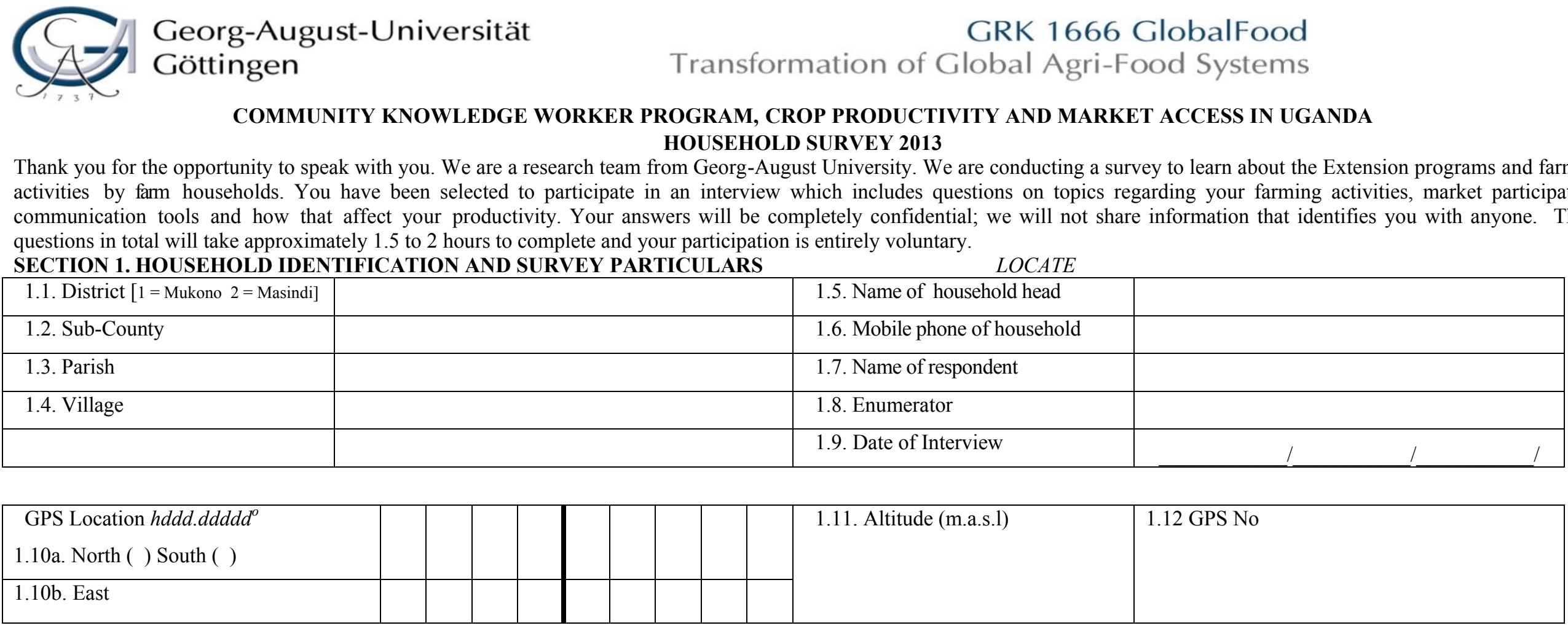

\begin{tabular}{|c|c|}
\hline 1.13. Sampling & $1=$ CKW participant $2=$ Control \\
\hline 1.14. Major religion of household & 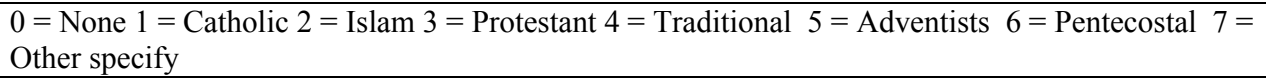 \\
\hline 1.15. Major ethnicity of household & $\begin{array}{l}1=\text { Baganda } 2=\text { Bamasaba/Bagisu } 3=\text { Busoga } 4=\text { Kalenjin } 5=\text { Iteso } 6=\text { Banyoro } 7=\text { Bagungu } \\
8=\text { Other specify }\end{array}$ \\
\hline \multicolumn{2}{|c|}{ 1.16. Year household started farming in this village (as an independent household) } \\
\hline \multicolumn{2}{|c|}{ 1.17. What type of household is this? $\quad 1=$ Male headed $2=$ Female headed } \\
\hline
\end{tabular}

Reference Period: Unless specified, we refer to the last 12months roughly as the period from October 2012 to the end of October 2013 


\section{SECTION 2. HOUSEHOLD DEMOGRAPHICS}

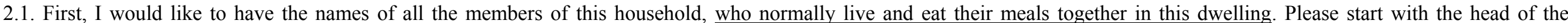

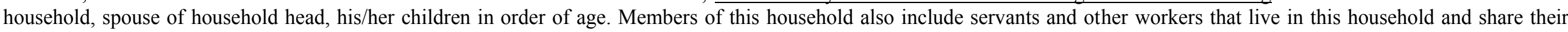
meals with the other household members. Tenants who live there and pay a rent are not considered to be members of the household. $D E M O$

\begin{tabular}{|c|c|c|c|c|c|c|c|c|c|c|c|c|c|}
\hline \multicolumn{2}{|c|}{ Name } & Age & \begin{tabular}{|l|} 
Is $[\ldots]$ \\
male \\
or \\
female \\
$1=$ Male \\
$2=$ Female \\
\end{tabular} & \begin{tabular}{|l|} 
What is $[\ldots]$ \\
relationship to \\
the household \\
head \\
$1=$ Head \\
$2=$ Spouse of head \\
$3=$ Son/daughter \\
$4=$ Son/daughter- \\
in-law \\
$5=$ Father/mother \\
$6=$ Sister/brother \\
$7=$ Niece/nephew \\
$8=$ Grandchild \\
$9=$ Servant/worker \\
$10=$ Other specify \\
\end{tabular} & \begin{tabular}{|l|} 
OOnly \\
persons \\
Aged $>10]$ \\
What is the \\
current \\
marital \\
status of \\
{$[\ldots .]$.} \\
$1=$ Single \\
2 \\
= Monogamous \\
$3=$ Polygamous \\
$4=$ Widowed \\
$5=$ Divorced/ \\
separated \\
$6=$ Other \\
specify \\
\end{tabular} & $\begin{array}{l}\text { Months } \\
{[\ldots]} \\
\text { lived at } \\
\text { home } \\
\text { in last } \\
12 \\
\text { months } \\
\\
\end{array}$ & \begin{tabular}{|l|} 
If residency \\
is less that \\
12 months \\
WHY? \\
$1=$ Staying \\
outside \\
village \\
2=Staying in \\
town \\
$3=$ Staying \\
outside \\
Uganda \\
$4=$ Abroad \\
$5=$ School \\
$6=$ Other \\
specify
\end{tabular} & \begin{tabular}{|l} 
[Only \\
persons \\
aged \\
$>$ 6] \\
Can $[\ldots]$ \\
read \\
and/or \\
write \\
$0=$ No \\
$1=$ Read \\
$2=$ Write \\
$3=$ Both \\
\end{tabular} & \begin{tabular}{|l|} 
How \\
many \\
years of \\
schooling \\
did $[\ldots]$ \\
have \\
\\
\end{tabular} & $\begin{array}{l}\text { What is the highest } \\
\text { Educational } \\
\text { qualification that } \\
{[\ldots] \text { has acquired }} \\
0=\text { Never attended school } \\
1=\text { Some primary } \\
2=\text { Primary } 1 \\
3=\text { Primary } 2 \\
4=\text { Primary } 3 \\
5=\text { Primary } 4 \\
6=\text { Primary } 5 \\
7=\text { Primary } 6 \\
8=\text { Primary } 7 / \text { Junior } 1 \\
9=\text { Secondary } 1 \text {, O-Level } 1 \text {, } \\
\text { Junior } 2 \\
\text { Codes continued } \\
\text { below }\end{array}$ & $\begin{array}{l}\text { Contribute } \\
\text { to farm } \\
\text { work } \\
1=\text { Yes } \\
2=\text { No }\end{array}$ & $\begin{array}{l}\text { Main } \\
\text { occupation } \\
0= \\
\text { Unemployed } \\
1=\text { Farmer } \\
2=\text { Wage } \\
\text { earner } \\
3=\text { Self } \\
\text { employed } \\
4=\text { Salaried } \\
\text { worker } \\
5=\text { Pensioned } \\
6=\text { Student } \\
7=\text { Boda } \\
\text { Boda } \\
8=\text { Others } \\
\text { specify }\end{array}$ & $\begin{array}{l}\text { Minor } \\
\text { occupation } \\
0= \\
\text { Unemployed } \\
1=\text { Farmer } \\
2=\text { Wage } \\
\text { earner } \\
3=\text { Self } \\
\text { employed } \\
4=\text { Salaried } \\
\text { worker } \\
5=\text { Pensioned } \\
6=\text { Student } \\
7=\text { Boda } \\
\text { Boda } \\
8=\text { Others } \\
\text { specify }\end{array}$ \\
\hline MID & NAME & AGE & SEX & RELAT & \begin{tabular}{|l|} 
MARY \\
\end{tabular} & LIVE & AWAY & LITE & SKUL & EDUC & FWOK & OCUP1 & OCUP2 \\
\hline 1 & & & & $1=$ Head & & & & & & & & & \\
\hline 2 & & & & & & & & & & & & & \\
\hline 3 & & & & & & & & & & & & & \\
\hline 4 & & & & & & & & & & & & & \\
\hline 5 & & & & & & & & & & & & & \\
\hline 6 & & & & & & & & & & & & & \\
\hline 7 & & & & & & & & & & & & & \\
\hline 8 & & & & & & & & & & & & & \\
\hline 9 & & & & & & & & & & & & & \\
\hline 10 & & & & & & & & & & & & & \\
\hline 11 & & & & & & & & & & & & & \\
\hline
\end{tabular}

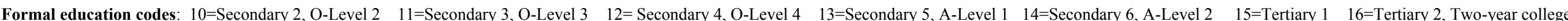

completed $17=$ Tertiary $3 \quad 18=$ Tertiary 4 , Four-year college completed $19=$ Tertiary $5 \quad 20=$ Post-graduate and above 


\section{SECTION 3. LAND HOLDINGS, TENURE AND CONSERVATION}

3.1. What is the total amount of land that the household currently own? a) Size

3.2. What is the total amount of land that the household owned 5 years ago? a) Size

3.3. What is the total area currently cultivated by the household? a) Size b) Unit

b) Unit b) Unit
$1=$ acres, $2=$ ha, $3=\mathrm{m} 2,4=$ feet 2

$1=$ acres, $2=$ ha, $3=\mathrm{m} 2,4=$ feet 2

3.4. What is the total area currently used for pastures by the household? a) Size b) Unit $1=$ acres, $2=$ ha, $3=\mathrm{m} 2,4=$ feet 2

3.5. Ask the characteristics of the plots owned or used by the household and conservation measures used. TEN $\overline{R E E}$

\begin{tabular}{|c|c|c|c|c|c|c|c|c|c|c|c|c|c|c|c|}
\hline \multirow{2}{*}{$\begin{array}{l}\text { Parcel } \\
\text { ID }\end{array}$} & \multirow{2}{*}{\begin{tabular}{|l} 
Parcel \\
Name \\
Complete \\
this \\
Column for \\
all parcels \\
Then ask \\
rows for \\
each parcel \\
before going \\
to the next \\
parcel.
\end{tabular}} & \multicolumn{2}{|c|}{$\begin{array}{l}\text { Size of this } \\
\text { parcel }\end{array}$} & \multirow{2}{*}{$\begin{array}{l}\text { Tenure } \\
\text { system } \\
\text { 1=Freehold } \\
2=\text { Leasehold } \\
3=\text { Mailo } \\
4=\text { Customary } \\
5=\text { Other } \\
\text { (specify) }\end{array}$} & \multirow{2}{*}{$\begin{array}{l}\text { Tenancy } \\
1=\text { Owner } \\
2=\text { Occupant } \\
3=\text { Tenant } \\
\text { (who actually } \\
\text { pays rents in } \\
\text { cash or in- } \\
\text { kind) } \\
4=\text { Other } \\
\text { specify }\end{array}$} & \multirow{2}{*}{\begin{tabular}{|l} 
In which \\
year did \\
you first \\
acquire \\
this \\
parcel \\
e.g., \\
1990
\end{tabular}} & \multirow{2}{*}{\begin{tabular}{|l|} 
How did you \\
acquire this \\
parcel \\
$1=$ Purchased \\
$2=$ Gift or \\
inheritance \\
$3=$ Rented-in \\
for fixed \\
payments \\
$4=$ \\
Sharecropped- \\
in \\
$5=$ Borrowed- \\
in \\
$6=$ Just walked \\
in \\
$7=$ Other \\
(snecifv) \\
\end{tabular}} & \multirow{2}{*}{$\begin{array}{l}\text { If rented- } \\
\text { in (PACQ } \\
=3 \text { ), how } \\
\text { much did } \\
\text { you pay } \\
\text { now } \\
\text { (Ush) }\end{array}$} & \multirow{2}{*}{$\begin{array}{l}\text { If share- } \\
\text { cropped-in } \\
(\mathrm{PACQ}=4), \\
\text { what } \\
\text { proportion of } \\
\text { produce did } \\
\text { you pay now }\end{array}$} & \multirow{2}{*}{$\begin{array}{l}\text { Do you } \\
\text { have a } \\
\text { formal } \\
\text { title: } \\
\text { certificate } \\
\text { of } \\
\text { occupant } \\
1=\text { Yes } \\
2=\text { No }\end{array}$} & \multirow{2}{*}{\begin{tabular}{|l|} 
Main \\
water \\
source \\
1=Irrigated \\
2=Rain-fed \\
3=Swamp
\end{tabular}} & \multirow{2}{*}{$\begin{array}{l}\text { Walking } \\
\text { time on } \\
\text { foot from } \\
\text { home-stead } \\
\text { (minutes) }\end{array}$} & \multirow{2}{*}{$\begin{array}{l}\text { Major } \\
\text { soil type } \\
\text { 1= Sandy } \\
2=\text { Sandy/ } \\
\text { loam } \\
3= \\
\text { Loamy/ } \\
\text { silt } \\
\text { 4=Clayey } \\
\text { 5=Other } \\
\text { (specify) }\end{array}$} & \multirow{2}{*}{\begin{tabular}{|l|} 
Any \\
conservation \\
measures on \\
plot \\
$1=$ Yes \\
$2=\mathrm{No}$
\end{tabular}} & \multirow{2}{*}{\begin{tabular}{|l} 
Conservation \\
type on plot \\
$1=$ Stone \\
bund/line \\
$2=$ Soil bund \\
$3=$ Grass strip \\
$4=$ Agro- \\
forestry \\
$5=$ Cover \\
crops \\
$6=$ Terrace \\
$7=$ Mulch \\
$8=$ Other \\
(specify)
\end{tabular}} \\
\hline & & Quantity & $\begin{array}{l}\text { Units } \\
1=\text { acres } \\
2=\text { ha } \\
3=\mathrm{m} 2\end{array}$ & & & & & & & & & & & & \\
\hline PID & PNAM & PSIZ & PUNI & TENU & TENA & PYR & PACQ & PRET & PSHR & PCET & PIRR & PTIM & SOIL & CONS & CONT \\
\hline 1 & & & & & & & & & & & & & & & \\
\hline 2 & & & & & & & & & & & & & & & \\
\hline 3 & & & & & & & & & & & & & & & \\
\hline 4 & & & & & & & & & & & & & & & \\
\hline 5 & & & & & & & & & & & & & & & \\
\hline 6 & & & & & & & & & & & & & & & \\
\hline 7 & & & & & & & & & & & & & & & \\
\hline 8 & & & & & & & & & & & & & & & \\
\hline 9 & & & & & & & & & & & & & & & \\
\hline
\end{tabular}


SECTION 4. CROP PLANTING AND MANAGEMENT. Capture all crops, fruit trees and vegetables grown in each growing season separately. Perennials repeat unless destroyed

4.1. Fill in columns for season, parcel ID and crops planted first. Make sure that the Parcel IDs are matched with Sections 3. Thereafter complete each row for crop management

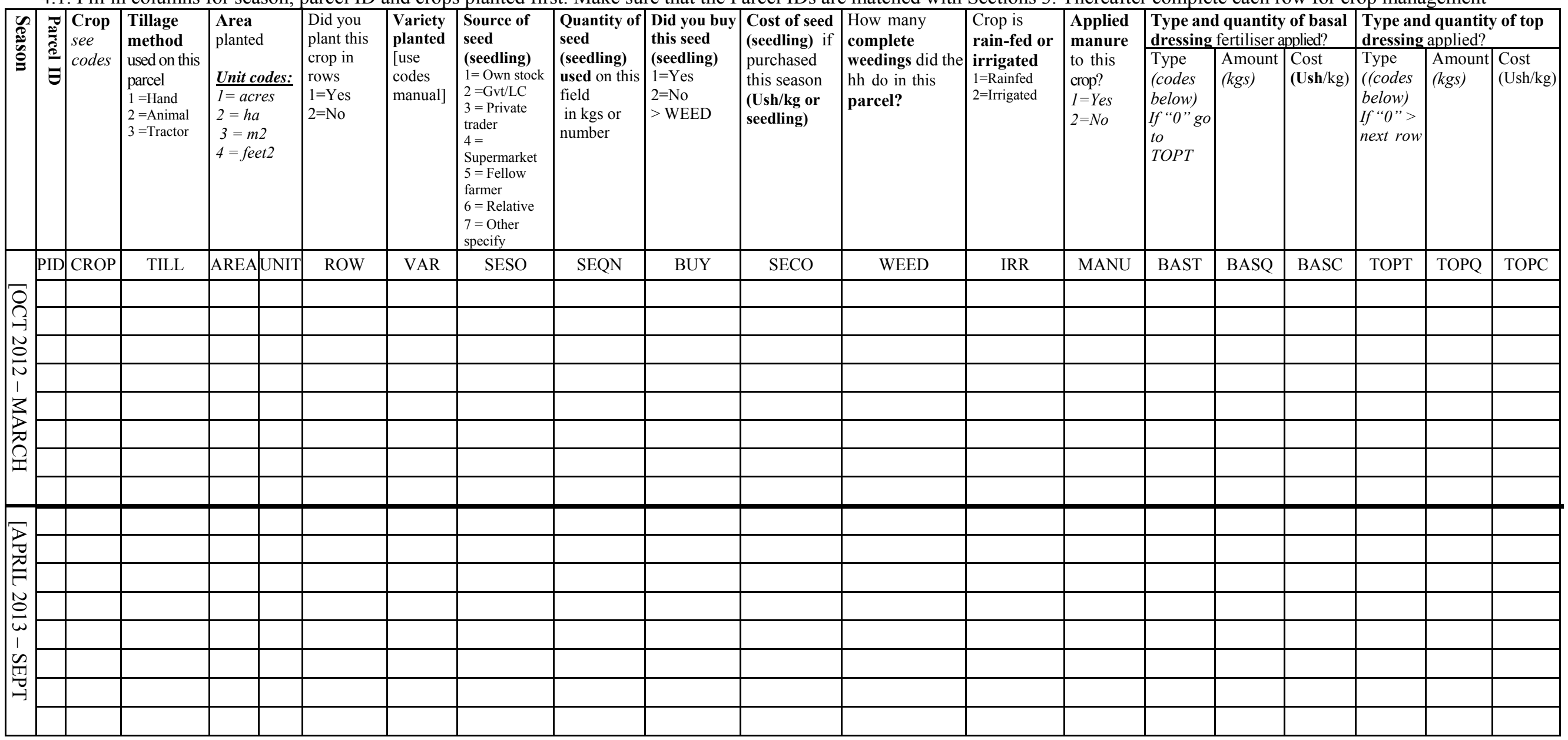

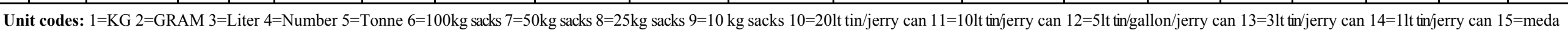

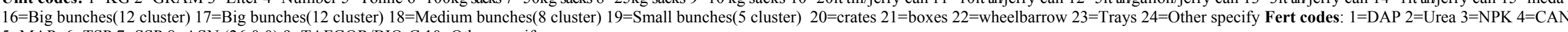
5=MAP $6=$ TSP $7=$ SSP $8=$ ASN (26:0:0) 9=TAFGOR/BIO-C 10=Other specify 


\section{SECTION 5. CROP PRODUCTION COSTS AND HARVEST. Capture all crops, fruit trees and vegetables grown in each growing season separately. Perennials repeat unless} destroyed

5.1. Fill in columns for season, parcel id and crops planted first. Make sure that the Parcel IDs are matched with Sections 3 and $4 \&$ crop with Section 4 .

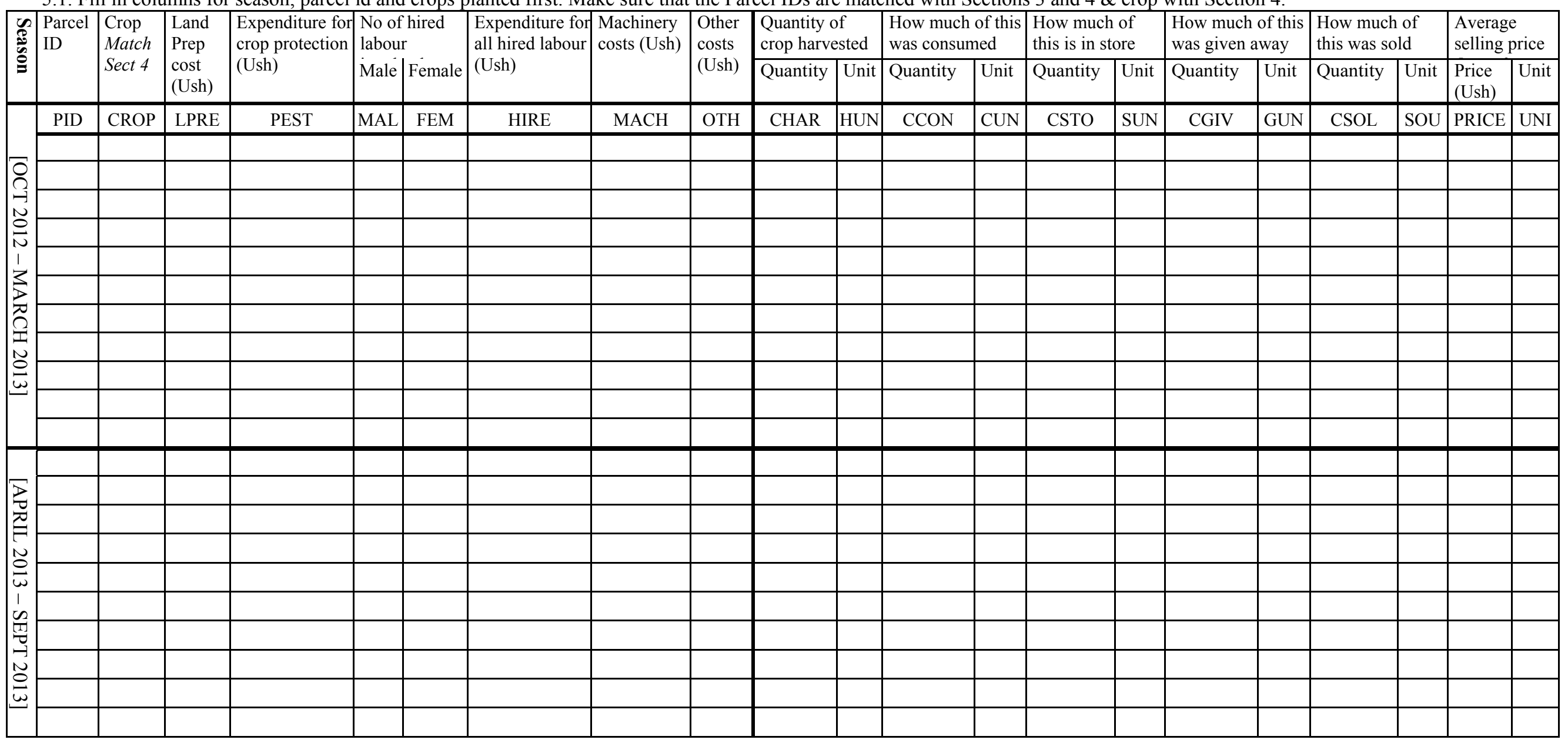

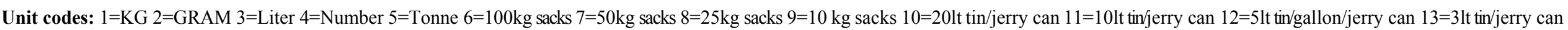
$14=1$ t tinjerry can $15=$ meda $16=$ Big bunches $(12$ cluster $) 17=$ Big bunches $(12$ cluster $) 18=$ Medium bunches $(8$ cluster) $19=$ Small bunches $(5$ cluster $) 20=$ crates $21=$ boxes $22=$ wheelbarrow $23=$ Trays 24=Other specify 
SECTION 6. CROP MARKETING - [This applies for all crops sold in Section 5] [Match Parcel ID and crop codes from Section 5] CSELL

\begin{tabular}{|c|c|c|c|c|c|c|c|c|c|c|c|c|c|}
\hline \multirow[t]{2}{*}{ 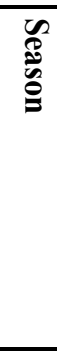 } & \multirow[t]{2}{*}{\begin{tabular}{|l|} 
Parcel \\
ID
\end{tabular}} & \multirow{2}{*}{$\begin{array}{l}\text { Crop } \\
\text { Match } \\
\text { with } \\
\text { SECT } 4 \\
\text { and } 5\end{array}$} & \multirow{2}{*}{\begin{tabular}{|l|} 
Who \\
primarily \\
decided to sell \\
this crop \\
$1=$ H-head \\
$2=$ Spouse \\
$3=$ Head \& \\
spouse \\
$4=$ Children \\
$5=$ Other specify \\
\end{tabular}} & \multirow{2}{*}{$\begin{array}{l}\text { Gender of } \\
\text { member } \\
\text { who made } \\
\text { sales } \\
\text { decision } \\
1=\text { Male } \\
2=\text { Female } \\
3=\text { Both }\end{array}$} & \multirow{2}{*}{$\begin{array}{l}\text { Where did } \\
\text { hhold sell } \\
\text { 1=Farm } \\
2=\text { Local market } \\
3=\text { Major market } \\
4=\text { Other area } \\
\text { (specify) }\end{array}$} & \multirow{2}{*}{$\begin{array}{l}\text { In which of } \\
\text { the following } \\
\text { markets were } \\
\text { the prices } \\
\text { known? }(\geq 1) \\
\text { 1=Farm gate } \\
\text { 2=Local market } \\
\text { 3=Major } \\
\text { Market } \\
\text { 4=None } \\
\end{array}$} & \multirow{2}{*}{$\begin{array}{l}\text { To whom did household } \\
\text { sell this crop } \\
1=\text { Trader } \\
2=\text { Retail shop } \\
3=\text { Individual consumer } \\
4=\text { Cooperative /association } \\
5=\text { Institution (e.g. school) } \\
6=\text { Supermarket } \\
7=\text { Company } \\
8=\text { Others specify }\end{array}$} & \multirow{2}{*}{$\begin{array}{l}\text { Was } \\
\text { buyer } \\
\text { known } \\
\text { ahead } \\
1=\text { Yes } \\
2=\text { No }\end{array}$} & \multirow{2}{*}{$\begin{array}{l}\text { Was price at } \\
\text { the outlet } \\
{[. .] \text { known }} \\
\text { ahead } \\
1=\text { Yes } \\
2=\text { No }\end{array}$} & \multirow{2}{*}{$\begin{array}{l}\text { Did you or } \\
\text { hhold } \\
\text { bargain for } \\
\text { the price at } \\
\text { outlet } \\
{[. .]} \\
1=\text { Yes } \\
2=\text { No }\end{array}$} & \multicolumn{2}{|c|}{$\begin{array}{l}\text { How far was the point } \\
\text { of sale from the hhold } \\
\text { Enter } 0 \text { if at farm gate }\end{array}$} & \multirow[t]{2}{*}{$\begin{array}{l}\text { Transport costs and } \\
\text { other costs for the } \\
\text { sale (USh) }\end{array}$} \\
\hline & & & & & & & & & & & Distance & $\begin{array}{l}\text { Unit } \\
1=\text { Km } \\
2=\text { Mile } \\
3=\mathrm{m}\end{array}$ & \\
\hline \multirow{11}{*}{ 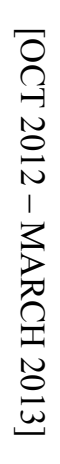 } & PID & CROP & $\mathrm{DEC}$ & SEX & PWE & QUA & CHA & BKA & PKA & PB & DIS & UNI & PTC \\
\hline & & & & & & & & & & & & & \\
\hline & & & & & & & & & & & & & \\
\hline & & & & & & & & & & & & & \\
\hline & & & & & & & & & & & & & \\
\hline & & & & & & & & & & & & & \\
\hline & & & & & & & & & & & & & \\
\hline & & & & & & & & & & & & & \\
\hline & & & & & & & & & & & & & \\
\hline & & & & & & & & & & & & & \\
\hline & & & & & & & & & & & & & \\
\hline & & & & & & & & & & & & & \\
\hline \multicolumn{14}{|l|}{$B$} \\
\hline 2 & & & & & & & & & & & & & \\
\hline N & & & & & & & & & & & & & \\
\hline \multicolumn{14}{|l|}{ 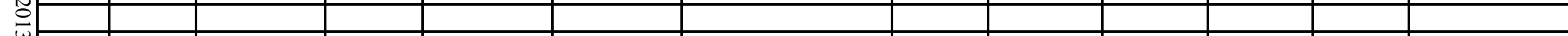 } \\
\hline $\begin{array}{l}\omega \\
1\end{array}$ & & & & & & & & & & & & & \\
\hline \multicolumn{14}{|l|}{$\frac{\pi}{\pi}$} \\
\hline \multirow{2}{*}{\multicolumn{14}{|c|}{$\begin{array}{l}\mathcal{G} \\
\text { N }\end{array}$}} \\
\hline & & & & & & & & & & & & & \\
\hline$\underline{\omega}$ & & & & & & & & & & & & & \\
\hline & & & & & & & & & & & & & \\
\hline
\end{tabular}

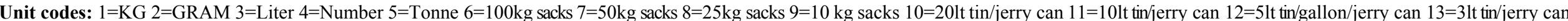
$14=11$ t tinjerry can $15=$ meda $16=$ Big bunches $(12$ cluster) $17=$ Big bunches $(12$ cluster $) 18=$ Medium bunches $(8$ cluster $) 19=$ Small bunches $(5$ cluster $) 20=$ crates $21=$ boxes $22=$ wheelbarrow $23=$ Trays

24=Other specify 


\section{SECTION 7a: MOBILE PHONE OWNERSHIP AND USAGE}

7.1. Did anyone in this household own a mobile phone in the past 12 months? $M O B O$ $1=$ Yes $2=$ No $>7.4$

7.2. How many mobile phones does this household have? $M O B$ :

7.3. Please fill in the table if household owns mobile phone. [If more than one - capture ownership details of up to three mobile phones actively used by household] MOBILE

\begin{tabular}{|c|c|c|c|c|c|c|c|c|c|}
\hline & $\begin{array}{l}\text { Who owns the } \\
\text { mobile phone } \\
1=\text { Head } \\
2=\text { Spouse } \\
3=\text { Head \& spouse } \\
4=\text { Children } \\
5=\text { Other member } \\
6=\text { Other specify }\end{array}$ & $\begin{array}{l}\text { Gender } \\
\text { of } \\
\text { mobile } \\
\text { phone } \\
\text { owner } \\
1=\text { Male } \\
2=\text { Female }\end{array}$ & $\begin{array}{l}\text { Year started } \\
\text { using this } \\
\text { mobile phone }\end{array}$ & \multicolumn{5}{|c|}{$\begin{array}{l}\text { Does the household use mobile phone to }[\ldots] ? \text { ? [Max } 5 \text { in order of importance] } \\
1=\text { Staying in contact with family and friends } \\
2=\text { To gather information about farm produce prices } \\
3=\text { To locate buyers of farm products } \\
4=\text { To get extension information from provider } \\
5=\text { To get weather information } \\
6=\text { To assist in running your own non-farm business } \\
7=\text { To send and/or receive money } 8=\text { None } 9=\text { News } 10=\text { Other specify }\end{array}$} & $\begin{array}{l}\text { How often does this household } \\
\text { use mobile phone for } \\
\text { agriculture related business per } \\
\text { month } \\
1=\text { Once, } 2 \text { = Twice } \\
3=\text { Thrice , } 4 \text { = Four times } \\
5=\text { Others specify }\end{array}$ \\
\hline & CEO & SEX & MYR & USE1 & USE2 & USE3 & USE4 & USE5 & MTI \\
\hline$M O B 1$ & & & & 1 & & & & & \\
\hline \multicolumn{4}{|l|}{$M O B 2$} & & & & & & \\
\hline$M O B 3$ & & & & & & & & & \\
\hline
\end{tabular}

7.4. How many network bars does your mobile phone display at your homestead? NET

$0,1,2,3$, or 4 (0 means there is no network coverage)

\section{SECTION 7b: MOBILE MONEY SERVICES}

7.5. Does anyone in this household use mobile money services? MMS

$$
1=\text { Yes } 2=\text { No }
$$

7.6. Does anyone in this household own a mobile money account (registered with mobile money)? MM $1=$ Yes $2=$ No $>8$

7.7. Which mobile money account does hhold own? MMA 1= MTN Mobile Money $2=$ Airtel Money $3=$ Warid Pesa $4=$ M-Sent (Uganda Telcom) $5=$ Orange Money $6=$ Other specify. NOTE: If more than one account, obtain answers for the mostly actively used account

7.8. In which year was this account opened? WAC

7.9. Gender of household member who own this mobile money account? GM $1=$ Male $2=$ Female

7.10. How many times did anyone in this household receive money via the mobile money during the last 12 months? MREC

$1=$ Once $2=$ Twice $3=$ Thrice $4=$ Four times $5=$ Five and above

7.11. On average how much did this household receive for each transaction via mobile money? $R E C$

7.12. How many times did anyone in this household send money or make payment via the mobile money during the last 12 months? MSEN

$1=$ Once $2=$ Twice $3=$ Thrice $4=$ Four times $5=$ Five and above 
7.14. Which activities did this household perform with mobile money? $A C 1$ $A C 2$ $A C 3$ $A C 4$ $A C 5$

relatives and friends $4=$ Transfer money to business partners $5=$ Transfer money to own bank account $6=$ Pay bills $7=$ Pay school fees $8=$ Buy airtime $9=$ Other specify

\section{SECTION 8: COMMUNITY KNOWLEDGE WORKER PROGRAM}

Name of $C K W$ for the parish

8.1. Did anyone in this household receive extension or market advice/information from CKW [mention name] in the past 12 months? HCKW $1=$ Yes $2=$ No

8.2. How did this household first learn about the CKW program? $L C K W$ $1=\mathrm{CKW} 2=$ Relative/Friends/Neighbour $3=$ Extension agent $4=$ Other specify

8.3. When did this household start accessing information from the CKW (Year). $Y C K W$

8.4. Fill in this table on the details of CKW program

$C K W$

\begin{tabular}{|c|c|c|c|c|c|c|c|c|c|c|c|c|c|c|}
\hline \multirow{2}{*}{\multicolumn{5}{|c|}{$\begin{array}{l}\text { What are the common types of } \\
\text { information that this hhd requested/ } \\
\text { received from CKW? } \\
\text { [Max 5] } \\
1 \text { = Agric prices } \\
2=\text { Marketing } \\
3=\text { Crop production } \\
4=\text { Livestock production } \\
5=\text { Agro-processing } \\
6=\text { Credit and finance } \\
7=\text { Weather } 8=\text { Farm inputs } 9=\text { Others } \\
\text { Specify }\end{array}$}} & \multirow{3}{*}{\begin{tabular}{l}
...from the type \\
of information \\
identified in \\
previous \\
column. \\
Which type of \\
information did \\
hhold \\
frequently \\
requested/ \\
received from \\
CKW \\
\multicolumn{1}{|c|}{ MAD } \\
\end{tabular}} & \multirow{3}{*}{$\begin{array}{l}\text { Which hhold } \\
\text { member } \\
\text { commonly } \\
\text { receive } \\
\text { information } \\
\text { from CKW } \\
1=\text { H-head } \\
2=\text { Spouse } \\
3=\text { Head \& } \\
\text { spouse } \\
4=\text { Children } \\
5=\text { Other } \\
\text { specify }\end{array}$} & \multirow{3}{*}{$\begin{array}{l}\text { Gender of } \\
\text { household } \\
\text { member who } \\
\text { commonly } \\
\text { receive } \\
\text { information } \\
\text { from CKW } \\
1=\text { Male } \\
2=\text { Female } \\
3=\text { Both } \\
\\
\\
\text { SEX }\end{array}$} & \multirow{3}{*}{$\begin{array}{l}\begin{array}{l}\text { On average how } \\
\text { many times did } \\
\text { the household } \\
\text { receive } \\
\text { information from } \\
\text { CKW in the last } \\
12 \text { months } \\
\text { TOTAL OF ALL } \\
\text { (CKW visiting } \\
\text { farm, member } \\
\text { visiting CKW, send } \\
\text { person, phone } \\
\text { calls etc) }\end{array} \\
\\
\text { FRQ }\end{array}$} & \multirow{3}{*}{\begin{tabular}{l} 
Common \\
channel hhold \\
access \\
information \\
from CKW \\
$1=$ CKW visit \\
farm \\
$2=$ Hhold visit \\
CKW \\
$3=$ Both $1 \& 2$ \\
$4=$ Sent person \\
$5=$ Phone call \\
$6=$ Other \\
specify \\
\multicolumn{2}{|c}{ CKFOM }
\end{tabular}} & \multirow{3}{*}{$\begin{array}{l}\text { Have this } \\
\text { household put } \\
\text { into practice } \\
\text { information } \\
\text { received from } \\
\text { CKW in the past } \\
12 \text { months } \\
1=\text { Yes } \\
2=\text { No } \\
\\
\text { CKUS }\end{array}$} & \multirow{2}{*}{$\begin{array}{l}\text { Rate the } \\
\text { usefulness of } \\
\text { the } \\
\text { information } \\
\text { received from } \\
\text { CKW* } \\
1=\text { Not very } \\
\text { useful } \\
2=\text { Somewhat } \\
\text { useful } \\
3=\text { Useful } \\
4=\text { Very useful }\end{array}$} & \multicolumn{3}{|c|}{$\begin{array}{l}\text { Distance to nearest } \\
\text { CKW }\end{array}$} \\
\hline & & & & & & & & & & & & Qnty & 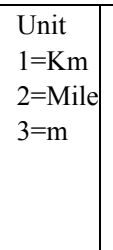 & $\begin{array}{l}\text { Walking } \\
\text { minutes }\end{array}$ \\
\hline ADV1 & ADV2 & ADV3 & ADV4 & ADV5 & & & & & & & RAT1 & DIS & DUN & MIN \\
\hline
\end{tabular}

8.5. What are the two major advantages the household get by accessing information through the CKW program? ADV1. ADV2. $1=$ Use local language $2=$ timely

information $3=$ advice for free $4=\mathrm{CKW}$ visit farm $5=$ Other specify 
8.6. Apart from disseminating agricultural information to farmers, what other services do you wish the CKW should provide to you and the community? SEV1 SEV2.

Stock and sell agro-inputs $2=$ Stock and sell vets and medicine $3=$ Mobile money agent $4=$ Vet farmers for loan applications $5=$ Other specify

\section{SECTION 9: EXTENSION SERVICES}

9.1. Did anyone in this household receive extension advice from any source [EXCEPT CKW] in the past 12 months? EXTE

$1=\mathrm{YES} 2=\mathrm{NO}>9.3$

9.2. Fill in the table below on details of extension services

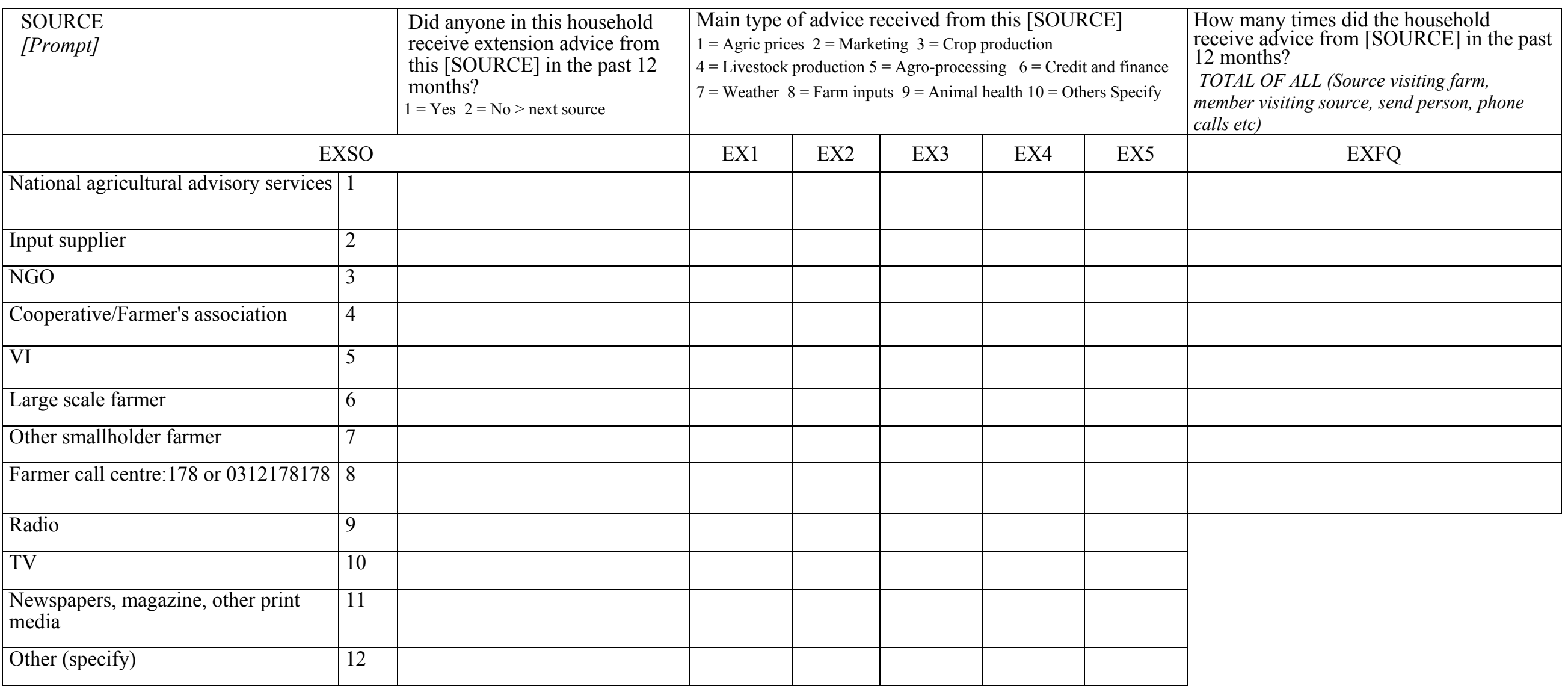


9.3. Did anyone in this household participated in the following group based extension activities in the past 3 years? GEXTEN

\begin{tabular}{|l|l|l|l|l|}
\hline Activity & $\begin{array}{l}\text { Participation } \\
1=\text { Yes 2 No }>\text { Next } \\
\text { activity }\end{array}$ & $\begin{array}{l}\text { How many times member (s) } \\
\text { participated in [..] TOTAL OF ALL }\end{array}$ & $\begin{array}{l}\text { The [..] was concerned with which farming issues } \\
1=\text { Maize 2= Rice 3=Beans 4= Potato 5=Other crops specify 6= Livestock 7=Conservation } \\
\text { techniques } \\
8=\text { Other specify }\end{array}$ \\
\hline GEA & STAT & GENO & TOP \\
\hline Demonstration/Trials & 1 & & & \\
\hline Field days/tours & 2 & & & \\
\hline Farmer Field Schools & 3 & & & \\
\hline
\end{tabular}

\section{SECTION 10: GROUP PARTICIPATION}

10.1. Fill in the table on household group participation

\section{GROUP}

\begin{tabular}{|c|c|c|c|c|c|c|c|c|c|}
\hline & & $\begin{array}{l}\text { Does any member of } \\
\text { household participate } \\
\text { in the following } \\
1=\text { Yes } 2=\text { No }\end{array}$ & Name of group & $\begin{array}{l}\text { Who in the household is } \\
\text { an active member } \\
1=\text { HH head } 2=\text { Spouse } 3=\text { Head } \\
\& \text { Spouse } 4=\text { Parents } 5=\text { Child } \\
6=\text { Other specify }\end{array}$ & $\begin{array}{l}\text { Gender } \\
\text { of } \\
\text { member } \\
1=\text { Male } \\
2=\text { Female } \\
3=\text { Both }\end{array}$ & $\begin{array}{l}\text { For how long } \\
\text { have they } \\
\text { been a } \\
\text { member } \\
\text { (years) }\end{array}$ & $\begin{array}{l}\text { Leadership role of } \\
\text { member in this } \\
\text { group (e.g. } \\
\text { chairman, secretary } \\
\text { etc) } \\
1=\text { Yes } 2=\text { No }\end{array}$ & \multicolumn{2}{|c|}{$\begin{array}{l}\text { What services do you get from this } \\
\text { group [List } 2 \text { major] } \\
0=\text { none } 1=\text { =xtension } \& \text { Training } 2=\text { Produce } \\
\text { marketing } 3=\text { =nput acquisition } 4=\text { =inancial e.g. } \\
\text { credit } 5=\text { =mergency support } 6=\text { =Savings } 7=\text { Other } \\
\text { specify }\end{array}$} \\
\hline \multicolumn{2}{|l|}{ GRUP } & GMEM & GNA & GWHO & SEX & GYR & GLR & GSV1 & GSV2 \\
\hline Farmer group & 1 & & & & & & & & \\
\hline Farmer's cooperative & 2 & & & & & & & & \\
\hline Women's group & 3 & & & & & & & & \\
\hline Credit and savings & 4 & & & & & & & & \\
\hline Health/Nutrition & 5 & & & & & & & & \\
\hline Other specify & 6 & & & & & & & & \\
\hline
\end{tabular}


SECTION 11: NETWORK ROSTER

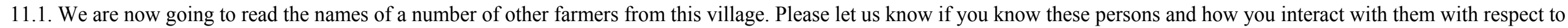
mobile financial services and agricultural production.

\begin{tabular}{|c|c|c|c|c|c|c|c|c|c|c|c|c|c|c|}
\hline & $\begin{array}{l}\text { Hhold } \\
\text { ID } \\
\text { number } \\
\text { (of other } \\
\text { hhd in } \\
\text { sample) }\end{array}$ & $\begin{array}{l}\text { Name of hhold } \\
\text { head } \\
\text { [link with } \\
\text { MID, Section } \\
2\end{array}$ & $\begin{array}{l}\text { Name of } \\
\text { respondent }\end{array}$ & $\begin{array}{l}\text { Do you } \\
\text { know } \\
\text { this } \\
\text { hhold } \\
1=\text { Yes } \\
2=\text { No } \\
>\text { next } \\
\text { row }\end{array}$ & $\begin{array}{l}\text { Since } \\
\text { when } \\
\text { have } \\
\text { you } \\
\text { known } \\
\text { this } \\
\text { hhold } \\
\text { (Year) }\end{array}$ & $\begin{array}{l}\text { What is } \\
\text { your } \\
\text { relationship } \\
\text { with this } \\
\text { hhold } \\
\text { (Codes A } \\
\text { next page) }\end{array}$ & $\begin{array}{l}\text { How often do } \\
\text { you or others in } \\
\text { your hhold talk } \\
\text { to members of } \\
\text { this hhold } \\
1=\text { Everyday } \\
2=\text { At least once a } \\
\text { week } \\
3=\text { At least once a } \\
\text { month } \\
4=\text { Less than once } \\
\text { a month }\end{array}$ & $\begin{array}{l}\text { Do you } \\
\text { belong } \\
\text { to the } \\
\text { same } \\
\text { group } \\
\text { (farmer, } \\
\text { religious } \\
\text { etc) } \\
\text { with this } \\
\text { hhold } \\
1=\text { Yes } \\
2=\text { No }\end{array}$ & $\begin{array}{l}\text { Do you or } \\
\text { others in } \\
\text { your } \\
\text { hhold talk } \\
\text { about the } \\
\text { mobile } \\
\frac{\text { money }}{\text { services }} \\
\text { with any } \\
\text { member } \\
\text { of this } \\
\text { hhold } \\
1=\text { Yes } 2= \\
\text { No }\end{array}$ & $\begin{array}{l}\text { Is this } \\
\text { farmer } \\
\text { registered } \\
\text { with } \\
\underline{\underline{\text { mobile }}} \\
\underline{\underline{\text { money }}} \\
1=\text { Yes } \\
2=\text { No }> \\
\text { RSE }\end{array}$ & $\begin{array}{l}\text { Which } \\
\text { mobile } \\
\text { money } \\
\text { provider does } \\
\text { this hhold use } \\
\text { 1= MTN } \\
\text { Mobile Money } \\
2=\text { Airtel } \\
\text { Money } \\
3=\text { Warid Pesa } \\
4=\text { M-Sent } \\
\text { (Uganda } \\
\text { Telcom) } \\
5=\text { Orange } \\
\text { Money } \\
6=\text { Other } \\
\text { specify }\end{array}$ & $\begin{array}{l}\text { Have you or } \\
\text { others in your } \\
\text { hhold } \\
\text { received } \\
\text { (send) } \\
\text { money via } \\
\text { the mobile } \\
\text { money from } \\
\text { (to) any } \\
\text { member of } \\
\text { this hhold in } \\
\text { past } 12 \\
\text { months } \\
1=\text { Yes } \\
2=\text { No }>\text { CRO }\end{array}$ & $\begin{array}{l}\text { How many } \\
\text { times } \\
\text { during the } \\
\text { last } 12 \\
\text { months } \\
1=\text { Once } \\
2=\text { Twice } \\
3=\text { Thrice } \\
4=\text { Four } \\
\text { times } \\
5=\text { Five and } \\
\text { above }\end{array}$ & 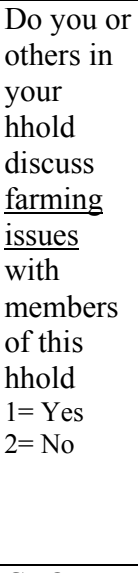 \\
\hline & & HHNME & GEN & VILL & YR & RELAT & TOK & AFFIL & MM & MA & MTY & RSE & TIM & CRO \\
\hline 1 & & & & & & & & & & & & & & \\
\hline 2 & & & & & & & & & & & & & & \\
\hline 3 & & & & & & & & & & & & & & \\
\hline 4 & & & & & & & & & & & & & & \\
\hline 5 & & & & & & & & & & & & & & \\
\hline
\end{tabular}

Codes A (Relationship) 1=Parent; 2=Child; 3=Brother/sister; $4=$ Grandparent; $5=$ Grandchild; $6=$ Nephew/Niece; $7=$ Uncle/aunt; 8=Cousin; 9=Same family lineage; 10=Mother/father in-law;

$11=$ Brother/sister in-law; 12=Other relative; 13=Fellow villager/Neighbor; 14=Attend same church/ mosque; 15=Professional/business colleague; 16=Other, specify

The following 2 questions refer to farmers other than those listed in table above

11.2. Do you know any other farmers in your village who are registered with Mobile Money? NMM $1=$ Yes $2=\mathrm{No}>12$

11.3. If yes how many? NSIZE 


\section{SECTION 12a CREDIT}

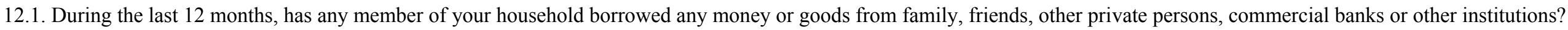
[CONSIDER ALSO VERY SMALL CREDITS] HCRE $1=$ Yes $2=$ No $>12.2$.

CRED

\begin{tabular}{|c|c|c|c|c|c|c|c|c|}
\hline $\begin{array}{l}\text { Which hh } \\
\text { member } \\
\text { received } \\
\text { the loan or } \\
\text { borrowed } \\
\text { money } \\
\text { [MATCH } \\
\text { MID } \\
\text { FROM } \\
\text { SECTION } \\
\text { 2] }\end{array}$ & $\begin{array}{l}\text { Source of credit/loan obtained } \\
1=\text { Relative } 2=\text { Friend } 3=\text { Employer } \\
4=\text { Landlord } 5=\text { Government agency } \\
6=\text { Commercial } \\
7=\text { Microfinance } \\
8=\text { NGO } 9=\text { CBO } 10=\text { Self Help } \\
\text { Group } \\
11=\text { Private money lender } \\
12=\text { Shop keeper } \\
13=\text { Others specify }\end{array}$ & $\begin{array}{l}\text { Main reason for } \\
\text { borrowing this loan? } \\
\text { To purchase... } \\
1 \text { = Farm inputs } \\
2 \text { = Farm equipment } \\
3=\text { Animals } \\
4=\text { Agric. land } \\
5=\text { Food } \\
6=\text { Pay school fees } \\
7=\text { Health services } \\
8=\text { Construction } \\
9=\text { For non-agric. business } \\
10=\text { Other specify }\end{array}$ & $\begin{array}{l}\text { Was this } \\
\text { credit in } \\
\text { cash or in } \\
\text { kind } \\
1=\text { in cash } \\
2=\text { in kind }\end{array}$ & $\begin{array}{l}\text { What was the } \\
\text { value of the } \\
\text { loan } \\
\text { [ESTIMATE } \\
\text { VALUE IN } \\
\text { CASH OR } \\
\text { IN KIND] } \\
\text { Ush }\end{array}$ & $\begin{array}{l}\text { Would you } \\
\text { have wanted a } \\
\text { larger loan at } \\
\text { the same } \\
\text { interest or } \\
\text { conditions } \\
1=\text { Yes } \\
2=\text { No }>\text { COLLA }\end{array}$ & $\begin{array}{l}\text { In total how } \\
\text { much would } \\
\text { you have } \\
\text { wanted } \\
\text { (Ush) }\end{array}$ & $\begin{array}{l}\text { Why did you } \\
\text { not receive what } \\
\text { you wanted? } \\
1=\text { Lack of } \\
\text { collateral } \\
2 \text { = Project not } \\
\text { profitable enough } \\
3=\text { Lending policy } \\
\text { of institution } \\
4=\text { Other specify }\end{array}$ & $\begin{array}{l}\text { What kind of } \\
\text { collateral did you } \\
\text { provide to obtain this } \\
\text { loan } \\
1 \text { = Agricultural land } \\
2=\text { Housing, building } \\
3=\text { Other assets, specify } \\
4=\text { Personal guarantee } \\
5=\text { Group lending } \\
6=\text { Co-signer } \\
7=\text { Payslip } \\
8=\text { None } \\
9=\text { Others specify } \\
\end{array}$ \\
\hline MID & CRES & CRER & CRET & CREV & WISH & WAMT & WHY & COLLA \\
\hline & & & & & & & & \\
\hline & & & & & & & & \\
\hline & & & & & & & & \\
\hline & & & & & & & & \\
\hline & & & & & & & & \\
\hline
\end{tabular}

\section{SECTION 12b SAVINGS ACCOUNT}

12.2. Does any member of this household have a Savings Account? $S A$ $1=$ Yes $2=$ No $>13$

12.3. If yes, with which Bank(s)/ Microfinance institution? BANK1 BANK2

12.4. Is the bank account linked to your mobile phone? LINK $1=$ Yes $2=$ No 
SECTION 13: LIVESTOCK OWNERSHIP

\begin{tabular}{|l|c|l|l|l|l|l|}
\hline \multicolumn{2}{|c|}{ Livestock } & $\begin{array}{l}\text { Number currently } \\
\text { owned }\end{array}$ & $\begin{array}{l}\text { Estimate value if sold } \\
\text { (Ush) }\end{array}$ & $\begin{array}{l}\text { Number owned 5 } \\
\text { years ago }\end{array}$ & $\begin{array}{l}\text { Did you sell this [... in the last } \\
12 \text { months } \\
1=\text { Yes 2=No }>\text { next column }\end{array}$ & $\begin{array}{l}\text { If yes what was the total value } \\
\text { in (Ush) }\end{array}$ \\
\hline LRID & 1 & LRCU & LRVAL & LR5 & & LSEL \\
\hline Cows & 2 & & & & & \\
\hline Bulls & 3 & & & & & \\
\hline Heifer & 4 & & & & & \\
\hline Calves & 5 & & & & & \\
\hline Goat & 6 & & & & & \\
\hline Sheep & 7 & & & & & \\
\hline Chicken- Local & 8 & & & & & \\
\hline Chicken- Improved & 9 & & & & & \\
\hline Pigs & 10 & & & & & \\
\hline Donkeys & 11 & & & & & \\
\hline Ducks & 12 & & & & \\
\hline Other specify & & & & \\
\hline
\end{tabular}

\section{SECTION 14: LIVESTOCK EXPENDITURE}

14.1. In the last 12 months, have you had any of the following expenditures related to livestock? LEXP

\begin{tabular}{|c|c|c|c|}
\hline Type of Expenditure & & Did you spend on any $[\ldots . .] 1=$. Yes $2=$ No $>$ Next type & Cash value (Ush) (if in kind, give estimated cash value) \\
\hline LRTY & & LEXP & LEXV \\
\hline Hired labour for herding & 1 & & \\
\hline Livestock/poultry feed & 2 & & \\
\hline Veterinary services/medicine & 3 & & \\
\hline Other expenses (Specify) & 4 & & \\
\hline
\end{tabular}




\section{SECTION 15: LIVESTOCK PRODUCTS AND INCOME}

15.1. Did you produce any livestock products in this household in the past 12 months? HLPO 15.2. Fill in the table below for details of livestock products and income

\begin{tabular}{|c|c|c|c|c|c|c|c|c|}
\hline \multirow{2}{*}{\multicolumn{2}{|c|}{ Livestock Product }} & \multirow{2}{*}{$\begin{array}{l}\text { Number of } \\
\text { production } \\
\text { months in the } \\
\text { past } \\
12 \text { months } \\
\text { if } 0> \\
\text { Next product }\end{array}$} & \multicolumn{2}{|c|}{$\begin{array}{l}\text { Average production per month } \\
\text { (during production months) }\end{array}$} & \multicolumn{2}{|c|}{$\begin{array}{l}\text { Average sales per month (during } \\
\text { production months) }\end{array}$} & \multirow{2}{*}{$\begin{array}{l}\text { What was the } \\
\text { average } \\
\text { consumption per } \\
\text { month (during } \\
\text { production months) } \\
\text { from own } \\
\text { production? }\end{array}$} & \multirow{2}{*}{$\begin{array}{l}\text { To whom do you mainly sell your } \\
\text { products? } \\
1=\text { Trader } \\
2=\text { Retail shop } \\
3=\text { Individual consumer } \\
4=\text { Cooperative association } \\
5=\text { Institution (e.g. school) } \\
6=\text { Supermarket } \\
7=\text { Company } 8=\text { Others specify }\end{array}$} \\
\hline & & & Quantity & $\begin{array}{l}\text { Unit } \\
1=\text { Kgs } \quad 3=\text { Litres } \\
23=\text { Trays } 4=\text { Numbers } \\
5=\text { Crate } 6=\text { Track } \\
7=\text { Other (specify) }\end{array}$ & Quantity & Total value in (Ush) & & \\
\hline & & LPNU & LPQTN & LPUNI & LSQTN & LSUN & LPEAT & LPSEL \\
\hline Cow Milk & 1 & & & & & & & \\
\hline Goat Milk & 2 & & & & & & & \\
\hline Sour Milk & 3 & & & & & & & \\
\hline Ghee & 4 & & & & & & & \\
\hline Eggs & 5 & & & & & & & \\
\hline Honey & 6 & & & & & & & \\
\hline Beef & 7 & & & & & & & \\
\hline Chicken & 8 & & & & & & & \\
\hline Goat Meat & 9 & & & & & & & \\
\hline Mutton & 10 & & & & & & & \\
\hline Pork & 11 & & & & & & & \\
\hline Other Meat & 12 & & & & & & & \\
\hline Hides and Skins & 13 & & & & & & & \\
\hline Blood & 14 & & & & & & & \\
\hline Cow dung & 15 & & & & & & & \\
\hline Other (specify) & 16 & & & & & & & \\
\hline
\end{tabular}




\section{SECTION 16: OFF-FARM INCOME}

16.1. Provide information on how much Off-farm income was earned by members of this household in the past $12 \mathrm{months} \mathrm{[Oct} \mathrm{2012} \mathrm{-} \mathrm{Oct} \mathrm{2013].}$

OFFARM

If OCUP1 and OCUP2 in Section 2 = Yes, all members who were engaged in off-farm activities (including farm labour) should appear here. If one is engaged in more than one

activity, use more than one row.

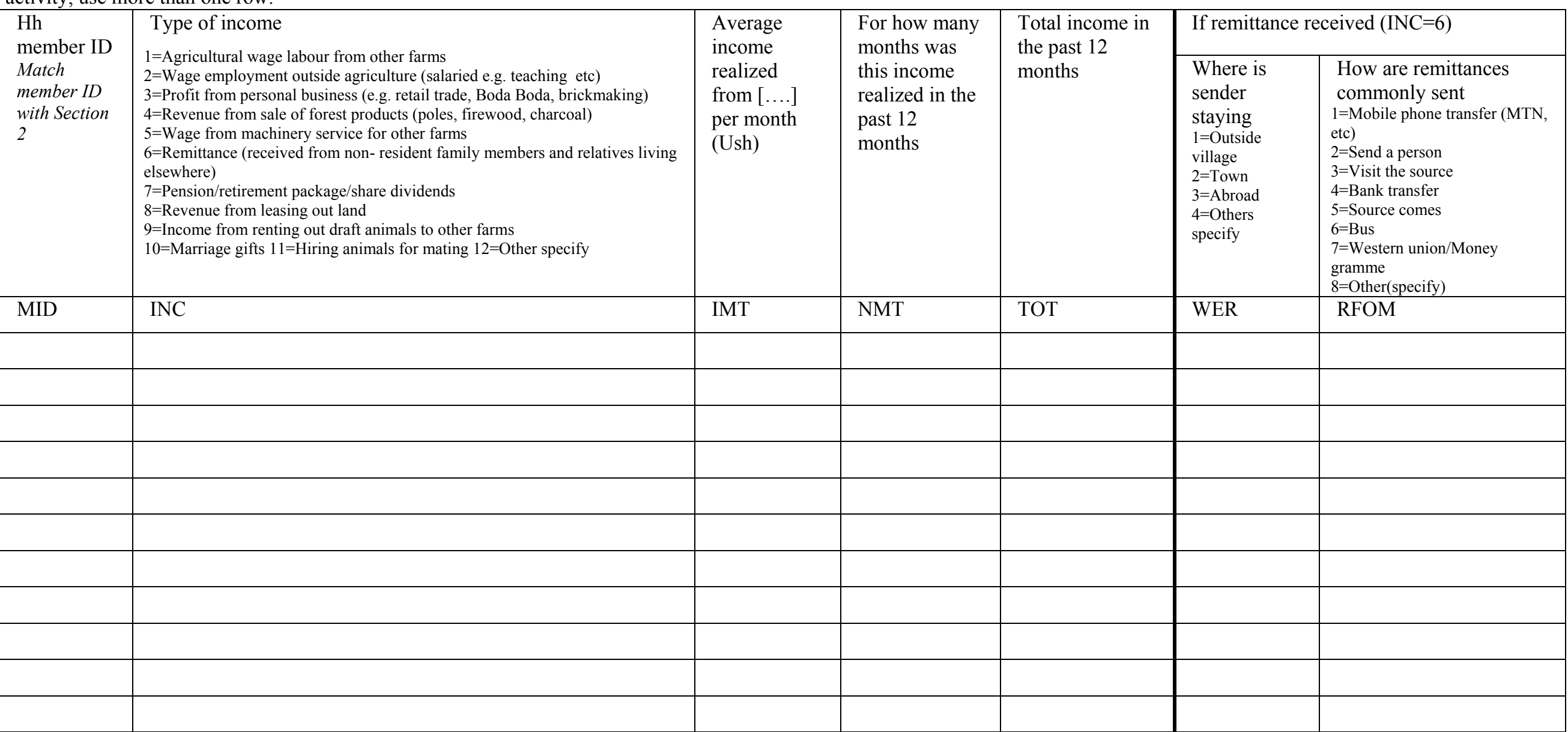




\section{SECTION 17: HOUSEHOLD ASSETS}

17.1. Fill in the assets in usable and repairable condition that this household own

\begin{tabular}{|c|c|c|c|c|c|c|c|c|c|}
\hline \multicolumn{2}{|l|}{ Asset } & $\begin{array}{l}\text { Number of items } \\
\text { currently owned } \\
\text { If none, record zero } \\
\text { and skip to next }\end{array}$ & $\begin{array}{l}\text { Estimate total } \\
\text { value of all } \\
\text { items } \\
\text { (Ush) }\end{array}$ & $\begin{array}{l}\text { Year when asset } \\
\text { was acquired } \\
\text { If several assets, } \\
\text { write year of first } \\
\text { acquired asset }\end{array}$ & \multicolumn{2}{|l|}{ Asset } & $\begin{array}{l}\text { Number of items } \\
\text { currently owned } \\
\text { If none, record zero } \\
\text { and skip to next }\end{array}$ & $\begin{array}{l}\text { Estimate total } \\
\text { value of all items } \\
\text { (Ush) }\end{array}$ & $\begin{array}{l}\text { Year when asset } \\
\text { was acquired } \\
\text { If several assets, } \\
\text { write year of first } \\
\text { acquired asset }\end{array}$ \\
\hline \multicolumn{2}{|l|}{ ASSET } & ASSNO & ASSVA & $\begin{array}{c}\text { ASSYR } \\
\end{array}$ & \multicolumn{2}{|l|}{ ASSET } & ASSNO & ASSVA & ASSYR \\
\hline Farm Equipment & & & & & Other Items & & & & \\
\hline Plough sets & 1 & & & & Bicycle & 13 & & & \\
\hline Carts & 2 & & & & Radio & 14 & & & \\
\hline Wheelbarrows & 3 & & & & (Car) Batteries & 15 & & & \\
\hline Borehole & 4 & & & & TV & 16 & & & \\
\hline Spray pumps & 5 & & & & Mobile Phones & 17 & & & \\
\hline Diesel pumps & 6 & & & & Chair & 18 & & & \\
\hline Water tanks & 7 & & & & Tables & 19 & & & \\
\hline Beehives & 8 & & & & Beds & 20 & & & \\
\hline Trailers & 9 & & & & Mosquito nets & 21 & & & \\
\hline Grinders/millers/Grinding & 10 & & & & Motorcycle & 22 & & & \\
\hline Hand hoe & 11 & & & & Vehicles & 23 & & & \\
\hline Storage facility(buildings) & 12 & & & & Tractor & 24 & & & \\
\hline & & & & & Other specify & 25 & & & \\
\hline
\end{tabular}




\section{SECTION 18: HOUSING}

18.1. Fill in the table on state of housing, drinking water, lighting and cooking fuel currently owned as well as 5 years ago

\begin{tabular}{|c|c|c|c|c|}
\hline \multirow{2}{*}{\multicolumn{2}{|c|}{ ITEM }} & $\begin{array}{l}\text { Current } \\
\text { state }\end{array}$ & $\begin{array}{l}\text { State } 5 \\
\text { years ago }\end{array}$ & \multirow{3}{*}{$\begin{array}{c}\text { CODES } \\
\text { [OBSERVE AND ASK] } \\
1=\text { Mud } 2=\text { Mud \& wattle } 3=\text { Bricks } / \text { Stones } 4=\text { Wood } 5=\text { Iron sheet } 6=\text { Grass } / \text { crop material } 7=\text { Other specify }\end{array}$} \\
\hline & & HCOWN & HOWN5 & \\
\hline Wall material of main house & 1 & & & \\
\hline Floor material of main house & 2 & & & $1=$ Cement $2=$ Earth $3=$ Wooden $4=$ Tiles 5 = Other specify \\
\hline Roof material of main house & 3 & & & $1=$ Grass thatch $2=$ Iron sheet $3=$ Roofing tiles $4=$ Wood $5=$ Cement $/$ Concrete $6=$ Asbestos $7=$ Other specify \\
\hline Mode of ownership of main & 4 & & & $1=$ Owned $2=$ Rented $3=$ Owned by relative $4=$ Other specify \\
\hline Type of toilet & 5 & & & $1=$ Bush $2=$ Flush $3=$ Ventilated latrine $4=$ Pit latrine 5 = Other specify \\
\hline $\begin{array}{l}\text { Main source of drinking } \\
\text { water }\end{array}$ & 6 & & & $\begin{array}{l}1=\text { Private tap } 2=\text { Public tap/borehole } 3=\text { River, stream, lake, pond, unprotected well, springs } 4=\text { Protected well } 5=\text { Rain water } 6= \\
\text { Other specify }\end{array}$ \\
\hline Main source of lighting & 7 & & & $\begin{array}{l}1=\text { Electricity } 2=\text { Paraffin lantern } 3=\text { Candles } 4=\text { Wick lamp } 5=\text { Gas } 6=\text { Solar } 7=\text { Biogas } 8=\text { Rechargeable lamps } 9=\text { Other } \\
\text { specify }\end{array}$ \\
\hline Main type of cooking fuel & 8 & & & $1=$ Electricity $2=$ Paraffin $/$ Kerosene $3=$ Firewood $4=$ Charcoal $5=$ Gas $6=$ Solar $7=$ Biogas $8=$ Other specify \\
\hline
\end{tabular}




\section{SECTION 19: ACCESS TO INFRASTRUCTURE}

19.1. Fill in the table on household access to infrastructure

\begin{tabular}{|c|c|c|c|c|c|c|}
\hline & & \multicolumn{2}{|c|}{$\begin{array}{l}\text { What is the distance from } \\
\text { your household to }[\ldots . .]\end{array}$} & \multirow{2}{*}{$\begin{array}{l}\text { How do you or other household members } \\
\text { usually get to }[\ldots . .] 1=\text { Walking } 2=\text { Own car } 3= \\
\text { Own motorbike } 4=\text { Bicycle } 5=\text { Taxi, boda, boda } 6 \\
=\text { Others, specify }\end{array}$} & \multirow{2}{*}{\multicolumn{2}{|c|}{$\begin{array}{l}\text { How long does it take to get to } \\
{[\ldots . .] \text { by using this means of }} \\
\text { transportation? }\end{array}$}} \\
\hline & & Quantity & $\begin{array}{l}\text { Unit } \\
1=\mathrm{Km} \\
2=\mathrm{Mile} \\
3=\mathrm{m} \\
\end{array}$ & & & \\
\hline \multicolumn{2}{|l|}{ INFRA } & QNTY & QUNI & INFTRA & TIME & $\begin{array}{l}\text { UNIT }[1=\text { Minutes } \\
2=\text { Hours }]\end{array}$ \\
\hline Nearest bus stop & 1 & & & & & \\
\hline Nearest all weather road & 2 & & & & & \\
\hline Nearest agricultural extension office (e.g NAADS) & 3 & & & & & \\
\hline Nearest place where you can buy farm inputs & 4 & & & & & \\
\hline Nearest market where you can sell your produce & 5 & & & & & \\
\hline $\begin{array}{l}\text { Nearest financial institution (e.g. Bank, } \\
\text { Microfinance) }\end{array}$ & 6 & & & & & \\
\hline Nearest Mobile Money Agent & 7 & & & & & \\
\hline Nearest health centre/ clinic/ doctor/drug store & 8 & & & & & \\
\hline Nearest school & 9 & & & & & \\
\hline
\end{tabular}




\section{SECTION 20: SHOCKS}

20.1. Over the past year, was your household negatively affected by any of the following events or developments? SHOCK

\begin{tabular}{|c|c|c|c|}
\hline \multirow{2}{*}{\multicolumn{2}{|c|}{ SHOCK }} & $\begin{array}{l}\text { Was the household affected by }[\ldots] \text { over the } \\
\text { past year } 1=\text { Yes } 2=\text { No }\end{array}$ & $\begin{array}{l}\text { If Yes in previous column, please rate the impact/degree of severity } \\
\text { of the shock on household welfare } 1=\text { Slight } 2=\text { Severe }\end{array}$ \\
\hline & & AFFECT & SEVERE \\
\hline Drought & 1 & & \\
\hline Too much rain or flood & 2 & & \\
\hline Erosion and gully formation/Landslides & 3 & & \\
\hline Frosts and hailstorm & 4 & & \\
\hline Pests or diseases that affected crops & 5 & & \\
\hline Hunger & 6 & & \\
\hline Theft of property (crops, livestock etc) & 7 & & \\
\hline Loss of livestock (death, illness, theft) & 8 & & \\
\hline Fire & 9 & & \\
\hline Lightning & 10 & & \\
\hline Conflict/violence & 11 & & \\
\hline Illness of male household head & 12 & & \\
\hline Illness of female household head & 13 & & \\
\hline Illness of other person & 14 & & \\
\hline Death of male household head & 15 & & \\
\hline Death of female household head & 16 & & \\
\hline Death of other person & 17 & & \\
\hline Rape & 18 & & \\
\hline Others specify & 19 & & \\
\hline
\end{tabular}


SECTION 21: CONSUMPTION AND EXPENDITURE ON MAJOR ITEMS (NON-DURABLE GOODS)

CONS

\begin{tabular}{|c|c|c|c|c|c|c|c|c|c|}
\hline & & Quantity & sumed & How muc & ame from 1 & rchases & & & Total expenditure \\
\hline & & Quantity & Unit & Quantity & Unit & \begin{tabular}{|l} 
Total \\
Expenditure
\end{tabular} & & & (Ush) \\
\hline During last 7 days & ITEM & FCQT & FCUN & FCPQT & FCPUN & FCPEX & During last 30 days & ITEM & NFEXP \\
\hline Staples & & & & & & & Sugar & 23 & \\
\hline Maize grain & 01 & & & & & & Salt & 24 & \\
\hline Maize meal/flour & 02 & & & & & & Cooking oil/Ghee & 25 & \\
\hline Millet/Sorghum & 03 & & & & & & Coffee/tea & 26 & \\
\hline Wheat flour & 04 & & & & & & Drinks: beer, beverages & 27 & \\
\hline Rice & 05 & & & & & & Tobacco/cigarettes & 28 & \\
\hline Cassava (Fresh form) & 06 & & & & & & Restaurant expenses & 29 & \\
\hline Cassava (Processed) & 07 & & & & & & During last 365 days: per annum & & \\
\hline Sweet potatoes & 08 & & & & & & Educational expenses (fees, uniform, textbooks & 30 & \\
\hline Irish potatoes & 09 & & & & & & Medicine/Medical care & 31 & \\
\hline Matooke & 10 & & & & & & Transport costs & 32 & \\
\hline Other staples (any) & 11 & & & & & & Clothing/Shoes & 33 & \\
\hline Non-Staple Fresh & & & & & & & Cooking/Lighting fuel & 34 & \\
\hline Chicken & 12 & & & & & & Soap/washing powder/care products & 35 & \\
\hline Meats (any) & 13 & & & & & & Contributions per annum & & \\
\hline Fish & 14 & & & & & & SACCO & 36 & \\
\hline Beans & 15 & & & & & & Remittances to relatives & 37 & \\
\hline Soybean & 16 & & & & & & Churches/Mosques & 38 & \\
\hline Groundnut/Peanut & 17 & & & & & & Credit repayments & 39 & \\
\hline Peas & 18 & & & & & & Mutual Support Groups (Funeral) & 40 & \\
\hline Vegetable/Fruits (any) & 19 & & & & & & Mutual Support Groups (Non - Funeral e.g. & 41 & \\
\hline Eggs & 20 & & & & & & Other local organizations & 42 & \\
\hline Milk & 21 & & & & & & & & \\
\hline Other dairy products & 22 & & & & & & & & \\
\hline
\end{tabular}

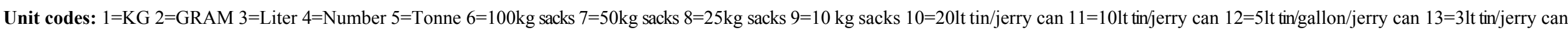
$14=11 \mathrm{t}$ tinjerry can $15=$ meda $16=$ Big bunches $(12$ cluster) $17=\operatorname{Big}$ bunches $(12$ cluster $) 18=$ Medium bunches $(8$ cluster $) 19=\operatorname{Small}$ bunches $(5$ cluster $) 20=$ crates $21=$ boxes $22=$ wheelbarrow $23=$ Trays 24=Other specify 
SECTION 22: HOUSEHOLD FOOD SECURITY (HFIAS Measurement Tool)

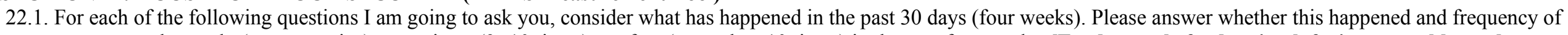
occurrence on scale, rarely (once or twice), sometimes (3-10 times) or often (more than 10 times) in the past four weeks. [Food - staple food, animal, fruits, vegetables etc]

\begin{tabular}{|c|c|c|c|}
\hline Domain & In the past four weeks....... & $\begin{array}{l}\text { Occurrence } \\
1=\text { Yes } \\
2=\mathrm{No}>\mathrm{Next} \\
\text { row }\end{array}$ & $\begin{array}{l}\text { Frequency-of-occurrence: How } \\
\text { often did this happen in the past } \\
\text { four weeks? } \\
1=\text { Rarely (once or twice) } \\
2 \text { = Sometimes (three to ten times) } \\
3=\text { Often (more than ten times) }\end{array}$ \\
\hline Anxiety & Did you worry that your household would not have enough food? & & \\
\hline \multirow{3}{*}{$\begin{array}{l}\text { Inadequate } \\
\text { Quality }\end{array}$} & Were you or any household member not able to eat the kinds of foods you preferred because of a lack of resources? & & \\
\hline & Did you or any household member have to eat a limited variety of foods due to a lack of resources? & & \\
\hline & $\begin{array}{l}\text { Did you or any household member have to eat some foods that you really did not want to eat because of a lack of } \\
\text { resources to obtain other types of food? }\end{array}$ & & \\
\hline \multirow{5}{*}{$\begin{array}{l}\text { Less } \\
\text { Quantity/ } \\
\text { Insufficient } \\
\text { Food } \\
\text { Intake }\end{array}$} & $\begin{array}{l}\text { Did you or any household member have to eat a smaller meal than you felt you needed because there was not enough } \\
\text { food? }\end{array}$ & & \\
\hline & Did you or any household member have to eat fewer meals in a day because there was not enough food? & & \\
\hline & Was there ever no food to eat of any kind in your household because of a lack of resources to get food? & & \\
\hline & Did you or any household member go to sleep at night hungry because there was not enough food? & & \\
\hline & $\begin{array}{l}\text { In the past four weeks, did you or any household member go a whole day and night without eating anything because } \\
\text { there was not enough food? }\end{array}$ & & \\
\hline
\end{tabular}


SECTION 23: DOSPERT ASSESSMENT

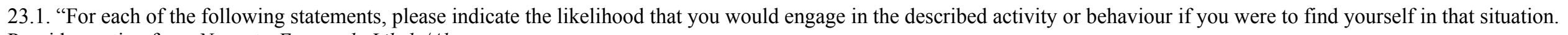

Provide a rating from Never to Extremely Likely/Always.

\begin{tabular}{|c|c|}
\hline What is the likelihood that you would engage in [..] & Rating $1=$ Never/Extremely unlikely $2=$ Unlikely $3=$ Not sure $4=$ Likely $5=$ Extremely likely/Always \\
\hline 1. Disagreeing with a village leader on a major issue & \\
\hline 2. Confronting one's family & \\
\hline 3. Drinking heavily at a social function & \\
\hline 4. Walking alone through a thick forest & \\
\hline 5. Walking home alone at night in an unsafe area of town/district & \\
\hline 6. Betting a day's income at a gamble & \\
\hline 7. Spending all the day's income on a drinking spree & \\
\hline 8. Revealing a friend's secret to someone else & \\
\hline 9. Not returning a wallet you found that contains $340000 \mathrm{Ush}$ & \\
\hline 10. Living your young children alone at home while running an errand & \\
\hline
\end{tabular}

